\title{
Atmospheric chemistry and physics in the atmosphere of a developed megacity (London): an overview of the REPARTEE experiment and its conclusions
}

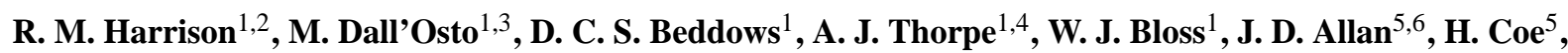
J. R. Dorsey ${ }^{5,6}$, M. Gallagher ${ }^{5}$, C. Martin ${ }^{5}$, J. Whitehead ${ }^{5}$, P. I. Williams ${ }^{5,6}$, R. L. Jones ${ }^{7}$, J. M. Langridge ${ }^{7,8}$,

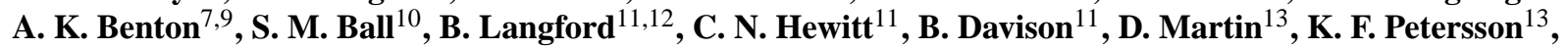
S. J. Henshaw ${ }^{13}$, I. R. White ${ }^{13}$, D. E. Shallcross ${ }^{13}$, J. F. Barlow ${ }^{14}$, T. Dunbar ${ }^{14}$, F. Davies ${ }^{15}$, E. Nemitz ${ }^{12}$, G. J. Phillips ${ }^{12,16}$, C. Helfter ${ }^{12}$, C. F. Di Marco ${ }^{12}$, and S. Smith ${ }^{17}$

${ }^{1}$ National Centre for Atmospheric Science, Division of Environmental Health \& Risk Management, School of Geography, Earth \& Environmental Sciences, University of Birmingham, Edgbaston, Birmingham B15 2TT, UK

${ }^{2}$ Department of Environmental Sciences/Center of Excellence in Environmental Studies, King Abdulaziz University, Jeddah, 21589, Saudi Arabia

${ }^{3}$ Institute of Environmental Assessment and Water Research (IDÆA), Consejo Superior de Investigaciones Científicas (CSIC), C/LLuis Solé i Sabarís S/N 08028 Barcelona, Spain

${ }^{4}$ AECOM, Enterprise House, 160 Croydon Road, Beckenham, Kent, BR3 4DE, UK

${ }^{5}$ Centre for Atmospheric Science, School of Earth, Atmospheric \& Environmental Sciences, The University of Manchester, Williamson Building, Oxford Road, Manchester M13 9PL, UK

${ }^{6}$ National Centre for Atmospheric Science, School of Earth, Atmospheric \& Environmental Sciences, The University of Manchester, Oxford Road, Manchester M13 9PL, UK

${ }^{7}$ Centre for Atmospheric Science, Chemistry Department, University of Cambridge, Cambridge, CB2 1EW, UK

${ }^{8}$ Cooperative Institute for Research in Environmental Sciences (CIRES), University of Colorado and NOAA Earth System Research Laboratory, Chemical Sciences Division, Boulder, CO, USA

${ }^{9}$ British Antarctic Survey, High Cross, Madingley Road, Cambridge, CB3 OET, UK

${ }^{10}$ Department of Chemistry, University of Leicester, Leicester LE1 7RH, UK

${ }^{11}$ Lancaster Environment Centre, Lancaster University, Lancaster LA1 4YQ, UK

${ }^{12}$ Centre for Ecology \& Hydrology, Bush Estate, Penicuik, Midlothian, EH26 0QB, UK

${ }^{13}$ Atmospheric Chemistry Research Group (ACRG), School of Chemistry, University of Bristol, Cantock's Close, Bristol BS8 1TS, UK

${ }^{14}$ Department of Meteorology, University of Reading, Earley Gate, P.O. Box 243, Reading RG6 6B, UK

${ }^{15}$ School of Environment and Life Sciences, Peel Building, University of Salford, Salford, Greater Manchester, M5 4WT, UK

${ }^{16}$ Max Planck Institute for Chemistry, Joh.-Joachim-Becher-Weg 27, 55128 Mainz, Germany

${ }^{17}$ Department of Earth Sciences, Royal Holloway, University of London, Egham, Surrey, TW20 0EX, UK

Correspondence to: R. M. Harrison (r.m.harrison@bham.ac.uk)

Received: 6 October 2011 - Published in Atmos. Chem. Phys. Discuss.: 8 November 2011

Revised: 22 February 2012 - Accepted: 23 February 2012 - Published: 30 March 2012

\begin{abstract}
The REgents PARk and Tower Environmental Experiment (REPARTEE) comprised two campaigns in London in October 2006 and October/November 2007. The experiment design involved measurements at a heavily trafficked roadside site, two urban background sites and an elevated site at 160-190 $\mathrm{m}$ above ground on the BT Tower, supplemented in the second campaign by Doppler lidar measurements of atmospheric vertical structure. A wide range
\end{abstract}

of measurements of airborne particle physical metrics and chemical composition were made as well as measurements of a considerable range of gas phase species and the fluxes of both particulate and gas phase substances. Significant findings include (a) demonstration of the evaporation of trafficgenerated nanoparticles during both horizontal and vertical atmospheric transport; (b) generation of a large base of information on the fluxes of nanoparticles, accumulation mode 
particles and specific chemical components of the aerosol and a range of gas phase species, as well as the elucidation of key processes and comparison with emissions inventories; (c) quantification of vertical gradients in selected aerosol and trace gas species which has demonstrated the important role of regional transport in influencing concentrations of sulphate, nitrate and secondary organic compounds within the atmosphere of London; (d) generation of new data on the atmospheric structure and turbulence above London, including the estimation of mixed layer depths; (e) provision of new data on trace gas dispersion in the urban atmosphere through the release of purposeful tracers; (f) the determination of spatial differences in aerosol particle size distributions and their interpretation in terms of sources and physicochemical transformations; (g) studies of the nocturnal oxidation of nitrogen oxides and of the diurnal behaviour of nitrate aerosol in the urban atmosphere, and (h) new information on the chemical composition and source apportionment of particulate matter size fractions in the atmosphere of London derived both from bulk chemical analysis and aerosol mass spectrometry with two instrument types.

\section{Introduction}

Air quality provides one of the main drivers for the study of atmospheric science. Whilst climate change presents a massive challenge to mankind on future decadal timescales, local air quality has presented major public health issues for past centuries, and continues to do so to this day. Although developed countries have made considerable progress in improving air quality, there remain major impacts upon public health in Europe and North America (Kunzli et al., 2000; Cohen et al., 2005; Brunekreef and Holgate, 2002). While much has been done to improve air quality on these continents, in less developed countries, and especially those undergoing rapid development, air quality is not improving and may indeed be deteriorating. Urban areas provide a natural focus for research on air quality as they face special problems due to the high emissions from space heating and road transport associated with their high population densities. In less developed countries, polluting industries may also be focussed largely within the confines of urban areas, greatly exacerbating urban air pollution problems. In the more developed world, industry is not only subject to tighter regulation, but has largely moved out of major cities. Thus in the United Kingdom, in the 1950s coal-fired power stations were a major local source of emissions in London, whilst nowadays the main electric power generating stations are located well outside of the main cities, with consequent sulphur dioxide concentrations having long ago converged between urban and rural areas.

London has a long history of air quality problems (Brimblecombe, 1987). These were only addressed with vigour following the Great Smog of 1952 which is estimated to have caused 4000 excess deaths (Brunekreef and Holgate, 2002). Smokeless fuel legislation and near-universal availability of cleaner energy from gas consumption led to a rapid decline in both black smoke and sulphur dioxide through the 1960s and 1970s in London. Concurrent with this change in emissions, a massive growth in road traffic took place, leading to problems with emissions of carbon monoxide and oxides of nitrogen, such that when a major pollution episode occurred in London in December 1991, the main toxic pollutants were nitrogen dioxide, which reached an hourly mean of $423 \mathrm{ppb}$, and black smoke, with daily concentrations of up to $148 \mu \mathrm{g} \mathrm{m}^{-3}$. Effects on health were measurable in terms of increased mortality and hospital admissions, but at a much lower level than in December 1952 (Anderson et al., 1995). The pollutant responsible appears most likely to have been particulate matter, which was not determined directly by mass in London until the advent of an automatic urban monitoring network in 1992. In the intervening period there has been a decline in sulphate accompanied by an increase in nitrate particles, and a reduction in vehicle exhaust particles. Three-way catalysts have led to a tremendous improvement in ambient concentrations of carbon monoxide and Volatile Organic Compounds (VOC), the latter assisted by controls on evaporative emissions from vehicles and petrol stations (Stage 1 control only). Emissions of sulphur dioxide and primary sulphate from road vehicles have declined to very low levels as a result of requirements for ultra-low and subsequently zero sulphur gasoline and diesel fuels. Despite progressively stricter emission standards for primary particles and precursors of secondary pollutants from traffic and industry, concentrations of airborne $\mathrm{PM}_{10}$ have changed little in London (and other UK cities) since 2000 for reasons which are poorly understood (Harrison et al., 2008), and highlight the need for improved source apportionment studies (Sanchez-Reyna et al., 2005). Urban road transport activity has increased across the UK by more than $15 \%$ over the last decade and a half (RTS, 2006) except for London, despite non-technological abatement proposals, and this currently contributes the majority of urban regional ultrafine particle emissions.

Charron et al. (2007) used spatial analysis to estimate the roadside traffic-generated and general urban increments in $\mathrm{PM}_{10}$. The Marylebone Road traffic increment in $\mathrm{PM}_{10}$ above the urban background measured at London, North Kensington was $12.6 \mathrm{\mu g} \mathrm{m}^{-3}$ at the annual average, and the urban background increment above rural Harwell was $6.3 \mu \mathrm{g} \mathrm{m}^{-3}$ for 2002-2004. Subsequently, Jones et al. (2008) used day-of-the-week differences in traffic emissions to estimate that for background sites in London, the traffic contribution to the urban increment was $1.6-4.4 \mu \mathrm{g} \mathrm{m}^{-3}$, with nontraffic sources contributing $2.1-2.7 \mu \mathrm{g} \mathrm{m}^{-3}$. As seen from the results of Charron et al. (2007), a large fraction of the particulate matter pollution in London arises from regional transport, and Abdalmogith and Harrison (2006) estimated 
that only $0.22 \mu \mathrm{g} \mathrm{m}^{-3}$ out of $2.90 \mu \mathrm{g} \mathrm{m}^{-3}$ of sulphate and $0.46 \mu \mathrm{g} \mathrm{m}^{-3}$ out of $3.72 \mu \mathrm{g} \mathrm{m}^{-3}$ of nitrate in central London in 2002-2004 arose from formation within London itself; rather they originate mainly from the regional background, which distinguishes London from cities such as Los Angeles and Mexico City where much of the secondary aerosol is formed within the urbanised area itself. Whilst a similar analysis is not available for secondary organic aerosol in London, data from the West Midlands, the UK's second major conurbation, indicate that much of the organic aerosol is regionally distributed and does not have a discrete urban source (Harrison and Yin, 2008). This is consistent with the paradigm proposed by Robinson et al. (2007) in which primary organic compounds in traffic-generated aerosol progressively desorb prior to oxidation and incorporation into secondary organic aerosol, a process that presumably acts at a time-scale too slow to create a marked urban increment in secondary organic aerosol.

Despite the importance of urban areas, and in particular mega-cities for population exposure to air pollution, they have in general been studied far less than the regional or global atmosphere. In the case of urban climatology, there have been significant advances in recent decades (Arnfield, 2003), but observations of meteorological variables within most cities remain very sparse, despite far stronger gradients in meteorological fields in three dimensions within urban as opposed to rural areas. The situation with respect to urban atmospheric chemistry is arguably the opposite: routine monitoring of composition for a very restricted range of air quality pollutants (typically $\mathrm{NO} / \mathrm{NO}_{2} / \mathrm{NO}_{\mathrm{x}}, \mathrm{SO}_{2}, \mathrm{O}_{3}$, $\mathrm{CO}, \mathrm{PM}_{10}$, and in some cases $\mathrm{PM}_{2.5}$ ) has become progressively more spatially intense as a result of public health concerns, but the amount of genuine process-oriented research on physico-chemical processes within the urban atmosphere itself has been very limited. Despite the relatively intensive monitoring activity, detailed three-dimensional studies of air pollution processes are notably lacking.

It is appropriate to highlight some of the earlier urban air quality/atmospheric chemistry experiments, focussing primarily upon Europe. The BERLIOZ (Berliner Ozonexperiment) campaign took place in Berlin in July/August 1998 (Platt et al., 2002). Over the period, 12 ground stations were operated, with measurements made both upwind and downwind of Berlin within a range of $80 \mathrm{~km}$. Additionally, LIDAR, SODAR, radio sondes, balloons and aircraft were deployed with measurements of $\mathrm{O}_{3}, \mathrm{NO}_{\mathrm{x}}$, VOC, $\mathrm{CO}, \mathrm{PAN}$, $\mathrm{HONO}, \mathrm{HNO}_{3}, \mathrm{H}_{2} \mathrm{O}_{2}$, carbonyls, organic peroxides, key free radicals and photolysis frequencies. The experiment contributed valuable knowledge on the contribution of the city of Berlin to regional photooxidant formation and the mechanisms involved.

The ESCOMPTE (Experience sur Site pour Contraindre des Modèles de Pollution Atmosphérique et de Transport d'Emissions) experiment took place in a $120 \times 120 \mathrm{~km}$ domain covering the city of Marseille and the adjacent indus- trial zone and pond of Berre in 2001 (Cros et al., 2004). One of the main goals was to produce a 3-D database of emissions, transport and air composition measurements during urban pollution episodes generating photooxidant and secondary aerosol. Process studies included the role of the sea breeze in pollution events, quantification of deposition onto aerosol, and aerosol formation in the urban plume, the interaction between aerosols and photooxidants and the chemical regime within which ozone formation occurred.

The PUMA study in Birmingham, England involved intensive campaigns within the city in the summer of 1999 and the winter of 1999/2000. The aims of the study were to understand urban photooxidant chemistry at a fundamental level, as well as to study aerosol composition and processes. There were both experimental and modelling components (Harrison et al., 2006; Baggott et al., 2006) and the major outcomes included a much improved understanding of seasonal influences on processes leading to hydroxyl radical formation (Emmerson et al., 2005), and work on aerosol composition which led to the development of the "pragmatic mass closure model" for aerosol, which has subsequently proved powerful in understanding the composition of aerosol at urban roadside, urban background and rural sites in the United Kingdom (Harrison et al., 2003; Yin and Harrison, 2008).

MILAGRO (Megacity Initiative: Local and Global Research Observations) was a very large experiment conducted in or near Mexico City commencing in March 2006. The experiment used ground-based, airborne and satellite instruments to study the urban plume downwind of the city with a special focus upon atmospheric chemistry and particulate matter. The overview paper (Molina et al., 2010) reviews over 120 papers from the campaign and summarises the main findings. Although the scientific advances made are impressive, they are of limited relevance to a European megacity with a temperate climate.

The focus of most past experiments has been upon urban plume chemistry and the impact of urban emissions upon downwind regions. This has necessitated the use of both ground-based and airborne observations. The latter have used aircraft to provide rapid measurement capability in three spatial dimensions. This is appropriate to making measurements within urban plumes which rapidly expand in the vertical plane, but less so to observational studies within the city itself, where the emissions have had less time to mix vertically and the lower altitude limits imposed by air traffic control requirements can provide a major limitation on the deployment. From this perspective, urban towers may provide a more suitable platform for measurements of vertical profiles and fluxes above the city.

There is limited information available of pollutant fluxes above urban areas. Fluxes of $\mathrm{CO}_{2}$ have now been measured in several conurbations, and the first long-term time-series are emerging (e.g. Helfter et al., 2011; Vogt et al., 2011a). However, most of these are focussed on residential, less dense locations because in many (notably US American) city 
centres the prevalence of highrise buildings makes flux measurements difficult. Particle number flux measurements have been made over only a few cities (e.g. Edinburgh, Helsinki, Stockholm and Münster; Dorsey et al., 2002; Schmidt and Klemm, 2008; Järvi et al., 2009; Nemitz et al., 2012b), and fluxes of volatile organic compounds have previously been reported for Mexico City and Houston. Over the lifetime of the REPARTEE study and the collaborating CityFlux project we have greatly improved the availability of flux measurements, and measured number fluxes over Manchester and London (Martin et al., 2009), fluxes of aerosol submicron chemical components over Edinburgh, Manchester and London (Phillips et al., 2012), VOCs over Manchester and London (Langford et al., 2009, 2010), and we have extended the approach further to make the first urban flux measurements of $\mathrm{N}_{2} \mathrm{O}, \mathrm{CO}$ and $\mathrm{O}_{3}$ (Famulari et al., 2010; and this paper).

London has a population of 7.6 million, whilst the Greater London metropolitan area has between 12.3 and 13.9 million, making it the largest in the European Union (Wroth and Wiles, 2007). It has substantial air quality problems, especially in relation to nitrogen dioxide (AQEG, 2007) and particulate matter (AQEG, 2005). One of the main stimuli for this research was the availability of an elevated sampling platform on the BT telecommunications tower in central London at heights of between 140-190 m, suitable for measurements both of concentrations and fluxes. The Tower lies within a typical commercial and residential area of central London and close to a major park (Regents Park) suitable for measurement of central urban background concentrations. Hence, the experiment was named the Regents PARk and Tower Environmental Experiment (REPARTEE).

\section{Objectives of REPARTEE}

- To study aerosol chemical and dynamical processes within the atmosphere of central London in three spatial dimensions.

- To measure the fluxes of selected aerosol and gas phase species above the city, and where possible to compare fluxes with estimates derived from emissions inventories. In this context, the work was coordinated with that on the CityFlux project in which fluxes were determined over a number of UK cities as well as Sweden and, in collaboration with MILAGRO, Mexico City. Work from CityFlux has also been published outside of this Special Issue (Martin et al., 2009; Petersson et al., 2010; Thomas, 2007; Famulari et al., 2010; Langford et al., 2009), while some CityFlux related activities in Edinburgh and Manchester are also included in the Special Issue to provide a fuller understanding of UK urban emission processes.

- To quantify gradients in selected aerosol and trace gas species from ground-level to altitudes of sampling on the BT tower and to use such information to better understand the respective roles of local emissions, local transformations and regional transport of pollutants in influencing the composition within and above London.

- To study the structure of the atmospheric boundary layer and the influence of boundary layer vertical structure upon trace gas and aerosol fluxes and air pollution processes, especially in the context of diurnal changes.

- To deploy purposeful tracer releases at ground level while monitoring at the surface and aloft in order to evaluate the dispersion of trace gases released at low level within the city.

- To determine spatial differences in aerosol particle size distributions and to interpret those differences in terms of the sources and physico-chemical transformations responsible.

- To study the properties of nitrate aerosol in the atmosphere of London, together with mechanisms of formation, physico-chemical properties and dynamics of nitrate particles.

- To throw new light on the source apportionment of $\mathrm{PM}_{1}$, $\mathrm{PM}_{2.5}$ and $\mathrm{PM}_{10}$ in the atmosphere of London.

Towards those ends, two campaigns of one-month duration each, were held in 2006 and 2007, with a host of advanced instruments deployed both at ground-level and aloft. In particular, the deployment of both Aerodyne Aerosol Mass Spectrometers (AMS) and a TSI Aerosol Time-ofFlight Mass Spectrometer (ATOFMS) has cast new light upon aerosol composition, sources and processes (Dall'Osto et al., 2009a, b; Allan et al., 2010; Phillips et al, 2012), and the use of a Doppler lidar to determine vertical atmospheric structure (Barlow et al., 2011) has aided the interpretation of vertical gradients in atmospheric composition and particle size distributions. Other highlights include novel urban dispersion experiments and generation of new insights into fluxes of gaseous and particulate species above the city (Martin et al., 2011a; Phillips et al., 2012; Langford et al., 2010; Helfter et al., 2011; Nemitz et al., 2012a, c).

\section{Campaigns, sites and instruments}

There were two intensive campaigns for the REPARTEE programme. Both used essentially the same sampling platforms, although the instruments deployed differed somewhat between the campaigns. In both campaigns, measurements were made aloft on the BT tower and at ground-level in Regents Park, $1.2 \mathrm{~km}$ apart. In the second campaign (REPARTEE II), a Doppler lidar instrument was deployed at a third site in the near vicinity. The main campaign sites, together with sites used additionally for traffic-impacted 


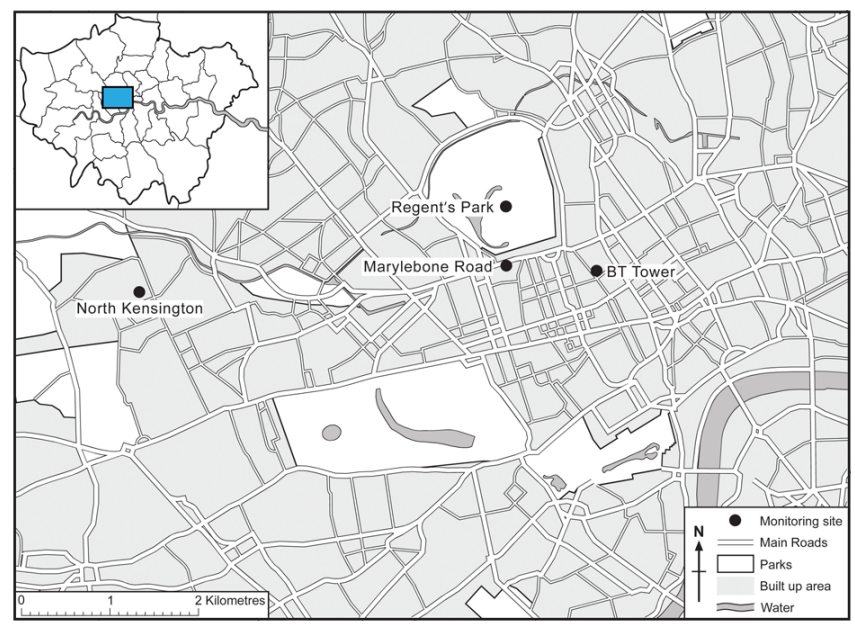

Fig. 1. Map of measurement sites used in REPARTEE. The lidar was sited adjacent to the Marylebone Road site.

(Marylebone Road) and background (North Kensington) measurements appear in Fig. 1. Some instruments located on the BT tower were also used for vertical flux estimation.

The campaign dates were as follows:

REPARTEE I 1-31 October 2006

REPARTEE II 17 October-15 November 2007

\subsection{The sampling sites}

$B T$ Tower (BT Tower). (lat $51^{\circ} 31^{\prime} 17.31^{\prime \prime} \mathrm{N}$; lon $0^{\circ} 8^{\prime}$ $\left.20.12^{\prime \prime} \mathrm{W}\right)$. This is the operational tower of British Telecom (60 Cleveland Street). It is a cylindrical tower, shown in Fig. 2, the top being 190 metres above ground-level. The main platform for instruments was a well-ventilated balcony (level T35) at a height of $160 \mathrm{~m}$ a.g.l. Inlet lines were installed from the top of the lattice tower to connect with instruments for flux determination which operated on level T35.

A 3 axis ultrasonic anemometer (R3-50, Gill Instruments, UK) and weather station (Vaisala WXT510) were installed on top of the BT Tower located approximately $1.2 \mathrm{~km}$ to the east of the lidar site (itself close to the Marylebone Road site shown in Fig. 1). The Tower is the tallest building within several kilometres of the site, with good exposure to winds in all directions. The anemometer was clamped to an open lattice scaffolding tower of $12 \mathrm{~m}$ height, situated on top of the main building structure and resulting in a measurement height of $190 \mathrm{~m}$, or approximately 9 times local mean building height (Barlow et al., 2009). The sampling rate was $20 \mathrm{~Hz}$ and data were rotated into the mean wind direction using the double-rotation method (Wilczak et al., 2001) prior to flux density calculation. For measurement of fluxes of particles and chemical constituents, air samples were drawn from an inlet adjacent to the ultrasonic anemometer through

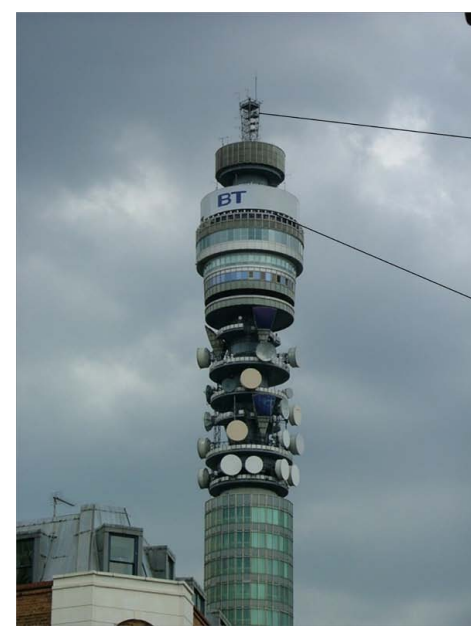

\section{BT TOWER}

Meteorological instruments and inlets for fast response pollution sensors (190 metres)

Height of most instruments (160 metres)

Fig. 2. The BT Tower, showing sampling locations.

$50 \mathrm{~m}$ long 1/2 inch o.d. copper and PTFE pipes, respectively, at $601 \mathrm{~min}^{-1}$ and subsampled into the measurement instruments. Given the length of the inlets, temperature variations are expected to have been smoothed out by the time the sampled air reaches the analysers. Thus, only the effect of density fluctuations due to fluctuations in the water vapour content were corrected for according to Webb et al. (1980), and only for those instruments that do not already correct for water vapour effects, such as the Aerosol Mass Spectrometer and the fast ozone analyser. The correction procedures applied ignore the fact that the long inlet tubes may have introduced a time-lag between the variations in water vapour concentration and the measured pollutant concentrations and the correction may therefore be overestimated (Ibrom et al., 2007). However, relative corrections were small given the large fluxes in the urban environment. Due to the slow turbulence high frequency losses in the inlet lines were estimated to be negligible. Low frequency losses are assessed in Sect. 4.10.2 below and demonstrate that $15 \%$ of the flux may be lost with the flux averaging time of $30 \mathrm{~min}$, which was nevertheless chosen for most instruments to balance the effects of flux losses and non-stationarities. A fuller description of the setup and analysis methods is given by Nemitz et al. (2012a).

Regents Park (R. Park) (lat 51 $31^{\prime} 44^{\prime \prime} \mathrm{N}$; lon $0^{\circ} 09^{\prime} 09^{\prime \prime} \mathrm{W}$ ). The park covers a total of about $2 \mathrm{~km}^{2}$ and mainly comprises heavily vegetated open parkland. There are two lightly trafficked circular roads within the park and major roads on three external boundaries. The park is home to London Zoo which is located $800 \mathrm{~m}$ from the air sampling site. Air sampling took place within the inner circle in an area used mainly for horticulture. Most instruments were housed in a sea container and a mobile laboratory, except a Partisol filter sampler which was free-standing.

In REPARTEE I, air was sampled from a height of $10 \mathrm{~m}$ through a vertical sample pipe of $150 \mathrm{~mm}$ diameter and was 
sub-sampled from the main flow in an isokinetic manner as described by Dall'Osto et al. (2009b). In REPARTEE II, sampling was from a mobile laboratory with an inlet at about $2 \mathrm{~m}$.

University of Westminster (lat $51^{\circ} 31^{\prime} 19.86^{\prime \prime} \mathrm{N}$; lon $0^{\circ} 09^{\prime}$ $21.58^{\prime \prime} \mathrm{W}$ ). A pulsed Doppler lidar (HALO Photonics), housed in a van, was located in a basement level car park at the University of Westminster. The lidar beam was emitted within $1 \mathrm{~m}$ of street level. Two modes of operation were used: continuous vertical stare, and three-beam line of sight to derive wind profiles every $30 \mathrm{~min}$ (Pearson et al., 2009). The general area was characterised by commercial and residential buildings: near the Marylebone Road the mean building height is $21 \mathrm{~m}$, plan area density is 0.4 (Barlow et al., 2009), whereas the source area for the BT Tower generally lies between 1 and $10 \mathrm{~km}$ distance, in which the mean building height is $9 \mathrm{~m}$ (Wood et al., 2010).

Marylebone Road (M. Road) (lat $51^{\circ} 31^{\prime} 21^{\prime \prime} \mathrm{N}$; lon $0^{\circ} 09^{\prime}$ $\left.17^{\prime \prime} \mathrm{W}\right)$. Instruments were installed in a permanent monitoring station located at kerbside, $1 \mathrm{~m}$ from the busy six-lane Marylebone Road carrying ca 80000 vehicles per day. Inlets were sited about $3 \mathrm{~m}$ a.g.l. at differing distances from the road, mostly 1-3 m distant.

North Kensington (NK) (lat $51^{\circ} 31^{\prime} 15^{\prime \prime} \mathrm{N}$; lon $0^{\circ} 12^{\prime}$ $\left.49^{\prime \prime} \mathrm{W}\right)$. This is a permanent station of the Automatic Urban and Rural Network located in the grounds of Sion Manning School within a highly trafficked suburban area of London. Inlets are located about $3 \mathrm{~m}$ a.g.l. The air pollution climate at this site has been analysed in detail by Bigi and Harrison (2010).

\subsection{Instruments and aerosol bulk chemical analyses}

Instruments were installed by a number of research groups, details of specific instruments appearing in Tables 1 and 2 . Bulk chemical analyses of aerosol collected using the dichotomous Partisol and MOUDI samplers were conducted according to the methods reported by Yin and Harrison (2008), who also describe the methods for measurement of PM mass on Partisol filters.

\subsection{Tracer release experiments}

During the 10 perfluorocarbon (PFC) tracer experiments conducted during these campaigns three different PFCs (perfluoromethylcyclopentane, perfluoromethylcyclohexane and perfluorodimethylcyclohexane) were used. The PFCs are inert, non-toxic, and non-depositing making them ideal to use as atmospheric tracers, good separation during analysis allows multiple tracers to be used in one experiment (Arnold et al., 2004; Colvile et al., 2004; Martin et al., 2008, 2010a, b, 2011a, b; Patra et al., 2008; Petersson et al., 2010; Shallcross et al., 2009, Simmonds et al., 2002; White et al., 2010; Wood et al., 2009). A detailed experimental description can be found in Martin et al. (2011a) and only a brief overview is provided here.

Gaseous PFCs (0.25-4 mole \%) were released from stainless steel silica lined canisters SA) with accurate monitoring of flow rate, canister pressure and temperature. The low (ppqv) atmospheric background concentration of the PFCs facilitates small release rates $\left(\sim 10^{-6} \mathrm{~kg} \mathrm{~s}^{-1}\right)$. Air samples were collected in 101 Tedlar bags, where the sampling flow rate $\left(0.2-11 \mathrm{~min}^{-1}\right)$ was constant during any one experiment. The air samples were analysed no more than 1 month following the tracer experiments by Gas Chromatography Mass Spectrometry run in Negative Ion Chemical Ionization Mode (GC-NICI-MS). Before introduction to the GC an Adsorption Desorption System (ADS) was used where a microtrap containing $10 \mathrm{mg}$ Carboxen 569, 40-50 Mesh (Supelco, Bellefonte, USA) maintained at $-50^{\circ} \mathrm{C}$ during sampling was used in order to pre-concentrate the sample without exceeding the theoretical breakthrough volumes (Martin et al., 2008, 2010a, b, 2011a, b; Patra et al., 2008; Petersson et al., 2010; Shallcross et al., 2009; Simmonds et al., 2002; Wood et al., 2009). A detection limit lower than the current atmospheric background mixing ratio in the $1-10$ ppqv range is achieved with a measurement uncertainty of about $5 \%$.

PFC Tracer experiments were conducted on five days; 2 June 2006 (01:30 to 01:40 p.m.) and 27 June 2006 (01:00 to 01:26 p.m.) in central Manchester (Petersson et al., 2010) and 25 October 2006 (01:50 to 01:50 p.m.), 26 October 2006 (01:50 to 02:50 p.m.) and 7 November 2007 (01:00 to $05: 20 \mathrm{pm}$ ) in central London (Martin et al., 2011a). The methodology employed for the REPARTEE I experiments in October 2006 was to release tracer at ground level, approximately $1000 \mathrm{~m}$ upwind of the receptors. Three receptors were located at the BT Tower (at altitudes of ground level, $150 \mathrm{~m}$ and $190 \mathrm{~m}$ ) and three others on an equidistant arc from the release point, also at ground level. During REPARTEE II a more complicated arrangement of release points and samplers was formulated (Martin et al., 2011a). Here, two tracer release points were set up and two sampling arcs downwind of these release points were made at ground level. Arc 1, with 3 samplers was $\sim 300 \mathrm{~m}$ and $750 \mathrm{~m}$ from the release points and arc 2, with five samplers (including one at the BT Tower) were $\sim 500 \mathrm{~m}$ and $950 \mathrm{~m}$ from the release points. In addition, two samplers were at elevated levels at the BT Tower as before and one ground level sampler was positioned between the two release points, about $350 \mathrm{~m}$ downwind from the most distant release point (relative to both arcs) and about $170 \mathrm{~m}$ upwind from the closer release point.

\section{Meteorological conditions and back trajectories}

\subsection{Meteorological variables: REPARTEE I}

The conditions through the campaign are summarised in Fig. 3. As expected, windspeeds were much higher on the BT 
Table 1. Summary of measurements in REPARTEE I and II at the BT Tower and Regents Park Sites.

\begin{tabular}{|c|c|c|c|c|c|c|c|c|}
\hline Species measured & $\begin{array}{l}\text { Analytical technique } \\
\text { (REPARTEE I/II) }\end{array}$ & $\begin{array}{l}\text { Instrument } \\
\text { (Manufacturer) }\end{array}$ & $\begin{array}{l}\text { Temporal } \\
\text { Resolution }\end{array}$ & $\begin{array}{l}\text { Detection } \\
\text { limit }\end{array}$ & $\begin{array}{l}\text { Measurement } \\
\text { Uncertainty }\end{array}$ & $\begin{array}{l}\text { Campaign } \\
\text { (REPARTEE- } \\
\text { I/II) }\end{array}$ & $\begin{array}{l}\text { Responsible } \\
\text { Institute }\end{array}$ & Reference \\
\hline \multicolumn{9}{|l|}{ BT Tower } \\
\hline Turbulence \& heat flux & Ultrasonic anemometer & $\begin{array}{l}\text { R3Research Anemome- } \\
\text { ter (Gill Instruments) }\end{array}$ & $\begin{array}{l}20 \mathrm{~Hz} \\
30 \mathrm{~min} \\
\text { flux }\end{array}$ & & & $\mathrm{I} / \mathrm{II}$ & $\begin{array}{l}\text { U. Read- } \\
\text { ing/CEH }\end{array}$ & \\
\hline $\begin{array}{l}\text { Meteorology ( } T, \mathrm{RH}, P, \\
\text { precipitation, wind speed } \\
\& \text { direction) }\end{array}$ & Capacitive detectors & $\begin{array}{l}\text { Weather Transmitter } \\
\text { WXT510 (Vaisala Ltd.) }\end{array}$ & $5 \mathrm{~min}$ & & & $\mathrm{I} / \mathrm{II}$ & $\mathrm{KCL} / \mathrm{CEH}$ & \\
\hline $\begin{array}{l}\text { Sub-micron non- } \\
\text { refractory } \mathrm{NH}_{4}^{+}, \mathrm{NO}_{3}^{-} \text {, } \\
\mathrm{SO}_{4}^{2-}, \mathrm{Cl}^{-}, \mathrm{Org} \& \text { size } \\
\text { distribution }(40-800 \mathrm{~nm})\end{array}$ & $\begin{array}{l}\text { Aerosol mass spectrome- } \\
\text { ter for concentration and } \\
\text { flux }\end{array}$ & $\begin{array}{l}\text { Q-AMS/HR-ToF-AMS } \\
\text { (Aerodyne Research } \\
\text { Inc.) }\end{array}$ & $\begin{array}{l}5 \text { min con- } \\
\text { centration; } \\
30 \text { min } \\
\text { flux }\end{array}$ & $\begin{array}{l}\text { Conc: } \\
10 \mathrm{ng} \mathrm{m}^{-3} \\
\text { Flux: } \\
5 \mathrm{ng} \mathrm{m}^{-2} \mathrm{~s}^{-1}\end{array}$ & $\begin{array}{l}\text { Max } \\
\left(100 \mathrm{ng} \mathrm{m}^{-3}\right. \\
\pm 20 \%)\end{array}$ & $\mathrm{I} / \mathrm{II}$ & $\mathrm{CEH}$ & $\begin{array}{l}\text { Jayne et } \\
\text { al. (2000); } \\
\text { DeCarlo et } \\
\text { al. (2006); } \\
\text { Nemitz et } \\
\text { al. (2008); } \\
\text { Phillips et al. } \\
\text { (2010a, b) }\end{array}$ \\
\hline $\begin{array}{l}\text { Reactive gases }\left(\mathrm{HNO}_{3} \text {, }\right. \\
\left.\mathrm{HCl}, \mathrm{NH}_{3}, \mathrm{SO}_{2}, \mathrm{HONO}\right) \\
\text { and water-soluble } \\
\text { aerosol components } \\
\text { in } \mathrm{PM}_{2.5} / \mathrm{TSP}\left(\mathrm{NH}_{4}^{+},\right. \\
\left.\mathrm{NO}_{3}^{-}, \mathrm{SO}_{4}^{2-}, \mathrm{Cl}^{-}\right)\end{array}$ & $\begin{array}{l}\text { Wet-chemistry analyser } \\
\text { linking denuder/steam } \\
\text { jet aerosol collector } \\
\text { sampling to online ion } \\
\text { chromatography }\end{array}$ & GRAEGOR & $60 \mathrm{~min}$ & $20 \mathrm{ng} \mathrm{m}^{-3}$ & $\begin{array}{l}\text { Max } \\
\left(200 \mathrm{ng} \mathrm{m}^{-3}\right. \\
\pm 20 \%)\end{array}$ & $\mathrm{I} / \mathrm{II}$ & $\mathrm{CEH}$ & $\begin{array}{l}\text { Thomas et } \\
\text { al. (2009); } \\
\text { Nemitz et } \\
\text { al. (2010) }\end{array}$ \\
\hline CO concentration \& flux & $\begin{array}{l}\text { Cold vapour fluores- } \\
\text { cence }\end{array}$ & AL-5002 (AeroLaser) & $\begin{array}{l}10 \mathrm{~Hz} \\
30 \mathrm{~min} \\
\text { flux }\end{array}$ & $1 \mathrm{ppb}$ & & $\mathrm{I} / \mathrm{II}$ & $\mathrm{CEH}$ & $\begin{array}{l}\text { Famulari et } \\
\text { al. (2010) }\end{array}$ \\
\hline $\begin{array}{l}\mathrm{CO}_{2} \text { concentration } \\
\& \text { flux }\end{array}$ & Infra-red gas analyser & $\begin{array}{l}\text { IRGA 7000/6262 } \\
\text { (LI-COR) }\end{array}$ & $\begin{array}{l}10 \mathrm{~Hz} \\
30 \mathrm{~min} \\
\text { flux }\end{array}$ & $1 \mathrm{ppm}$ & & $\mathrm{I} / \mathrm{II}$ & $\mathrm{CEH}$ & \\
\hline $\begin{array}{l}\text { Concentration \& flux of } \\
\text { selected VOC (isoprene, } \\
\text { monoterpenes, } \\
\text { methanol, acetone, } \\
\text { acetaldehyde, ...) }\end{array}$ & $\begin{array}{l}\text { Proton transfer reaction } \\
\text { mass spectrometer }\end{array}$ & PTR-MS (Ionicon) & $\begin{array}{l}2 \mathrm{~Hz} \\
30 \mathrm{~min} \\
\text { flux }\end{array}$ & & & I & $\begin{array}{l}\text { Lancaster/ } \\
\mathrm{CEH}\end{array}$ & $\begin{array}{l}\text { Langford et } \\
\text { al. }(2009 \text {, } \\
2010)\end{array}$ \\
\hline $\begin{array}{l}\mathrm{H}_{2} \mathrm{O} \text { concentration \& } \\
\text { flux }\end{array}$ & Infra-red gas analyser & IRGA 7000 (LI-COR) & $\begin{array}{l}10 \mathrm{~Hz} \\
30 \mathrm{~min} \\
\text { flux }\end{array}$ & $10 \mathrm{ppm}$ & & $\mathrm{I} / \mathrm{II}$ & $\mathrm{CEH}$ & \\
\hline $\mathrm{O}_{3}$ flux & $\begin{array}{l}\text { Fast dry chemilumines- } \\
\text { cence analyser }\end{array}$ & ROFI (CEH) & $\begin{array}{l}2 \mathrm{~Hz} \\
30 \mathrm{~min} \\
\text { flux }\end{array}$ & & & I & $\mathrm{CEH}$ & \\
\hline $\begin{array}{l}\text { Size-segregated } \\
\text { number flux } \\
1000 \mathrm{~nm})\end{array}$ & $\begin{array}{l}\text { Optical Particle Spec- } \\
\text { trometer }\end{array}$ & $\begin{array}{l}\text { UHSAS (Particle Mea- } \\
\text { surement Systems) }\end{array}$ & $\begin{array}{l}10 \mathrm{~Hz} \\
30 \mathrm{~min} \\
\text { flux }\end{array}$ & & & $\mathrm{I} / \mathrm{II}$ & $\mathrm{CEH}$ & \\
\hline Ozone & Uv photometry & $\begin{array}{l}\text { Model 205 (2B Tech- } \\
\text { nologies) }\end{array}$ & $5 \mathrm{~min}$ & $1 \mathrm{ppb}$ & $\pm 2 \%$ & II & Univ B'ham & \\
\hline $\mathrm{NO} / \mathrm{NO}_{2} / \mathrm{NO}_{\mathrm{x}}$ & $\begin{array}{l}\text { Chemiluminescence } \\
\text { with Mo converter }\end{array}$ & $\begin{array}{l}42 \mathrm{C}-\mathrm{TL} \\
\text { (Thermo-Electron) }\end{array}$ & $5 \mathrm{~min}$ & $50 \mathrm{ppt}$ & $\pm 15 \%$ & II & Univ B'ham & \\
\hline$\Sigma \mathrm{NO}_{3}+\mathrm{N}_{2} \mathrm{O}_{5}$ & LED-BBCEAS & & $15 \mathrm{~s}$ & $2 \mathrm{ppt}$ & $10-16 \%$ & II & $\begin{array}{l}\text { Univ } \\
\text { Cambridge }\end{array}$ & $\begin{array}{l}\text { Benton et al. } \\
(2010)\end{array}$ \\
\hline Particle number and flux & Butanol condensation & CPC 3010A (TSI Inc.) & $1 \mathrm{~s}$ & $\begin{array}{l}D_{\mathrm{p}}> \\
10 \mathrm{~nm}\end{array}$ & & $\mathrm{I} / \mathrm{II}$ & $\begin{array}{l}\text { Univ } \\
\text { Manchester }\end{array}$ & \\
\hline Particle size distribution & Electrical mobility & SMPS 3080L (TSI Inc.) & $90 \mathrm{~s}$ & $\begin{array}{l}14.9< \\
D_{\mathrm{P}} \\
<673 \mathrm{~nm}\end{array}$ & & $\mathrm{I} / \mathrm{II}$ & $\begin{array}{l}\text { Univ } \\
\text { Manchester }\end{array}$ & \\
\hline Particle size distribution & Time-of-Flight & APS 3321 (TSI Inc) & $1 \mathrm{~s}$ & $\begin{array}{l}0.5< \\
D_{\mathrm{p}}< \\
20 \mu \mathrm{m}\end{array}$ & & $\mathrm{I} / \mathrm{II}$ & $\begin{array}{l}\text { Univ } \\
\text { Manchester }\end{array}$ & \\
\hline $\begin{array}{l}\mathrm{PM}_{10}, \mathrm{PM}_{2.5} \text {, sulphate, } \\
\text { nitrate, chloride, organic } \\
\text { and elemental carbon } \\
(24 \mathrm{~h})\end{array}$ & Dichotomous sampler & Partisol 2025D & $24 \mathrm{~h}$ & $<0.1 \mu \mathrm{g} \mathrm{m}^{-3}$ & & I & Univ B'ham & \\
\hline $\begin{array}{l}\text { Size and composition of } \\
\text { individual particles }\end{array}$ & $\begin{array}{l}\text { Transmission electron } \\
\text { microscope }\end{array}$ & $\begin{array}{l}\text { Philips FEI CM200 } \\
\text { FEGTEM STEM }\end{array}$ & $2 \mathrm{~h}$ & & & I & KCL & $\begin{array}{l}\text { Smith et al. } \\
\text { (2012) }\end{array}$ \\
\hline
\end{tabular}


Table 1. Continued.

\begin{tabular}{|c|c|c|c|c|c|c|c|c|}
\hline Species measured & $\begin{array}{l}\text { Analytical } \\
\text { technique } \\
\text { (REPARTEE I/II) }\end{array}$ & $\begin{array}{l}\text { Instrument } \\
\text { (Manufacturer) }\end{array}$ & $\begin{array}{l}\text { Temporal } \\
\text { Resolution }\end{array}$ & Detection limit & $\begin{array}{l}\text { Measurement } \\
\text { Uncertainty }\end{array}$ & $\begin{array}{l}\text { Campaign } \\
\text { (REPARTEE- } \\
\text { I/II) }\end{array}$ & $\begin{array}{l}\text { Responsible } \\
\text { Institute }\end{array}$ & Reference \\
\hline \multicolumn{9}{|l|}{ Regents Park } \\
\hline $\begin{array}{l}\text { Meteorology ( } T, \mathrm{RH}, P \text {, } \\
\text { precipitation, wind speed } \\
\& \text { direction) }\end{array}$ & Capacitive detectors & $\begin{array}{l}\text { Weather Transmitter } \\
\text { WXT510 (Vaisala Ltd) }\end{array}$ & $5 \mathrm{~min}$ & & & $\mathrm{I} / \mathrm{II}$ & $\mathrm{CEH}$ & \\
\hline $\mathrm{NO} / \mathrm{NO}_{2} / \mathrm{NO}_{\mathrm{x}}$ & $\begin{array}{l}\text { Chemiluminescence us- } \\
\text { ing thermal converter }\end{array}$ & $\begin{array}{l}42 \mathrm{C}-\mathrm{TL} \text { (Thermo Envi- } \\
\text { ron.) }\end{array}$ & $5 \mathrm{~min}$ & $50 \mathrm{ppt}$ & & I & $\mathrm{CEH}$ & \\
\hline $\mathrm{O}_{3}$ & UV photometry & 49 (Thermo Environ) & $5 \mathrm{~min}$ & $1 \mathrm{ppb}$ & & I & $\mathrm{CEH}$ & \\
\hline $\mathrm{SO}_{2}$ & $\begin{array}{l}\text { Pulsed chemilumines- } \\
\text { cence }\end{array}$ & 43S (Thermo Environ.) & $5 \mathrm{~min}$ & & & I & $\mathrm{CEH}$ & \\
\hline Particle size distribution & Electrical mobility & SMPS 3080L (TSI Inc) & $90 \mathrm{~s}$ & $\begin{array}{l}14.9< \\
D_{\mathrm{p}}< \\
673 \mathrm{~nm}\end{array}$ & & $\mathrm{I} / \mathrm{II}$ & $\begin{array}{l}\text { Univ } \\
\text { Manchester }\end{array}$ & \\
\hline Particle size distribution & Time-of-Flight & APS 3321 (TSI Inc) & $1 \mathrm{~s}$ & $\begin{array}{l}0.5< \\
D_{\mathrm{p}}< \\
20 \mu \mathrm{m}\end{array}$ & & $\mathrm{I} / \mathrm{II}$ & $\begin{array}{l}\text { Univ } \\
\text { Manchester }\end{array}$ & \\
\hline Particle number & Butanol condensation & UCPC 3776 (TSI Inc.) & $1 \mathrm{~s}$ & $\begin{array}{l}D_{\mathrm{p}}> \\
2.5 \mathrm{~nm}\end{array}$ & & $\mathrm{I} / \mathrm{II}$ & $\begin{array}{l}\text { Univ } \\
\text { Manchester }\end{array}$ & \\
\hline Particle size distribution & Electrical mobility & $\begin{array}{l}\text { DMPS (Univ. } \\
\text { Manchester) }\end{array}$ & $1 \mathrm{~s}$ & $\begin{array}{l}5.05< \\
D_{\mathrm{p}}< \\
783 \mathrm{~nm}\end{array}$ & & & $\begin{array}{l}\text { Univ } \\
\text { Manchester }\end{array}$ & \\
\hline Particle size distribution & Light scattering & Model 1.108 (Grimm) & $1 \mathrm{~s}$ & $\begin{array}{l}0.3< \\
D_{\mathrm{p}}< \\
20 \mu \mathrm{m}\end{array}$ & & $\mathrm{I} / \mathrm{II}$ & $\begin{array}{l}\text { Univ } \\
\text { Manchester }\end{array}$ & \\
\hline Black carbon & $\begin{array}{l}\text { Multi-angle absorption } \\
\text { photometer }\end{array}$ & $\begin{array}{l}\text { MAAP } 5012 \text { (Thermo } \\
\text { Scientific) }\end{array}$ & & & & $\mathrm{I} / \mathrm{II}$ & $\begin{array}{l}\text { Univ } \\
\text { Manchester }\end{array}$ & $\begin{array}{l}\text { Petzold and } \\
\text { Schonlinner } \\
(2004)\end{array}$ \\
\hline Particle number and flux & Butanol concentration & CPC 3010A (TSI Inc.) & $1 \mathrm{~s}$ & $\begin{array}{l}D_{\mathrm{P}}> \\
10 \mathrm{~nm}\end{array}$ & & $\mathrm{I} / \mathrm{II}$ & $\begin{array}{l}\text { Univ } \\
\text { Manchester }\end{array}$ & \\
\hline Soot & $\begin{array}{l}\text { Particle soot absorption } \\
\text { photometer }\end{array}$ & $\begin{array}{l}\text { PSAP (Radiance } \\
\text { Research) }\end{array}$ & & $0-5 \times 10^{-5} \mathrm{~m}^{-1}$ & & II & $\begin{array}{l}\text { Univ } \\
\text { Manchester }\end{array}$ & \\
\hline $\begin{array}{l}\text { Size and composition of } \\
\text { individual particles }\end{array}$ & $\begin{array}{l}\text { Aerosol Time-of-Flight } \\
\text { mass spectrometry }\end{array}$ & ATOFMS 3800 (TSI Inc) & $<20 \mathrm{~s}^{-1}$ & & & I & Univ B'ham & $\begin{array}{l}\text { Gard et al. } \\
(1997)\end{array}$ \\
\hline $\begin{array}{l}\mathrm{PM}_{10}, \mathrm{PM}_{2.5} \text {, sulphate, } \\
\text { nitrate, chloride, organic, } \\
\text { and elemental carbon } \\
(24 \mathrm{~h})\end{array}$ & Dichotomous sampler & Model 2025D (Partisol) & $24 \mathrm{~h}$ & $<0.1 \mu \mathrm{g} \mathrm{m}^{-3}$ & & I & Univ B'ham & \\
\hline Windspeed, direction & Sonic anemometry & $\begin{array}{l}\text { Research Anemometer } \\
\text { (Gill Instruments) }\end{array}$ & $1 \mathrm{~Hz}$ & $0.02 \mathrm{~cm} \mathrm{~s}^{-1}$ & & $\mathrm{I} / \mathrm{II}$ & $\begin{array}{l}\text { Univ } \\
\text { Manchester }\end{array}$ & \\
\hline $\begin{array}{l}\text { Temperature/relative hu- } \\
\text { midity }\end{array}$ & & HMT 107 (Vaisala Ltd.) & & & $\begin{array}{l}+0.2^{\circ} \mathrm{C} \pm 2 \% \\
\mathrm{RH}\end{array}$ & $\mathrm{I} / \mathrm{II}$ & $\begin{array}{l}\text { Univ } \\
\text { Manchester }\end{array}$ & \\
\hline $\begin{array}{l}\text { Sub-micron non- } \\
\text { refractory } \mathrm{NH}_{4}^{+}, \mathrm{NO}_{3}^{-} \text {, } \\
\mathrm{SO}_{4}^{2-}, \mathrm{Cl}^{-}, \text {org and size } \\
\text { dist }{ }^{\mathrm{n}}\end{array}$ & $\begin{array}{l}\text { Aerosol mass spectrome- } \\
\text { try }\end{array}$ & $\begin{array}{l}\text { C-TOF-AMS (Aerdoyne } \\
\text { Research Inc.) }\end{array}$ & $5 \mathrm{~min}$ & $10 \mathrm{ng} \mathrm{m}^{-3}$ & $\begin{array}{l}\text { Max } \\
100 \mathrm{ng} \mathrm{m}^{-3} \\
\pm 20 \%\end{array}$ & I & $\begin{array}{l}\text { Univ } \\
\text { Manchester }\end{array}$ & $\begin{array}{l}\text { Canagaratna } \\
\text { (2007); Allan } \\
\text { et al. (2010) }\end{array}$ \\
\hline $\begin{array}{l}\text { Sub-micron non- } \\
\text { refractory } \mathrm{NH}_{4}^{+}, \mathrm{NO}_{3}^{-} \text {, } \\
\mathrm{SO}_{4}^{2-}, \mathrm{Cl}^{-} \text {, org and size } \\
\text { dist }^{\mathrm{n}}\end{array}$ & $\begin{array}{l}\text { Aerosol mass spectrome- } \\
\text { try }\end{array}$ & $\begin{array}{l}\text { HR-TOF-AMS (Aer- } \\
\text { doyne Research Inc.) }\end{array}$ & $5 \mathrm{~min}$ & $10 \mathrm{ng} \mathrm{m}^{-3}$ & $\begin{array}{l}\text { Max } \\
100 \mathrm{ng} \mathrm{m}^{-3} \\
\pm 20 \%\end{array}$ & II & $\begin{array}{l}\text { Univ } \\
\text { Manchester }\end{array}$ & $\begin{array}{l}\text { Drewnick et } \\
\text { al. (2005) }\end{array}$ \\
\hline \multicolumn{9}{|l|}{$\begin{array}{l}\text { University of } \\
\text { Westminster }\end{array}$} \\
\hline $\begin{array}{l}\text { Atmospheric vertical } \\
\text { structure (Doppler } \\
\text { velocity and backscatter) }\end{array}$ & Pulsed Doppler Lidar & & $0.25-1 \mathrm{~Hz}$ & & & II & $\begin{array}{l}\text { Univ Salford/ } \\
\text { Reading }\end{array}$ & \\
\hline \multicolumn{9}{|l|}{ Various Locations } \\
\hline $\begin{array}{l}\text { Perfluorocarbon tracer } \\
\text { experiments }\end{array}$ & $\begin{array}{l}\text { Bag sampling/ } \\
\text { GC-NICI-MS }\end{array}$ & $\begin{array}{l}\text { GC } 5973 \\
\text { (Hewlett Packard) }\end{array}$ & & $1-10 \mathrm{ppq}$ & $\pm 5 \%$ & $\mathrm{I} / \mathrm{II}$ & Univ Bristol & $\begin{array}{l}\text { Martin et al. } \\
(2010 a, b \\
\text { 2011a) }\end{array}$ \\
\hline
\end{tabular}

Note: KCL is Kings College, London and CEH is Centre for Ecology and Hydrology. 
Table 2. Summary of measurements in REPARTEE I and II at the Marylebone Road and North Kensington sites.

\begin{tabular}{llll}
\hline Species measured & Analytical Technique & Operator & \\
\hline Marylebone Road & & & Campaign \\
\hline $\mathrm{NO} \mathrm{NO}_{2} / \mathrm{NO}_{\mathrm{x}}$ & Chemiluminescence & AURN & I/II \\
Ozone & u.v. absorption & AURN & I/II \\
Sulphur dioxide & u.v. fluorescence & AURN & I/II \\
$\mathrm{PM}_{10}$ mass & TEOM (grav. equiv.) & AURN & I/II \\
$\mathrm{PM}_{2.5}$ mass & TEOM (grav. equiv.) & AURN & I/II \\
Particle number concentration & TSI 3022A CPC & NPL & I/II \\
Particle number distribution & TSI 3080 + TSI 3776 CPC & II \\
& TSI 3321 APS & Birmingham & II \\
\hline North Kensington & & & I/II \\
\hline NO/NO $/ \mathrm{NO}_{\mathrm{x}}$ & Chemiluminescence & AURN & I/II \\
Ozone & u.v. absorption & AURN & AURN \\
Sulphur dioxide & u.v. fluorescence & AURN \\
PM mass & TEOM (grav. equiv.) & NPL \\
Particle number & TSI 3022A CPC & I/II \\
\hline
\end{tabular}

Note: AURN = Automatic Urban \& Rural Network operated on behalf of Dept. for Environment, Food \& Rural Affairs.

NPL = National Physical Laboratory, operating particle counting and sizing instruments on behalf of Dept. for Environment, Food \& Rural Affairs.

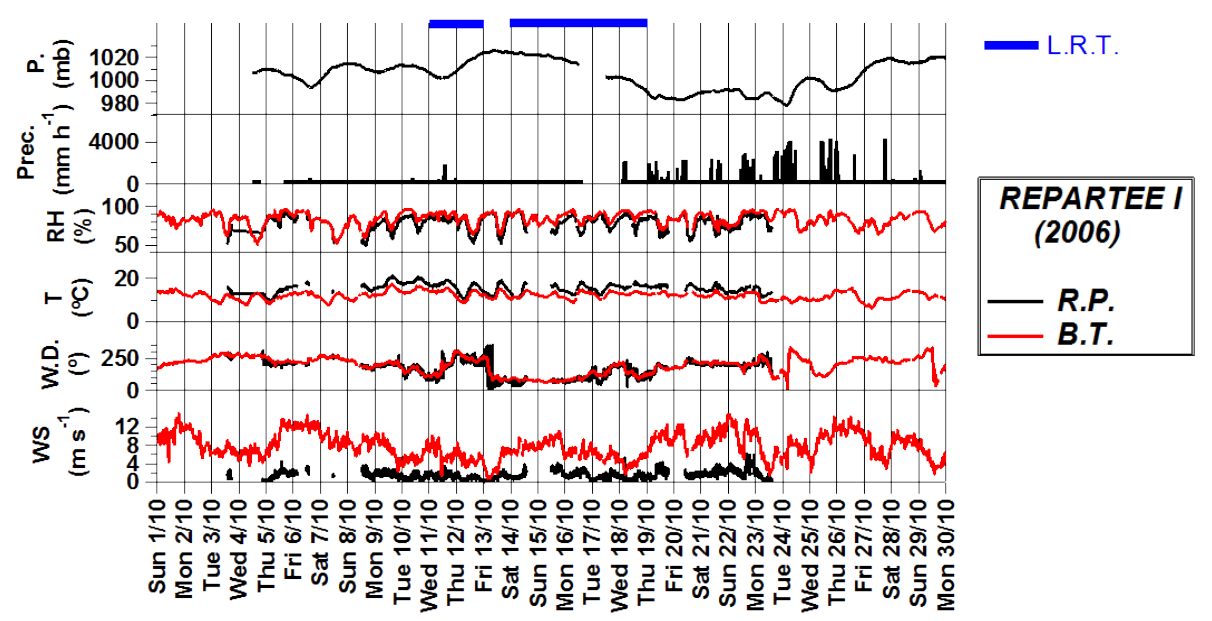

Fig. 3. Local meteorological measurements from the R. Park and BT Tower sites during REPARTEE I. LRT indicates periods of long-range transport.

Tower, averaging $7.6 \pm 0.3 \mathrm{~m} \mathrm{~s}^{-1}$ (s.d. of daily means) compared to $1.5 \pm 0.8 \mathrm{~m} \mathrm{~s}^{-1}$ at the Regents Park site. Wind directions varied little between the sites, reflecting the good exposure and lack of building effects at both sites. There is little suggestion of a consistent directional wind shear (Fig. 3). Temperature in REPARTEE I was consistently higher at the ground-level R. Park site, typically by about $2{ }^{\circ} \mathrm{C}$, but on some nights the temperatures converged, suggesting a stable atmosphere. Relative humidities averaged around $80 \%$ (typical of the UK) with a typical diurnal variation anti-correlated with temperature. Relative humidities were generally higher on the Tower than in Regents Park, consistent with the lower temperatures. While during daytime, average wind speeds increased in Regents Park (Fig. S1 in Supplement), there was a slight decrease in average windspeed on the BT tower between 07:00 and 15:00 (Fig. S1).

\subsection{Meteorological variables: REPARTEE II}

Meteorological conditions during REPARTEE II appear in Fig. 4. Average wind speed values for the BT Tower were slightly lower $\left(6.4 \pm 3 \mathrm{~m} \mathrm{~s}^{-1}\right)$ relative to REPARTEE I. Average temperature at the $\mathrm{BT}$ tower $\left(7.7 \pm 2^{\circ} \mathrm{C}\right)$ and R. Park $\left(10.4 \pm 3{ }^{\circ} \mathrm{C}\right)$ were cooler than during REPARTEE I, and the 


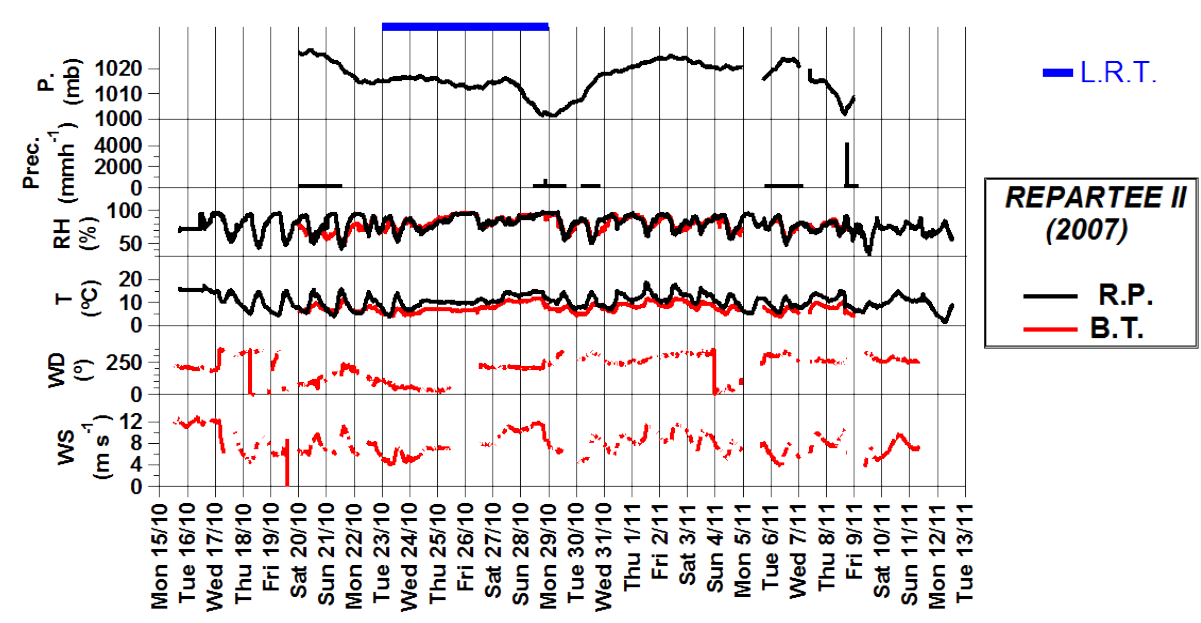

Fig. 4. Local meteorological measurements from the R. Park and BT Tower sites during REPARTEE II.
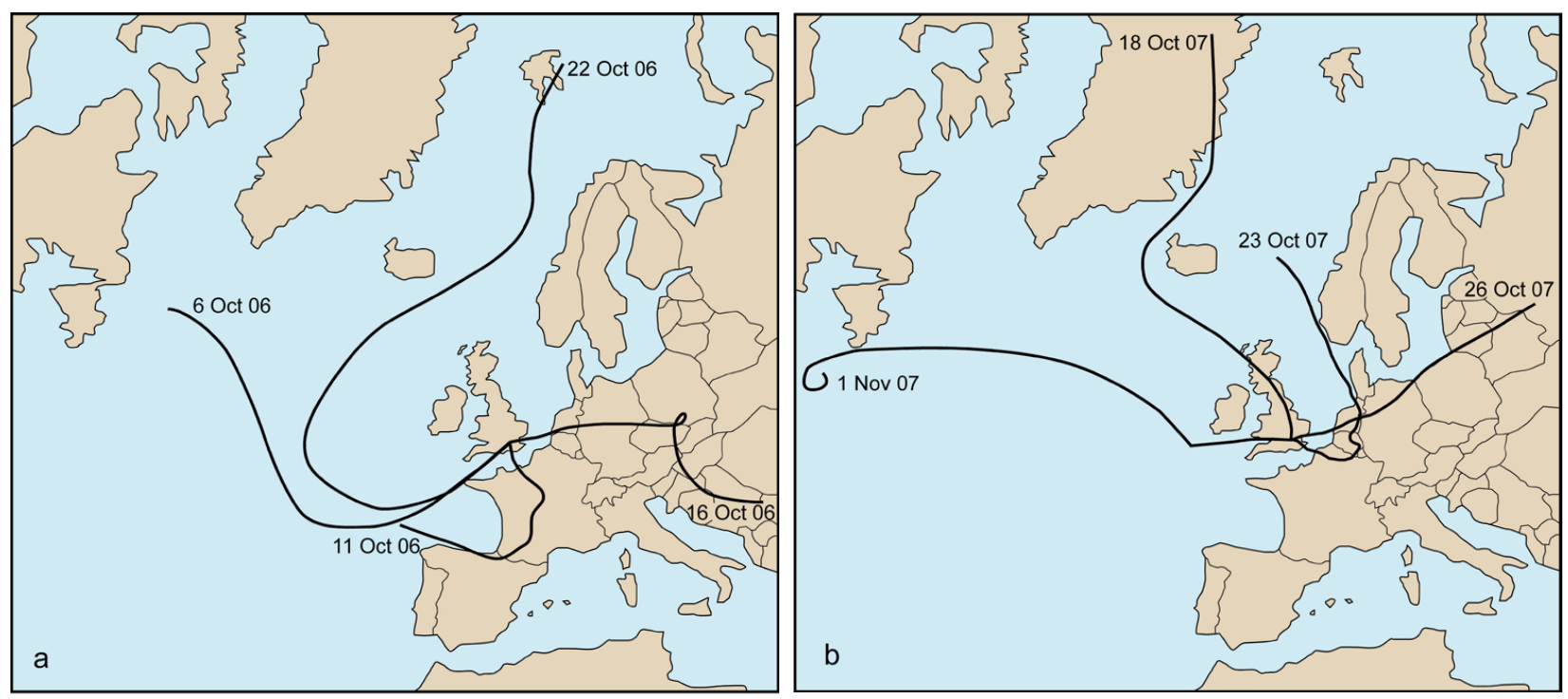

Fig. 5. Examples of the types of air mass trajectory experienced in (a) REPARTEE I and (b) REPARTEE II.

$\mathrm{RH}$ at the BT Tower $(79.3 \pm 11 \%)$ and R. Park $(77.7 \pm 12 \%)$ were similar.

Probably the largest difference between the two field studies was observed for the atmospheric pressure (corrected to sea level), with higher values for the second field study $(1016 \pm 6 \mathrm{mb})$ relative to the first campaign $(1005 \pm 12 \mathrm{mb})$. The higher variety of different air masses encountered for the REPARTEE I was also reflected in a higher standard deviation for REPARTEE I. The relatively high pressures in REPARTEE II were frequently associated with cloudless night skies, reflected in shallow nocturnal boundary layers (Barlow et al., 2011).

A number of precipitation events were recorded during REPARTEE I (especially during the second part of the field study; 18-26 October 2006) whilst only two events were observed during REPARTEE II (28 October and 8 November 2009).

\subsection{Back trajectories during REPARTEE I}

Five day trajectories terminating in London at altitudes of 200, 500 and $1000 \mathrm{~m}$ were calculated by the HYSPLIT online model. These were categorised according to the origins of the air masses received at midnight and 1200 each day. The trajectories varied greatly from almost pure maritime air (12:00 UTC on 6 October 2006), to those travelling over France and Spain (12:00 UTC on 11 October 2006) or with largely polar origins (00:00 UTC on 22 October 2006) to air masses which had travelled over the European mainland for several days (00:00 UTC on 16 October 2006). These 
Table 3. Classification of air mass origins during REPARTEE.

\begin{tabular}{|c|c|}
\hline Date & Air mass origin \\
\hline \multicolumn{2}{|l|}{ REPARTEE I } \\
\hline 1-3 October 2006 & N. Atlantic \\
\hline $3-5$ October & Polar/Scandinavia \\
\hline 5-8 October & N. Atlantic \\
\hline $8-12$ October & Atlantic across France/Spain \\
\hline 12-14 October & N. Atlantic \\
\hline 14-17 October & European continent (east) \\
\hline 17-19 October & European continent (south) \\
\hline 19-24 October & N. Atlantic across France/Spain \\
\hline 24-25 October & N. Atlantic \\
\hline 25-27 October & Atlantic across France/Spain \\
\hline 27-28 October & Polar \\
\hline 29-31 October & N. Atlantic \\
\hline \multicolumn{2}{|l|}{ REPARTEE II } \\
\hline 17-20 October 2007 & Polar \\
\hline 21-23 October & Polar via Scandinavia and near continent \\
\hline 23-25 October & European continent (north) \\
\hline 25-29 October & European continent (various) \\
\hline 29 October-2 November & N. Atlantic \\
\hline 3-4 November & N. Atlantic across France \\
\hline 4-8 November & N. Atlantic \\
\hline 9 November & South across France \\
\hline 9-12 November & N. Atlantic \\
\hline 12 November & Polar \\
\hline 13-14 November & N. Atlantic \\
\hline 15 November & Central Europe across Scandinavia \\
\hline
\end{tabular}

examples appear in Fig. 5a. A generic classification of air mass origins appears in Table 3.

The month of October started with the dominance of North Atlantic air, which continued until 3 October, when air masses became more northerly, arriving after crossing northern Scandinavia. By 5 October, the Atlantic air masses had once again taken over, with some trajectories to the UK passing over France and Spain for a number of days from 8-12 October. From 13-17 October the UK was subject to high pressure and from 14-17 October air masses approached from continental Europe, initially from the east, but by 18-20 October, a maritime circulation had re-established, but with air reaching the UK from a southerly sector crossing France. These conditions persisted until 27 October when there was a brief spell of polar air, returning to a North Atlantic circulation for the remainder of the month.

\subsection{Back trajectories during REPARTEE II}

The early days of the campaign were characterised by air masses originating over polar regions, typically northern Greenland (e.g. 12:00 UTC on 18 October, see Fig. 5b). By 23 October, although still with northerly origins, the air masses were crossing the near-continent before arriving in the UK (e.g. 00:00 UTC on 23 October). This was followed by a few days of persistently continental air masses (e.g. 12:00 UTC on 26 October, Fig. 5b). By 29 October, North Atlantic air had re-established its dominance (e.g. 00:00 UTC on 1 November). Although, in some cases briefly crossing France, Atlantic or polar air re-established itself for the remainder of the campaign, until the last day (25 November), when an easterly circulation originating over central Europe took over. Typical examples of back trajectories appear in Fig. 5b, and Table 3 summarises the entire campaign.

\subsection{Boundary layer structure}

Boundary layer structure over urban areas can be complex due to the heterogeneous, rough surface, and the urban heat island, caused by anthropogenic heat emissions, reduced albedo and the delayed cooling of the urban surface at night (Roth, 2000). Both of these factors affect the mixing height, up to which surface-released pollutants are transported. During REPARTEE II, as part of the experimental strategy a Doppler lidar was deployed at the 
a)

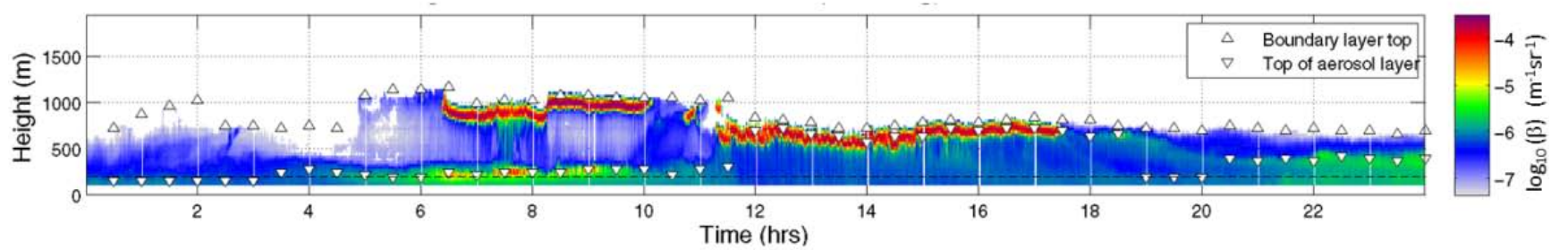

b)

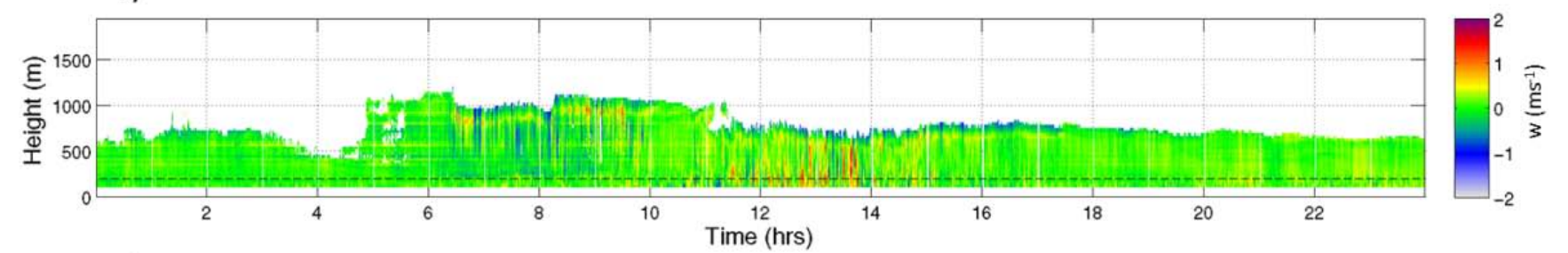

c)

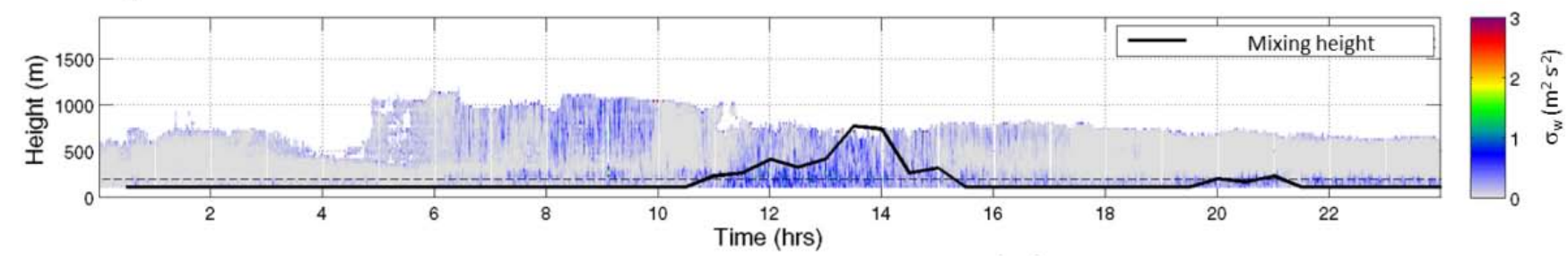

Fig. 6. Doppler lidar observations on 31 October 2007 of backscatter $\beta\left(\mathrm{m}^{-1} \mathrm{sr}^{-1}, \log _{10}\right.$ scale), vertical wind velocity $w\left(\mathrm{~m} \mathrm{~s}{ }^{-1}\right)$ and variance of vertical wind velocity $\sigma_{w}^{2}\left(\mathrm{~m}^{2} \mathrm{~s}^{-2}\right)$. Observations show $1 \mathrm{~min}$ averages of $0.278 \mathrm{~Hz}$ data. Derived heights of boundary layer top, aerosol layer and mixing height are also shown. Dashed line shows height of BT Tower $(190 \mathrm{~m})$.

study site to provide continuous measurements of boundary layer turbulence. The set-up and results are reported in this Special Issue (http://www.atmos-chem-phys-discuss. net/special_issue95.html) (Barlow et al., 2011), and are the first quantitative observations of the structure of central London's boundary layer, following Spanton and Williams (1988) sodar observations of mixing height.

The lidar operated in vertical stare mode with a $3.6 \mathrm{~s}$ integration time: Fig. 6 shows Doppler lidar observations of backscatter, Doppler velocity and velocity variance for 31 October 2007. Note that the lidar wavelength is $1.5 \mu \mathrm{m}$ thus the backscatter is mainly from relatively coarse aerosol particles. Many interesting features can be seen: from 00:00 to 06:00, high backscatter near the ground indicates an aerosol layer of depth $z_{\mathrm{AER}}$, the top of which is marked. During the same period, the variance shows there is little turbulence in the layer. From 06:00 to 10:00, a layer of cloud is indicated by high backscatter at ca. $1000 \mathrm{~m}$; the vertical wind velocity shows downward mixing associated with the cloud, and an increase in turbulence in the layer at the ground - this is marked by a black line as the mixing height, $z_{\mathrm{MH}}$. After a brief break in cloud, the daytime convective mixing begins from ca. 10:00 onwards: there is an increase in variance and mixing height and the backscatter decreases as aerosol is dispersed. Cloud tops the boundary layer until ca. 17:00. Thereafter $z_{\mathrm{MH}}$ decreases rapidly as solar heating of the ground

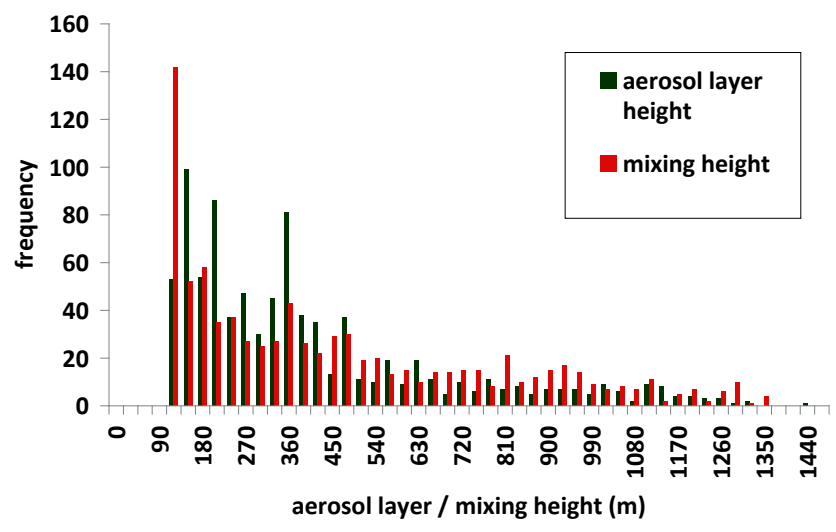

Fig. 7. Histogram of aerosol layer height, $z_{\mathrm{AER}}$, and mixing height, $z_{\mathrm{MH}}$ in REPARTEE II derived from Doppler lidar data. Bin width equals lidar gate depth.

ceases, and the backscatter shows distinct layers of aerosols at different heights which evolve in the nocturnal boundary layer.

Figure 7 shows the frequency of occurrence of the two derived heights, $z_{\mathrm{AER}}$ and $z_{\mathrm{MH}}$, for the 18 days of operation for $30 \mathrm{~min}$ averaged periods. The lidar gates are $30 \mathrm{~m}$ in depth, and the lowest operational gate was 90 to $120 \mathrm{~m}$ to which both $z_{\mathrm{AER}}$ and $z_{\mathrm{MH}}$ defaulted if layers were below 


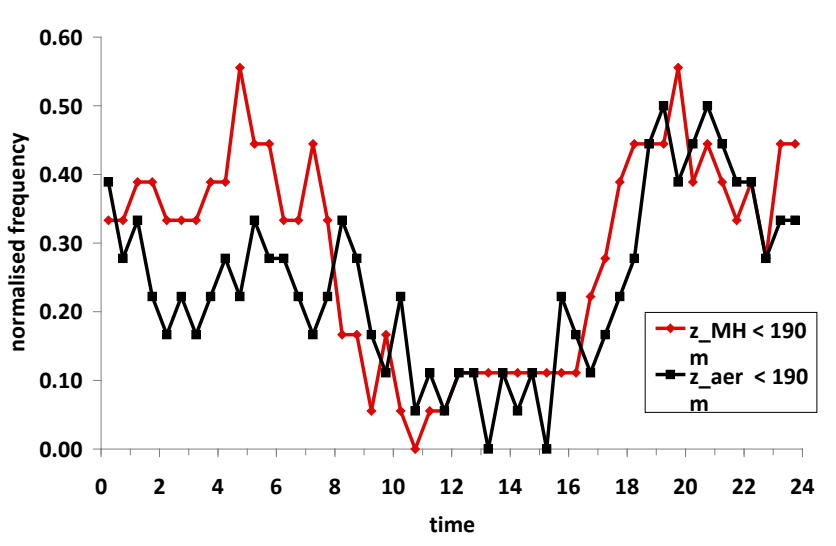

Fig. 8. Normalised frequency of occurrence of aerosol layer $\left(z_{\mathrm{AER}}\right)$ and mixing height $\left(z_{\mathrm{MH}}\right)$ being lower than BT Tower $(190 \mathrm{~m})$ during REPARTEE II campaign.

this height, and thus undetectable. It can be seen that most of the time, both turbulence and aerosol layers were below ca. $500 \mathrm{~m}$ - given the autumnal timing of the campaign the boundary layer was not expected to be deep. The observations showed a significant number of occasions when the aerosol or turbulent layers appeared to be lower than the BT Tower $(190 \mathrm{~m})$ according to the height derivation algorithms. Figure 8 shows the diurnal cycle of the frequency of occurrence of $z_{\mathrm{AER}}$ and $z_{\mathrm{MH}}<190 \mathrm{~m}$. There are significant numbers of events at night where both layers appear to be lower than the BT Tower - this indicates that the nocturnal urban boundary layer in London can become stratified; and that the BT Tower measurements were then decoupled from the surface. It is also notable that the two layer heights behave differently at night: the aerosol layer tends to deepen at night, whilst the mixing height becomes shallower (Barlow et al., 2011), hence the difference in Fig. 8. It should be noted that atmospheric pressure was unusually high during the campaign compared to the UK climatology: high pressure systems can lead to clear sky periods, and in turn to a more stable boundary layer. Analysis of a longer term dataset would be required to establish how representative the current results are.

\section{Overview of results and discussion}

\subsection{Particulate matter, $\mathbf{P M}_{2.5}, \mathrm{PM}_{10}$ and $\mathbf{P M}_{2.5-10}$}

\subsubsection{REPARTEE I}

$\mathrm{PM}_{2.5}$ and $\mathrm{PM}_{10}$ daily gravimetric measurements were taken during REPARTEE I at the BT Tower site and the R. Park site. Moreover, data from the monitoring stations at M. Road and NK were also included in the analysis (see Fig. 9). $\mathrm{PM}_{2.5}$ data for different sites gave minimum, maximum, average and one sigma standard deviation (all in $\mu \mathrm{g} \mathrm{m}^{-3}$ ) as: R. Park (5, 30, $10 \pm 6)$, BT Tower $(4,37,10 \pm 8)$ and M. Road (11, 46, $24 \pm 7)$; whereas $\mathrm{PM}_{10}$ data for the four sites gave minimum, maximum, average and one sigma standard deviation (all in $\mu \mathrm{g} \mathrm{m}^{-3}$ ) as: NK $(15,65,26 \pm 11)$, M. Road (31, 91, 56 \pm 13$)$, BT Tower $(9,49,17 \pm 9)$ and R. Park $(10,44,18 \pm 8)$, respectively. Strong correlations were found between $\mathrm{PM}_{10} \mathrm{NK}$ and $\mathrm{PM}_{10}$ R. Park $\left(R^{2}=0.95\right.$; $\left.Y_{\mathrm{RP}}=0.67 X_{\mathrm{NK}}\right)$ and together with the zero intercept reflect the strong correlation between the two sites. Strong $\mathrm{PM}_{10}$ correlations were also found between the BT Tower site and the two background sites of $\mathrm{NK}\left(R^{2}=0.94 ; Y_{\mathrm{BT}}=\right.$ $\left.0.77 X_{\mathrm{NK}}-3\right)$ and R. Park $\left(R^{2}=0.96 ; Y_{\mathrm{BT}}=1.11 X_{\mathrm{NK}}-3\right)$. The coarse fraction $\mathrm{PM}_{2.5-10}$ was also found to be highly correlated between R. Park and BT Tower $\left(R^{2}=0.7 ; Y_{\mathrm{RP}}=\right.$ $0.8 X_{\mathrm{BT}}+1.5$ ). Much weaker $\mathrm{PM}_{10}$ correlations were found between the roadside site M. Road and NK or R. Park $\left(R^{2}=0.45 ; Y_{\mathrm{MR}}=0.78 X_{\mathrm{NK}}+35\right)$, whereas the coarse fraction $\left(\mathrm{PM}_{2.5-10}\right)$ was found to be poorly correlated between M. Road and R. Park $\left(R^{2}=0.3 ; Y_{\mathrm{MR}}=1.8 X_{\mathrm{RP}}+18\right)$ reflecting the additional sources of coarse aerosols for the M. Road site likely to be associated with road dust and abrasion products.

The daily $\mathrm{PM}_{10}$ Limit Value of $50 \mu \mathrm{g} \mathrm{m}^{-3}$ was exceeded for 3 days at NK (15-17 October) and almost every day at the M. Road site but for only one day (16 October) for both BT Tower and R. Park. The period of the 15-17 October was subject to long range transport (LRT) of nitrate (Dall'Osto et al., 2009b; Nemitz et al., 2012a), which was an appreciable component of the aerosol mass loadings. Figure 9 shows that for the NK, R. Park and BT Tower sites the impact of the long range transport period of 14-17 October was evident in the $\mathrm{PM}_{10}$ fraction, whilst although an increment was seen during the same period for the M. Road site, the trend was less pronounced. The coarse mode $\mathrm{PM}_{2.5-10}$ for the three sites (Fig. 9b) did not show much variation for the month of October. By contrast, the fine component $\mathrm{PM}_{2.5}$ showed the highest concentrations during LRT periods, with an enhancement of about a factor of 4 relative to the other days at the background sites (Fig. 9c).

\subsubsection{REPARTEE II}

$\mathrm{PM}_{\mathrm{x}}$ data were not available for the R. Park and BT Tower sites, but $\mathrm{PM}_{10}$ data from the M. Road and NK air quality monitoring stations were analysed (see Fig. 10). Minimum, maximum, average and one sigma standard deviation (all in $\mu \mathrm{g} \mathrm{m}^{-3}$ ) for the two sites were: NK $(12,73,29 \pm 11)$ and M. $\operatorname{Road}(24,107,48 \pm 18) . \mathrm{PM}_{2.5}$ concentrations were available only for the M. Road site $\left(11,70,24 \pm 11 \mu \mathrm{g} \mathrm{m}^{-3}\right)$ and were on average about $65 \%$ of the total $\mathrm{PM}_{10}$ mass. $\mathrm{PM}_{10}$ exceeded the daily $50 \mu \mathrm{g} \mathrm{m}^{-3}$ Limit Value on about $50 \%$ of days at M. Road, but only 3 times at the NK site (19 October, 4 and 5 November). Comparing the REPARTEE I and II campaigns, average concentrations were fairly similar. However, while concentrations at M. Road were found to 


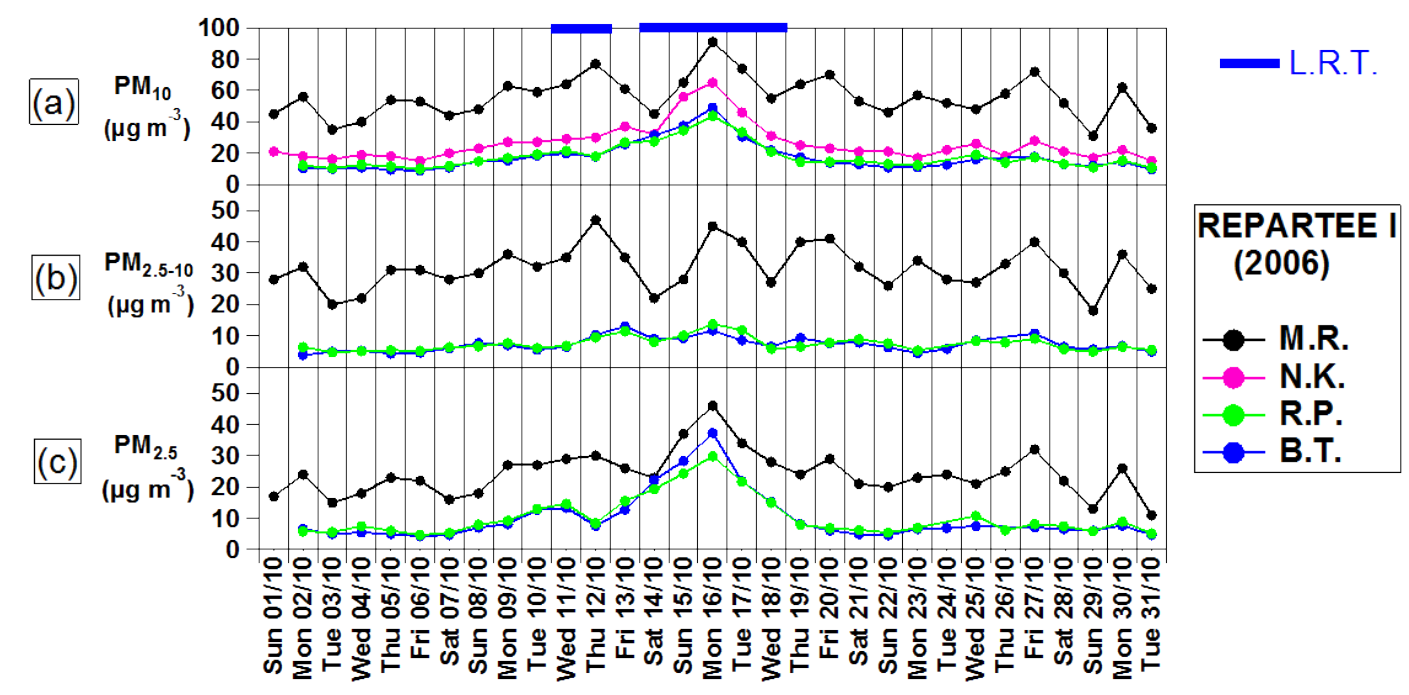

Fig. 9. $\mathrm{PM}_{\mathrm{X}}$ temporal trends for the REPARTEE I experiment in fractions (a) $\mathrm{PM}_{10}$, (b) $\mathrm{PM}_{2.5-10}$ and (c) $\mathrm{PM}_{2.5}$.

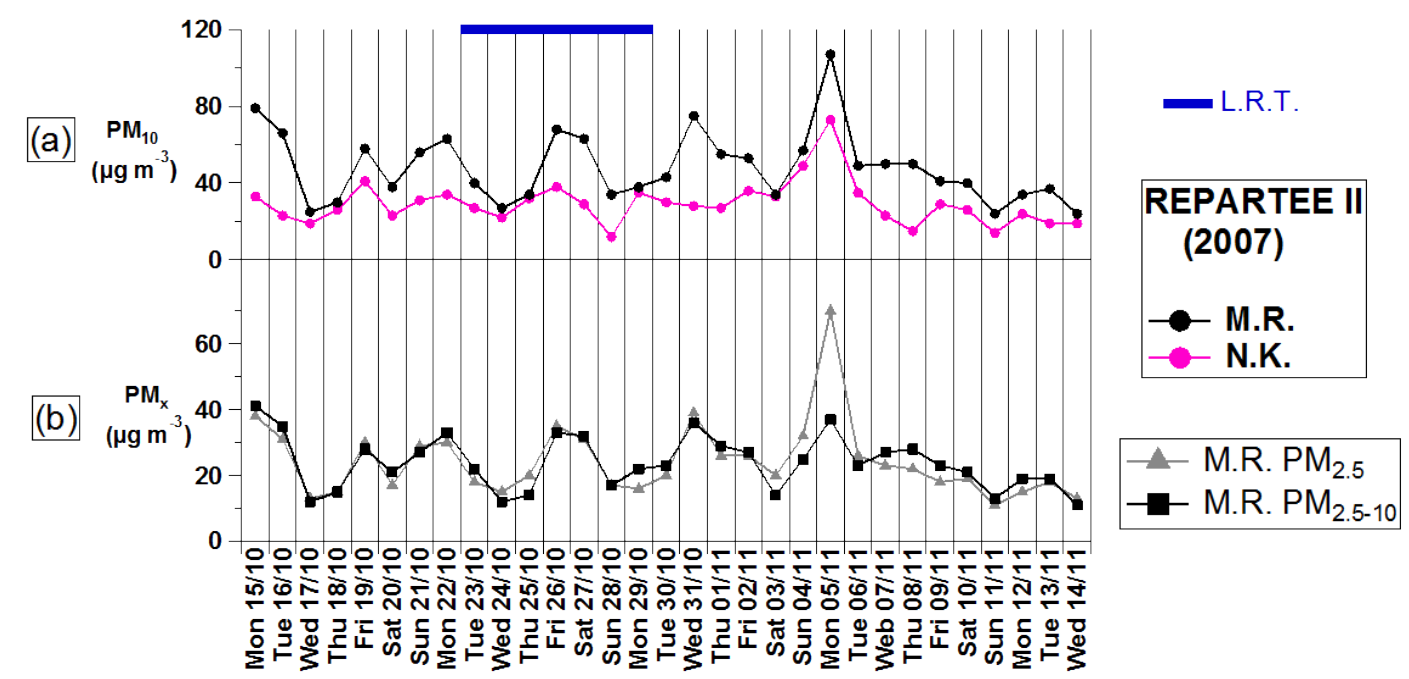

Fig. 10. $\mathrm{PM}_{\mathrm{X}}$ temporal trends for the REPARTEE II experiment in fractions (a) $\mathrm{PM}_{10}$ at different stations and (b) $\mathrm{PM}_{2.5}$ and $\mathrm{PM} 2.5-10$ for the MR site.

exceed $50 \mu \mathrm{g} \mathrm{m}^{-3}$ on almost every day during REPARTEE I, they exceeded only for about half of days during REPARTEE II, which was also reflected by average concentrations that were higher in the first campaign $\left(56 \pm 13 \mu \mathrm{g} \mathrm{m}^{-3}\right.$ versus $48 \pm 18 \mu \mathrm{g} \mathrm{m}^{-3}$ for REPARTEE I and II, respectively). The explanation for this difference lies with the street canyon nature of the Marylebone Road sampling site. This is located on the southern side of the canyon such that as a result of the vortex set up within the canyon, the on-road traffic emissions are sampled in addition to the local background when winds have a southerly component, but when winds are from the northerly sector, the sampling site is exposed predominantly to background air from outside of the canyon. During the REPARTEE I campaign, there was a much higher pre- dominance of winds from the southerly sector than during REPARTEE II.

\subsection{Major component composition}

Daily samples of fine and coarse particulate matter from the R. Park and BT Tower sites collected in REPARTEE I were analysed for major components, i.e. $\mathrm{SO}_{4}^{2-}, \mathrm{NO}_{3}^{-}, \mathrm{Cl}^{-}$, OC (Organic Carbon), EC (Elemental Carbon). The results for nitrate and sulphate in the fine fraction appear in Fig. 11a and $b$. The two ions show a strong divergence in behaviour with sulphate concentrations at the two sites tracking one another closely (Fig. 11a). It is only for samples in the declining period of the long-range transport episode of 13-18 October that sulphate concentrations on the BT Tower exceeded 


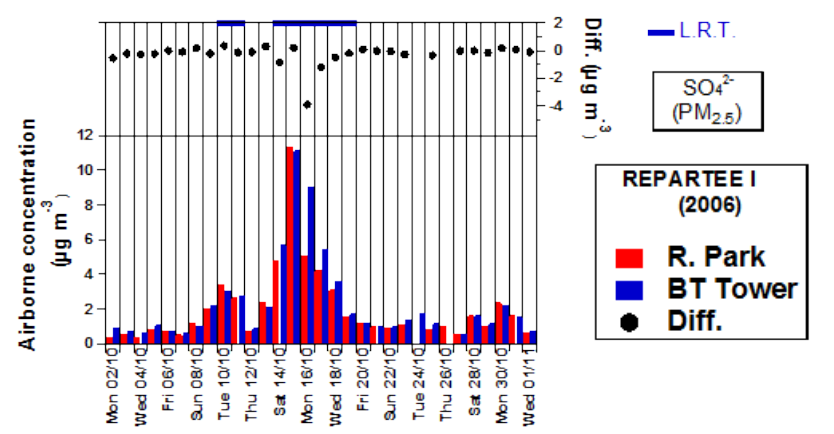

(a)

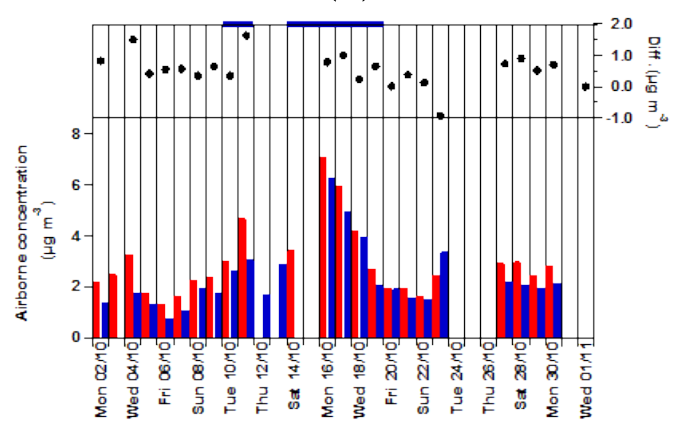

(c)

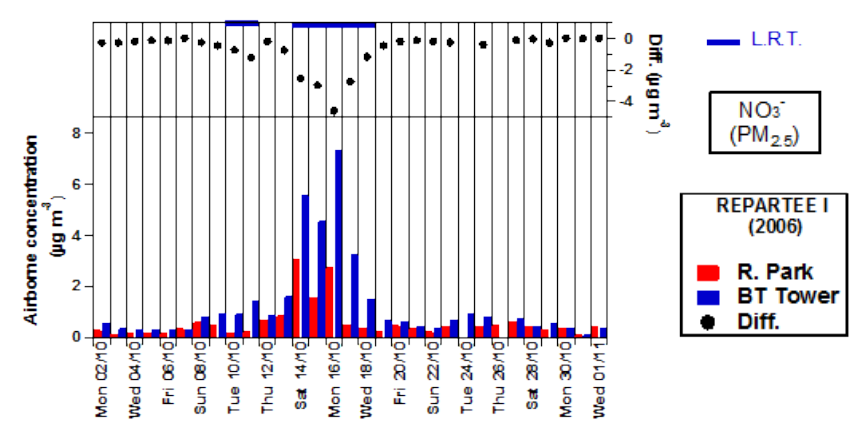

(b)

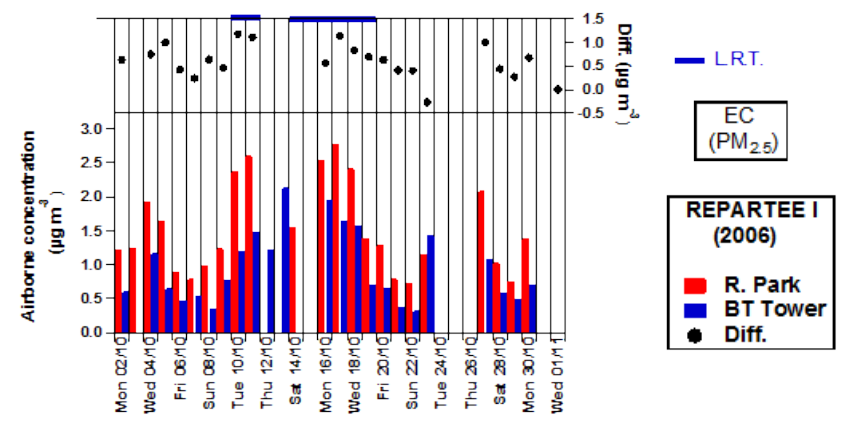

(d)

Fig. 11. Aerosol mass loadings concentrations in $\mathrm{PM}_{2.5}$ at R. Park and the BT Tower during REPARTEE I sampling campaign and difference (Park minus Tower) for (a) sulphate, (b) nitrate, (c) organic carbon and (d) elemental carbon.

those at ground-level (R. Park). In contrast, nitrate (Fig. 11b) exhibited much lower concentrations at the R. Park site, most probably due to the response of volatile ammonium nitrate to local conditions. Over semi-natural vegetation $\mathrm{NH}_{4} \mathrm{NO}_{3}$ evaporation is expected (Allen et al., 1989; Nemitz and Sutton, 2004),

$\mathrm{NH}_{4} \mathrm{NO}_{3} \rightleftharpoons \mathrm{HNO}_{3}+\mathrm{NH}_{3}$

because the park is expected to be a strong sink for nitric acid and ammonia, unless subject to heavy fertiliser use in the case of ammonia (Yamulki et al., 1996; Nemitz et al., 2009). By contrast, the cooler temperatures and higher relative humidity on the tower shift the gas/aerosol equilibrium towards the aerosol phase. The nitrate deposition gradient between BT Tower and R. Park, also confirmed by the two AMS systems, is in contrast to the observation of net nitrate emission derived from the AMS eddy-covariance flux measurements on the Tower (cf. Section "Chemically resolved mass fluxes"). As discussed in more detail by Nemitz et al. (2012a), the likely reason is that the Park is a local sink region for $\mathrm{NH}_{3}, \mathrm{HNO}_{3}$ and $\mathrm{NH}_{4} \mathrm{NO}_{3}$, while, averaged over the city, ground level concentrations are elevated, e.g. due to the emission of $\mathrm{NH}_{3}$ from catalytic converters.

The loss of nitrate in the park probably accounts for the lower $\mathrm{PM}_{2.5}$ concentrations at $\mathrm{R}$. Park during this period shown in Fig. 9. Su et al. (2011) have reported reduced concentrations of $\mathrm{PM}_{2.5}$ and $\mathrm{NO}_{2}$ in public parks relative to local neighbourhoods in the Los Angeles area.

Chloride (data not shown) was predominantly in the coarse particles and showed consistently high concentrations on the BT Tower consistent with a source external to London (i.e. the sea).

Concentrations of OC and EC appear in Fig. 11c and d, respectively. These were measured by a Thermo-optical method (Yin and Harrison, 2008). Concentrations of OC were typically higher at the ground-level R. Park site, and this was also the case for the submicron organic mass measured with Aerosol Mass Spectrometers (AMS) at both sites (Nemitz et al., 2012a), but in some instances there was little difference in concentrations between BT Tower and R. Park. This is consistent with a ground-level source (mainly traffic), but a major contribution of regional transport of mainly secondary particles, as seen in the UK West Midlands (Harrison and Yin, 2008), and confirmed for the REPARTEE campaigns by the factor analysis of the organic aerosol fraction derived from the AMS measurements (Sect. 4.4 below). This view is confirmed by the larger relative vertical gradient in EC seen in Fig. 11d reflecting the ground-level source (mainly road traffic) and exclusively primary source of this pollutant. 

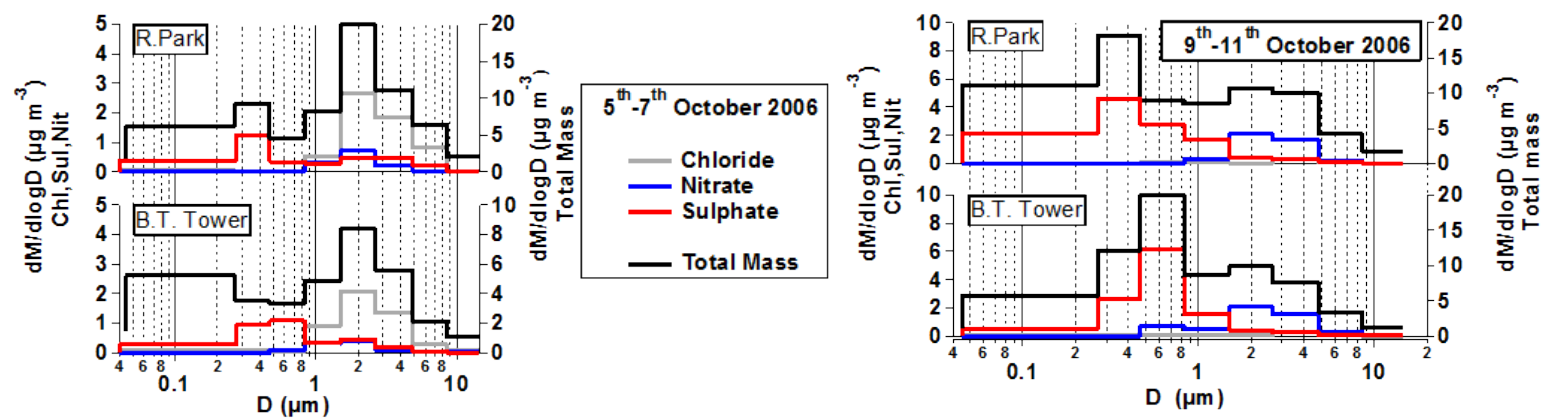

(a)

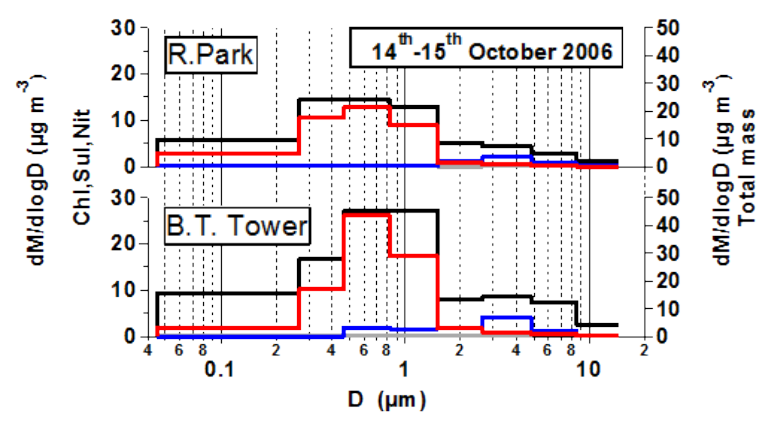

(c) (b)

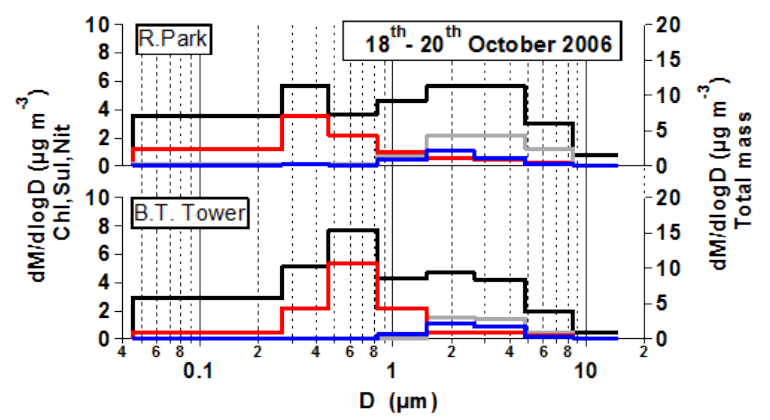

(d)

Fig. 12. Size distribution of particle mass and major anion components collected by MOUDI impactor at R. Park and BT Tower during REPARTEE I.

Applying the factors from our Pragmatic Mass Closure Model (Harrison et al., 2003) gave a very close agreement between reconstructed mass $(y)$ and gravimetrically determined mass $(x)$ concentrations in the $\mathrm{PM}_{2.5}$ fraction, i.e.

for R. Park : $y=0.84 x+1.42 \mu \mathrm{g} \mathrm{m}^{-3} R^{2}=0.988$

for BT Tower : $y=1.06 x-0.08 \mu \mathrm{g} \mathrm{m}^{-3} R^{2}=0.985$

This indicates a fine fraction aerosol whose major component composition is well described by the sum of ammonium nitrate, ammonium sulphate, sodium chloride, elemental carbon and organic compounds.

\subsection{Particle size distributions}

\subsubsection{MOUDI}

MOUDI impactors were deployed at both sites (R. Park and BT Tower) during REPARTEE I for a total of four periods of $48 \mathrm{~h}$ each. The total aerosol mass loadings over the size range up to $14.5 \mu \mathrm{m}$ are shown in Fig. 12. Three out of four samples (Fig. 12a, b, d) showed a clear bimodal size distribution peaking at about $0.5 \mu \mathrm{m}$ and $3 \mu \mathrm{m}$ at the R. Park site, whereas in the BT Tower data the coarse mode is less prominent. This suggests a different general picture for the two sites, with a lower abundance of coarse mode particles at the BT Tower for most of the samples. The highest mass loading with a distribution peaking at $900 \mathrm{~nm}$ was found for the sample of 14-15 October, which is the period when London was subject to long range transport of pollutants. Moreover, a systematically higher value of aerosol mass can be seen during this period (Figs. 9 and 12c) at the BT Tower site relative to the R. Park. For this sample (Fig. 12c), a strong enhancement of particles at about $900 \mathrm{~nm}$ can be seen also at the R. Park site. Samples taken during 5-7 October (Fig. 12a) present a stronger mode at about $3 \mu \mathrm{m}$, associated with marine air masses and the mode in the chloride distribution.

When considering inorganic anion mass loadings (nitrate, sulphate and ammonium) in Fig. 12, it is clear that the coarse mode seen at both sites (Fig. 12a, d) is partly due to chloride, reflecting the sea salt transport from marine areas and the air mass back trajectories (Table 3). By contrast, the mode at about $900 \mathrm{~nm}$ seems to be dominated by sulphate aerosols. Sulphate was found systematically higher at all size ranges at the BT Tower site, showing also a shift towards coarser sizes for all samples relative to the R. Park site (Fig. 12a, d). Nitrate mass loadings were found fairly similar for samples shown in Fig. 12a, b and d. However, the 14-15 October sample (Fig. 12c) showed a higher nitrate concentration in the fine mode at the BT Tower relative to the R. Park site. Much of the nitrate is lost in the MOUDI by evaporation (Huang et al., 2004). 
Table 4. SMPS spectral clusters identified at REPARTEE sites.

\begin{tabular}{lllll}
\hline Cluster & Site(s) & Period & Mode(s) & Intensity \\
\hline 1 & MR & all & $25 \mathrm{~nm} ; 100 \mathrm{~nm}(\mathrm{sh})$ & strong \\
2 & BT & night & $100 \mathrm{~nm}$ & strong \\
3 & RP, BT (few) & day & $<20 \mathrm{~nm}$ & weak \\
4 & RP, MR (few) & day & $20 \mathrm{~nm}$ & weak \\
5 & BT & night & broad & weak \\
6 & BT & night & broad & v. weak \\
7 & MR & evening & $25 \mathrm{~nm} ; 100 \mathrm{~nm}(\mathrm{sh})$ & strong \\
8 & MR/RP/BT & night & $100 \mathrm{~nm}$ & medium \\
9 & RP & midday & $25 \mathrm{~nm} ; 100 \mathrm{~nm}$ & medium \\
10 & RP/BT & night & $75 \mathrm{~nm}$ & strong \\
11 & BT & all & $90 \mathrm{~nm}$ & strong \\
12 & MR/RP & night & $25 \mathrm{~nm} ; 75 \mathrm{~nm}(\mathrm{sh})$ & strong \\
13 & RP/BT & day & $20 \mathrm{~nm} ; 80 \mathrm{~nm}$ & medium \\
14 & MR/RP & day & $28 \mathrm{~nm} ; 70 \mathrm{~nm}$ & strong \\
15 & BT & night & $95 \mathrm{~nm}$ & strong \\
\hline
\end{tabular}

Note: $\mathrm{sh}=$ shoulder

\subsubsection{SMPS and SMPS/APS}

A range of instruments summarised in Tables 1 and 2 were used in the REPARTEE campaigns in order to measure the particle size distributions. In REPARTEE I, these were mainly limited to the range measureable by electrical mobility, whereas in REPARTEE II, the range was extended by the inclusion of Aerodynamic Particle Sizers. Additionally, some measurements were made at R. Park using a Grimm aerosol spectrometer. The main findings of the measurements using SMPS or DMPS instruments in the range up to around $500 \mathrm{~nm}$ have been described extensively elsewhere (Beddows et al., 2009; Dall'Osto et al., 2011) and will be only briefly summarised here.

Beddows et al. (2009) took particle size spectra from R. Park, M. Road and BT Tower and analysed the pooled data by k-means cluster analysis. This technique is able to summarise a large set of hourly average particle size distributions as a much smaller number of clusters characteristic of specific combinations of sources/meteorological conditions. When applied to the three-site dataset, a total of 15 clusters were identified and are listed in Table 4. The attribution of clusters to specific source contributions was based upon the sites at which they were observed, the size distribution measured and the typical diurnal variation. Some clusters were found to be specific to individual sampling sites (see Table 4) whilst others were observed at a range of sites. Some clusters were characteristic of traffic emissions, others showed size distributions much more characteristic of the regional background. Not unexpectedly, the spectra observed at M. Road were dominated by traffic emissions and those at BT Tower by the regional background. Those observed at R. Park appeared to correspond to either aged traffic aerosol or regional background with aged traffic aerosol superimposed. The observation that size distributions observed at R. Park sometimes exhibited a mode smaller than that at M. Road, but nonetheless showed a temporal profile typical of trafficgenerated primary pollutants (Fig. S2 in Supplement shows the median diurnal pattern of particles $<10 \mathrm{~nm}$ ) led to a more detailed investigation of the processes involved. Dall'Osto et al. (2011) looked in detail at the particle size distributions measured in REPARTEE I and REPARTEE II, identifying a regional transport mode at all sites as well as a mode associated with traffic emissions. However, at R. Park, there was an additional mode peaking below $10 \mathrm{~nm}$ diameter which could only be explained by evaporation of the semi-volatile component of the traffic emissions. Examination of particle number count to elemental carbon ratios showed a relative loss of particles (by number) at the BT Tower site. This led to an examination of clustered size distributions which showed that the count of particles less than $30 \mathrm{~nm}$ at the BT Tower site correlated strongly $\left(r^{2}=0.86\right)$ with the turbulence as represented by the variance of the vertical velocity as estimated from the lidar. It was inferred that at the longer vertical transport times associated with lower levels of turbulence (i.e. relatively stable atmosphere), particles were evaporating to sizes below those measured by the condensation particle counter or SMPS system (Dall'Osto et al., 2011).

During REPARTEE II, SMPS instruments based upon a TSI 3080 classifier and 3022A or 3776 CPC were deployed at all three sites (M. Road, R. Park and BT Tower). To extend the particle size range above the upper limit detected by the SMPS instruments, concurrent measurements were made using TSI Aerodynamic Particle Sizers, measuring particle diameters within the range $0.5-20 \mu \mathrm{m}$. The data collected from these instrument pairs, located at the three sites, were averaged into hourly spectra and merged into one particle size spectrum matrix (dia. 14.9-10000 nm) according to the method of Beddows et al. (2010). Surface area and volume spectra are calculated using assumed spherical particle geometry and mass distributions using the density derived from the merging routine. Figure 13 shows the average merged spectra for the three sites. The top row of spectra shows the average number, surface area and mass spectra measured at M. Road; the number spectrum is typical of a roadside spectrum, differentiated from other London sites in Beddows et al. (2009) by having a notable peak between 0.02 and $0.03 \mu \mathrm{m}$ and shoulder at $0.1 \mu \mathrm{m}$ which becomes more evident in the average surface area plot. From the plot of $\mathrm{d} m / \mathrm{d} \log \left(D_{\mathrm{p}}\right)$ vs. $D_{\mathrm{p}}$, two peaks are observed centred at $0.2-$ $0.3 \mu \mathrm{m}$ and $2.0-3.0 \mu \mathrm{m}$. The middle row of Fig. 13 shows the average merged spectra from R. Park. In comparison to the measurements at M. Road, the average number spectrum has a smaller number of counts and the spectra show an increase in the accumulation mode relative to the nucleation mode. The accumulation mode in the average surface area spectrum is seen to shift by roughly $0.05 \mu \mathrm{m}$ to a higher modal diameter and a similar shift is seen in the average mass size spectra. The bottom row of Fig. 13 presents the average spectra collected at the BT Tower. The nucleation mode is again smaller 

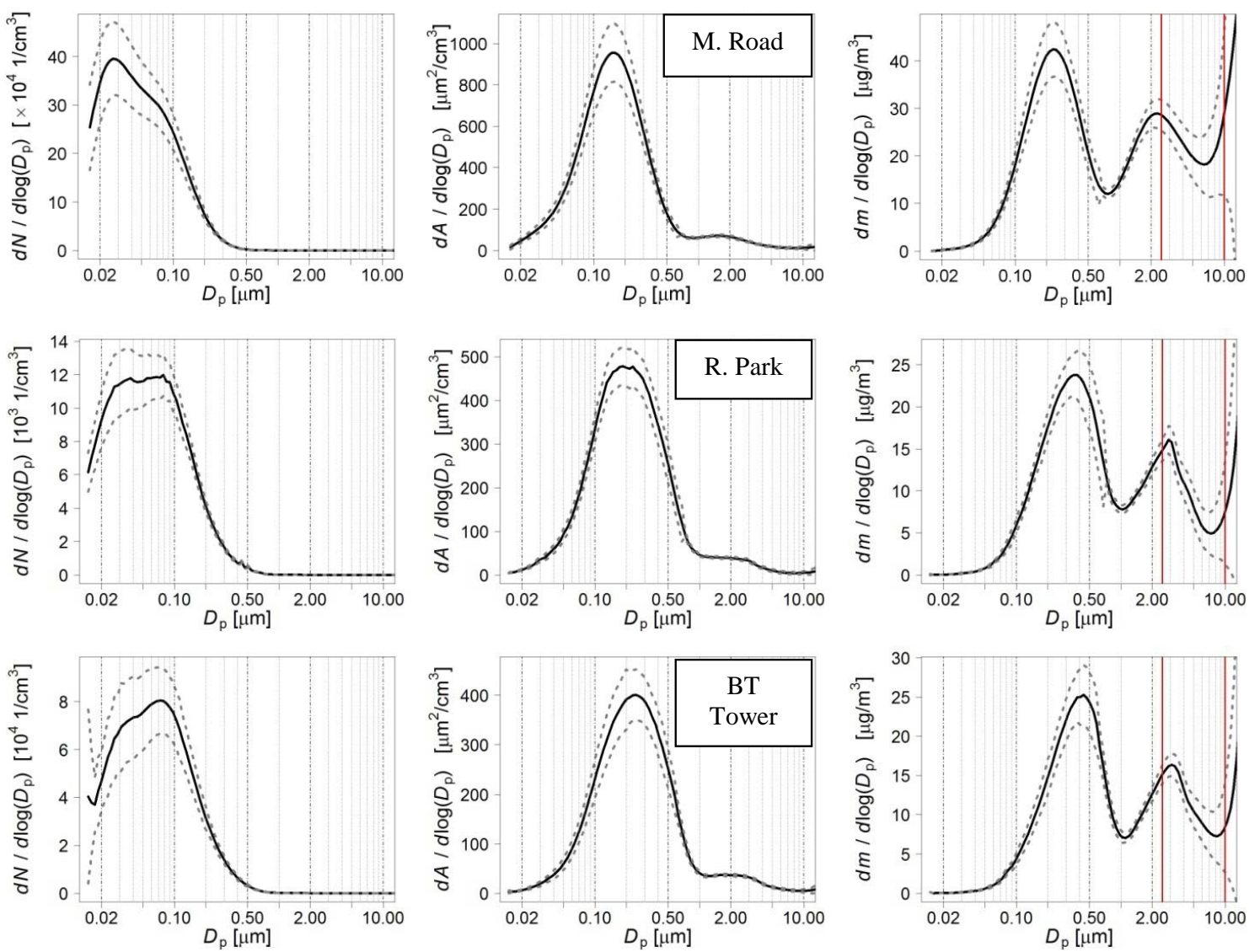

Fig. 13. The mean \pm 1 standard deviation of the spectra of the merged data collected from the M. Road, R. Park and BT Tower during REPARTEE II expressed as number (left), surface area (centre) and mass (right).
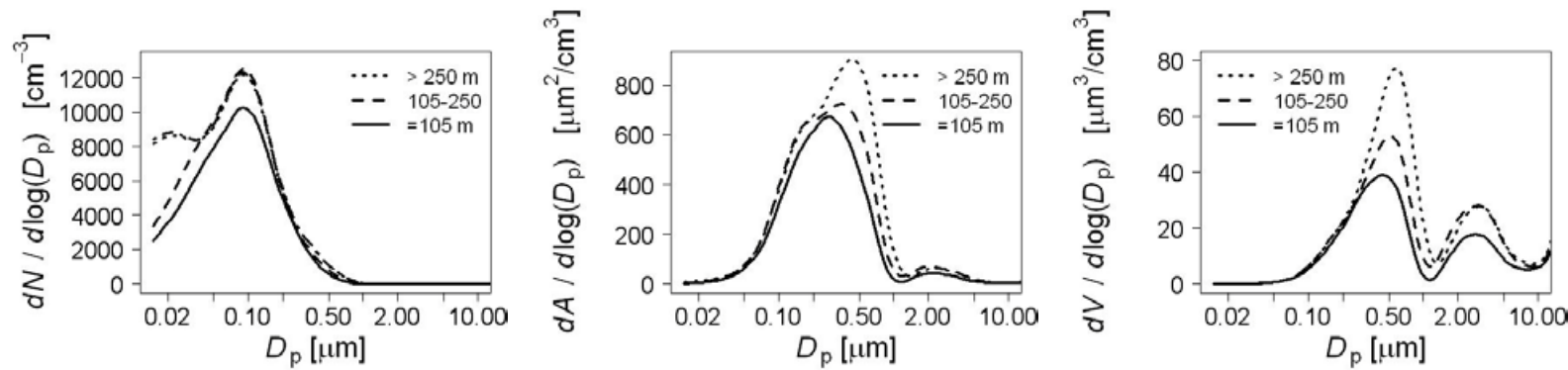

Fig. 14. Particle count data measured at the BT Tower presented as number, surface area and volume and according to the boundary layer height.

in comparison to the accumulation mode in the number spectra and the modal diameters of the accumulation and coarse mode are shifted to higher values. Further characteristics of the merged SMPS-APS spectra, measured at the BT Tower, were observed when the spectra were averaged according to the boundary layer height, measured using lidar (shown in Fig. 14). When the boundary layer height is below $250 \mathrm{~m}$, the tower is more likely to sample air above the boundary layer transported from the regional background. This is reflected in the average spectra where a clear accumulation mode (modal diameter ca. $200 \mathrm{~nm}$ ) which classically contains well aged aerosol particles is seen. When the boundary layer is above $250 \mathrm{~m}$ the sampling site is well within the boundary layer and anthropogenic contributions from traffic are observed with the emergence of a mode at $20 \mathrm{~nm}$ in the number spectrum and a mode at $400 \mathrm{~nm}$ in the surface area spectrum.

Further insights into the sources of particles on M. Road have been gained from applying Positive Matrix Factorisation to hourly average wide range particle size distributions measured on M. Road (Harrison et al., 2011) during 
REPARTEE II. The PMF analysis was able to identify 10 separate size distributions contributing to the overall average size distribution at Marylebone Road including four that were clearly associated with emissions on the road and six associated with the regional background. This separation was possible by including in the PMF analysis traffic and meteorological variables and examining both the diurnal variation of the component spectra (factors) and their association with regional wind direction. This allowed a clear differentiation of emissions within the canyon from those outside. The results showed that emissions on M. Road were responsible for $71.9 \%$ of the total integrated particle number within the spectra and $40.5 \%$ of the particle volume, the remainder coming from regional and local sources external to the street canyon. The analysis separately identified solid and semivolatile particle modes within the on-road emissions as well as particles associated with brake dust and resuspension from the road surface.

Interestingly, the volume distribution reported from the Grimm aerosol spectrometer sited at the R. Park site featured a mode at around $2.5 \mu \mathrm{m}$. The corresponding size channel shows a diurnal trend that peaks around midnight. Given the proximity of the measurement location to vegetation, it is possible that this corresponds to fungal spores (Gabey et al., 2010). The peak at night is possibly due to the spore ejection mechanisms, which can occur during periods of higher humidity. However, given the similarity to the OOA diurnal profile (see Sect. 4.4), it may be that secondary processes are more responsible for this profile.

\subsection{Aerosol Mass Spectrometer (AMS)}

AMS instruments were deployed at both sites during the REPARTEE I and II campaigns (see Table 1 for details). A detailed analysis of selected results is given by Allan et al. (2010), Phillips et al. (2012) and Nemitz et al. (2012a). The AMS is sensitive to non-refractory components in the sub-micrometre size range (Canagaratna et al., 2007) and hence concentrations are not directly comparable to the filter and impactor data. The AMS on the BT Tower were operated in an eddy-covariance flux mode (see Sect. 4.10), and the concentration analysis here is therefore based on the instruments in R. Park. The standard calibration and data analysis procedures were employed (Allan et al., 2003, 2004) and a collection efficiency of 0.5 was used, consistent with the particulate matter composition measured (Matthew et al., 2008) and validated using DMPS data (Allan et al., 2010).

The overall mass loadings detected using the AMS and MAAP (Fig. 15) showed contrasts between the two campaigns. In spite of the overlap in the calendar, the ambient temperatures were lower during REPARTEE II hence increasing the requirement for space heating. Conversely, REPARTEE I was more influenced by regional sources (Dall'Osto et al., 2009b), showing periods of high concentrations of secondary species such as sulphate that lasted a number of days. Interestingly, the equivalent black carbon reported by the MAAP also increased with the larger loadings of secondary material. This could be in part regional transport by black carbon but could also be related to an increase in the mass specific absorption of the black carbon as a result of being coated by secondary material (Bond et al., 2006).

Major findings of this work arose from the application of Positive Matrix Factorisation (Paatero, 1997; Ulbrich et al., 2009) to the organic component of the AMS data, as presented by Allan et al. (2010). This was able to numerically separate the different components of the organic fraction into primary hydrocarbon-like organic aerosol (HOA) from traffic emissions, secondary oxygenated organic aerosol (OOA), organic aerosol from cooking (COA) and organic aerosol from solid fuel burning (SFOA). These were identified by inspecting the mass spectral profiles and diurnal trends of the different factors (see Fig. 16) and comparing with previously published material and laboratory data. The results were also found to be largely consistent with wintertime data taken in central Manchester (Allan et al., 2010).

The HOA was found to be consistent with previous studies of diesel emissions (Canagaratna et al., 2004; Schneider et al., 2006) and could be linked to $\mathrm{NO}_{\mathrm{x}}$ concentrations measured at the site; an emission factor of $31.6 \mu \mathrm{g} \mathrm{m}^{-3} \mathrm{ppm}^{-1}$ was derived (Allan et al., 2010), which corresponds to a mass emission ratio of 0.026 (assuming $\mathrm{NO}_{\mathrm{x}}$ is emitted as $\mathrm{NO}$ ). The diurnal trend peaked in the morning, coincident with rush hour. The OOA was also consistent with previous measurements of highly processed secondary organic aerosols (Jimenez et al., 2009; McFiggans et al., 2005) and were significantly more prevalent during REPARTEE I, which experienced more regional pollution generally. The COA diurnal pattern showed peaks corresponding to lunch and evening meal time and presented a greater fractional contribution than was expected. Its mass spectral profile was consistent with previous ambient results (Lanz et al., 2007) but it was not identical to previously published spectra from laboratory charbroiling simulations (Mohr et al., 2009). As was presented by Allan et al. (2010), a closer mass spectral match was found to particles from heated cooking oil baths, implying that the oils used in frying may have been more important for the aerosol formation. The SFOA factor was only discernable during the campaign with cooler weather (REPARTEE II) and featured mass spectral markers consistent with wood burning (Alfarra et al., 2007). This typically peaked at night, consistent with space heating, and was also prevalent during the weekend of "bonfire night" (5 November).

\subsection{Single particle analyses by ATOFMS and TEM}

The Aerosol Time-of-Flight Mass Spectrometer (ATOFMS; TSI-Model 3800-100) provides information on a polydisperse aerosol, acquiring precise aerodynamic diameter $( \pm 1 \%$ ) within the range 0.2 to $3 \mu \mathrm{m}$ and individual particle 


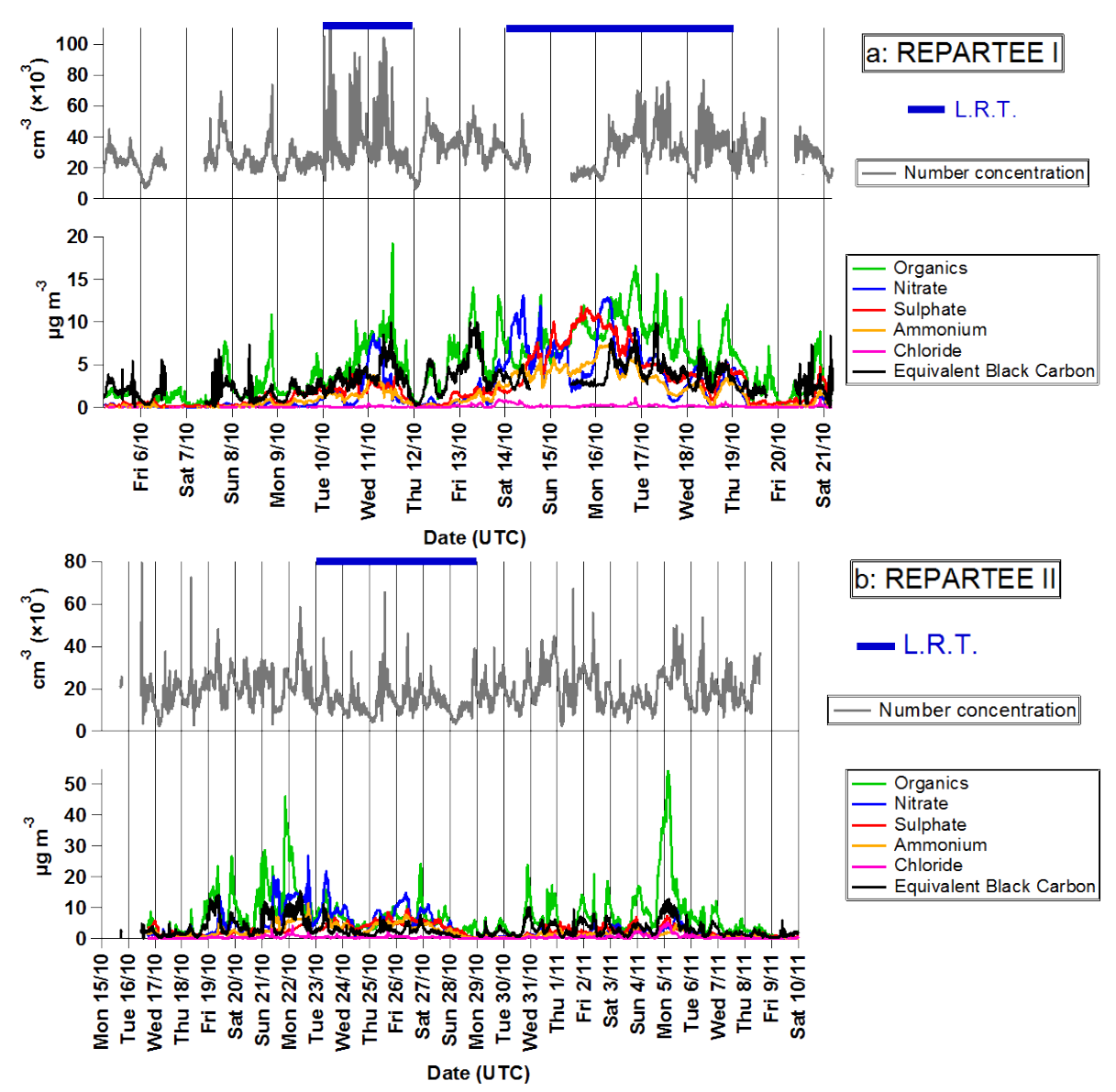

Fig. 15. Time series of species concentrations measured by AMS and MAAP together with particle number counts (TSI 3776) at R. Park in the two campaigns. (Note the different time periods described by upper and lower graphs)

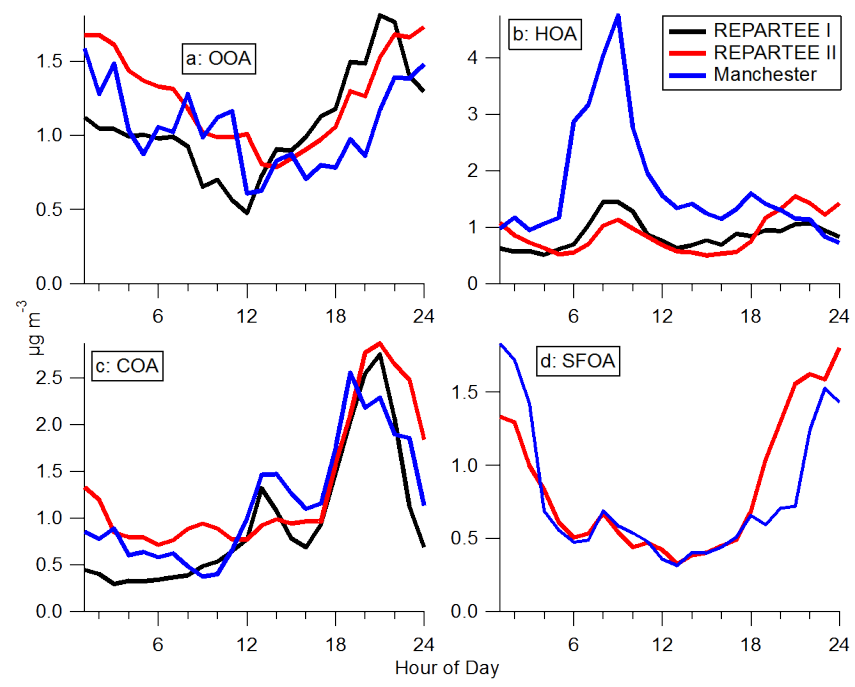

Fig. 16. Average diurnal profiles of AMS factors (defined in text) observed in REPARTEE I and II and in Manchester (originally published in Allan et al., 2010). positive and negative mass spectral data in real time. TSI ATOFMS data are imported into YAADA (Yet Another ATOFMS Data Analyzer, version 1.30) and analysed with the powerful ART-2a tool, an artificial intelligence algorithm that sorts single particle mass spectra into specific particle types or clusters. The ATOFMS was deployed at R. Park for 19 days, between 4 and 22 October 2006 in REPARTEE I. In total, 153595 particles were hit by ATOFMS and the positive and negative mass spectra of individual particles were recorded. By running ART-2a, 306 clusters were found initially but many were merged if they presented similar temporal trends, size distributions and similar mass spectra. By merging similar clusters, the total number of clusters describing the whole database was reduced to 15 . These appear in Table 5.

Quantification of ATOFMS data can only be achieved through labour-intensive scaling with independent data (Dall'Osto et al., 2006) which were not available. This has not been attempted and hence the data should be regarded as only semi-quantitative. Analysis of ATOFMS and AMS data together proved valuable in understanding in real time atmospheric processes occurring during the REPARTEE I 
Table 5. Summary description of ATOFMS particle clusters found in REPARTEE I (defined in Dall'Osto et al., 2009b).

\begin{tabular}{llrr}
\hline Main & ATOFMS cluster & $N$ particles & \% cluster \\
\hline \multirow{5}{*}{ Secondary } & LRT nitrate & 43516 & 33.7 \\
& LRT core & 10278 & 8.0 \\
& Local nitrate & 29563 & 22.9 \\
& Amine & 2306 & 1.8 \\
& HMOC (fog) & 4865 & 3.8 \\
& MSA (fog) & 245 & 0.2 \\
& SOA-PAH & 2834 & 2.2 \\
& Ca-EC & 5496 & 4.3 \\
& OC & 4671 & 3.6 \\
& PAH & 269 & 0.2 \\
& EC & 2001 & 1.5 \\
& Na-OC-EC & 2207 & 1.7 \\
& NaCl only & 3637 & 2.8 \\
Inorganic & Aged NaCl & 15638 & 12.1 \\
& Fe & 1748 & 1.4 \\
\hline & TOTAL & 129274 & 100.0 \\
\hline
\end{tabular}

campaign which have been described in detail elsewhere (Dall'Osto et al., 2009a, b). Two main inorganic ATOFMS particle types were identified. The first was rich in iron $(\mathrm{Fe}$, $1.4 \%$ of the total particles) with strong signals at $\mathrm{m} / \mathrm{z} 54$ and $56\left({ }^{54} \mathrm{Fe}\right.$ and ${ }^{56} \mathrm{Fe}$, respectively) internally mixed with sodium, nitrate, sulphate and elemental carbon. This particle type was found mainly distributed in the fine mode below $1 \mu \mathrm{m}$ in aerodynamic diameter, whereas previous ATOFMS studies found this particle type mainly distributed in the coarser mode and attributed it to local dust sources. During REPARTEE, Fe-rich particles were found to correlate with LRT nitrate and were associated with long range transport of pollutants. The small mode of this particle type reflects the fact that only fine fraction particles were likely to travel long distances relative to the coarser ones which were lost during transport. The second inorganic class sampled by the ATOFMS was due to $\mathrm{NaCl}$, which accounted for $14.9 \%$ of the total particles sampled. Two sub-classes were further identified $(\mathrm{NaCl}$ only and aged $\mathrm{NaCl}$, accounting for about $20 \%$ and $80 \%$ of this inorganic particle type, respectively). The $\mathrm{NaCl}$ cluster presented the peaks typical of sodium chloride clusters $\left([\mathrm{Na}]^{+}(\mathrm{m} / \mathrm{z} 23),[\mathrm{K}]^{+}(\mathrm{m} / \mathrm{z} 39)\right.$, $\left[\mathrm{Na}_{2}\right]^{+}(\mathrm{m} / \mathrm{z}, 46),\left[\mathrm{Na}_{2} \mathrm{Cl}\right]^{+}(\mathrm{m} / \mathrm{z} 81$ and 83$),\left[\mathrm{Na}_{3} \mathrm{Cl}_{2}\right]^{+}$ $\left(\mathrm{m} / \mathrm{z}, 139\right.$ and 141); $[\mathrm{Na}]^{-}(\mathrm{m} / \mathrm{z} 23),[\mathrm{Cl}]^{-}(\mathrm{m} / \mathrm{z}, 35$ and 37$)$, $[\mathrm{NaCl}]^{-}\left(\mathrm{m} / z 58\right.$ and 60), $\left[\mathrm{NaCl}_{2}\right]^{-}(\mathrm{m} / z, 93,95$ and 97$)$ and $\left[\mathrm{Na}_{2} \mathrm{Cl}_{3}\right]^{-}(\mathrm{m} / \mathrm{z} 151,153$ and 155$)$ whilst aged $\mathrm{NaCl}$ also exhibited nitrate peaks $(\mathrm{m} / \mathrm{z}-46$ and $\mathrm{m} / \mathrm{z}-62)$ reflecting the reaction between $\mathrm{NaCl}$ and $\mathrm{HNO}_{3}$ and the replacement of chloride by nitrate. $\mathrm{NaCl}$ was mainly detected during air masses that had travelled over oceanic regions (5-6 and 2023 October), also reflected in both the MOUDI and Partisol samples taken during REPARTEE I and in the GRAEGOR measurements on the tower (Nemitz et al., 2012a).
Twelve of the 15 clusters were associated with organiccontaining aerosols, accounting for $83.7 \%$ of the total particles classified. Of these, the 3 main clusters were rich in nitrate and have already been discussed in Dall'Osto et al. (2009b). Two specific ATOFMS clusters associated with a secondary organic aerosol production during a fog event have also been discussed in Dall'Osto et al. (2009a). Cluster EC was found to present a strong elemental carbon signature but represented only $1.5 \%$ of the total particles sampled and did not show a clear temporal profile. By contrast, the cluster Amine was found to correlate very well with the cluster LRT nitrate and AMS nitrate concentrations $\left(R^{2}=0.85\right)$, spiking mainly during nighttime, consistent with a semi-volatile nature of this aerosol. These particles exhibited a relatively coarse size distribution, with key peaks in the positive and negative mass spectra occurring at $\mathrm{m} / z 59$ (Angelino et al.,

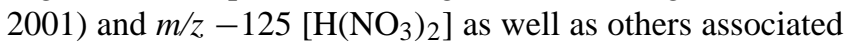
with EC, nitrate and sulphate. Amines were also found to increase substantially in number concentration during the fog event of 13 October 2006 (Dall'Osto et al., 2009a).

The ATOFMS cluster named PAH presented two main spikes on 4 (23:00-01:00) and 12 (07:00-10:00) October 2006. This class represented only $0.2 \%$ of the particles sampled, but other ATOFMS particle classes also spiked during these two periods, indicating a contribution from an unidentified local source. Clusters $\mathrm{Ca}-\mathrm{EC}$ and $\mathrm{OC}$ were found to spike during rush hour morning traffic, while Na-EC-OC was found to spike mainly during evenings. These primary organic aerosol ATOFMS classes, together with cluster SOAPAH, are discussed in Dall'Osto and Harrison (2011).

Comparison of results from the ATOFMS with the AMS has been conducted. While fundamental issues mean that the data from the two mass spectrometers are not completely analogous, certain common trends were found. The ATOFMS identified two clusters that could be associated with traffic emissions (denoted Ca-EC and OC), which were found to have a temporally similar behaviour as the AMS HOA. While a cluster could not be directly associated with OOA, Dall'Osto et al. (2009b) found that the prevalence of more aged aerosols (confirmed by the AMS data) altered the mass spectral response to nitrate, allowing the different profile to be used as a marker for regional (as opposed to local) influence.

ATOFMS and AMS are powerful techniques for characterizing the atmospheric aerosol but give a very incomplete picture over the whole size range and of the different types of particles, however in combination they provide a much improved coverage (Dall'Osto et al., 2009a, b; Allan et al., 2010). The transmission electron microscope (TEM) offers a complementary technique for characterising particles across a wide range of sizes, nanometers through to micrometers, and in terms of their morphology and their elemental composition. During REPARTEE I, size-fractionated particles were collected and subjected to TEM and Energy Dispersive $\mathrm{X}$-Ray analysis (EDX). During the TEM study period, the 


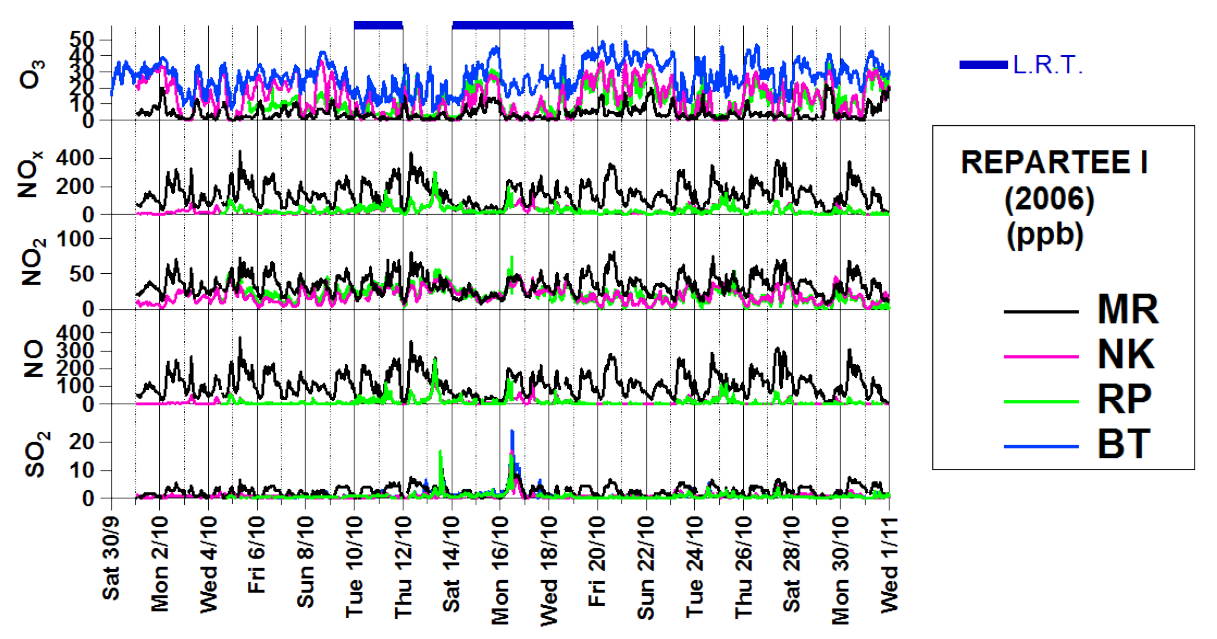

Fig. 17. Time series of gas phase species in the REPARTEE I campaign at ground-level sites.

ATOFMS at R. Park was in operation and therefore provided a basis for a comparing the particle types observed by both methodologies (Smith et al., 2012).

TEM analysis revealed eight main particle types that were common to samples taken from R. Park and BT Tower. Of these, amorphous carbonaceous aggregates (soot-like) containing $\mathrm{C}$ and $\mathrm{O}$ and often including $\mathrm{Ca}, \mathrm{K}$ and $\mathrm{Fe}$ were the most common especially in the fractions $<1.2 \mu \mathrm{m}$. Also common were beam-sensitive sulphur-rich particles, including $\mathrm{Na}$ and $\mathrm{Cl}$, in amorphous and crystalline forms. Iron and titanium were common elements in other types of particles.

During the concurrent sampling period, 600 particles were examined by TEM and about 1300 particles were measured by ATOFMS. Of the 15 particle clusters classified by ATOFMS for the whole campaign (Dall'Osto et al., 2009a, b), 13 were found in the overlap period. Three types of particle (out of eight) identified by TEM had analogues (but not direct equivalents) in the ATOFMS clusters. Many of the particle types identified by the ATOFMS were vacuumvolatile (e.g. nitrates) and therefore not seen by the TEM.

TEM, even more than ATOFMS, gives a very biased picture of aerosol composition. Its strengths lie in source tracing of involatile particle components, especially those rich in metals. Whilst ATOFMS is capable of processing thousands of particles per hour, TEM is a manual and time-consuming methodology. Both techniques provide valuable information on internal mixing of particles.

\subsection{Gases}

\subsubsection{REPARTEE I}

$\mathrm{O}_{3}, \mathrm{NO}, \mathrm{NO}_{2}$ and $\mathrm{NO}_{\mathrm{x}}$ were measured during REPARTEE I at the R. Park site. Data from the NK and M. Road air quality monitoring stations have also been included. Measurement techniques are listed in Tables 1 and 2. Concentrations are given as the arithmetic average and 1 standard deviation of hourly measurements. Values of NO (ppb) were comparable at NK $(11 \pm 18)$ and R. Park $(10 \pm 21)$, but much higher at the M. Road site (84 \pm 137$)$. Values of $\mathrm{NO}_{\mathrm{x}}(109 \pm 202)$ and $\mathrm{NO}_{2}$ $(27 \pm 65)$ were also higher at the M. Road site relative to NK $\left(\mathrm{NO}_{\mathrm{x}}: 29 \pm 26 ; \mathrm{NO}_{2}: 19 \pm 10\right)$ and R. Park $\left(\mathrm{NO}_{\mathrm{x}}: 30 \pm 28\right.$; $\mathrm{NO}_{2}: 20 \pm 11$ ) background sites. For ozone, the concentrations (ppb) at R. Park (12 \pm 9 ) were slightly lower than at NK $(14 \pm 10)$ possibly due to enhanced dry deposition processes at the Park, whilst even lower concentrations were found at the M. Road site $(4 \pm 4)$ due to titration by NO emissions. Ozone at the BT Tower was always higher, consistent with the city acting as an efficient chemical sink for regional $\mathrm{O}_{3}$, which was also confirmed by strong downward fluxes of $\mathrm{O}_{3}$ measured on the BT Tower (Nemitz et al., 2012a). There was a gradient in concentrations of $\mathrm{SO}_{2}$ (ppb) between M. Road (1.9 \pm 2.6$)$, NK (1.1 \pm 1.2$)$ and R. Park $(0.7 \pm 1.0)$, reflecting greater deposition at the R. Park site and road traffic emissions at M. Road. Concentrations of selected volatile organic compounds (VOCs) were measured on the Tower during REPARTEE I and $\mathrm{NH}_{3}, \mathrm{HNO}_{3}$ and $\mathrm{HCl}$ were measured during both campaigns. The data are discussed elsewhere (Langford et al., 2010; Nemitz et al., 2012a).

Figure 17 shows the temporal trends of $\mathrm{SO}_{2}$, $\mathrm{NO} / \mathrm{NO}_{2} / \mathrm{NO}_{\mathrm{x}}$ and $\mathrm{O}_{3}$ mentioned above over the month of October 2006. $\mathrm{SO}_{2}$ presented two main spikes in the afternoon of 13 and in the morning of 16 October. This was a period of easterly winds and the peaks probably arise from emissions from the East Thames power stations. NO and $\mathrm{NO}_{2}$ levels were highest in the morning of 13 October when stagnant conditions were recorded as already described in Dall'Osto et al. (2009a, b). Ozone concentrations were generally lower during the period affected by long range transport (13-19th), presumably due to enhanced chemical depletion under conditions that did not favour formation by photochemistry. 


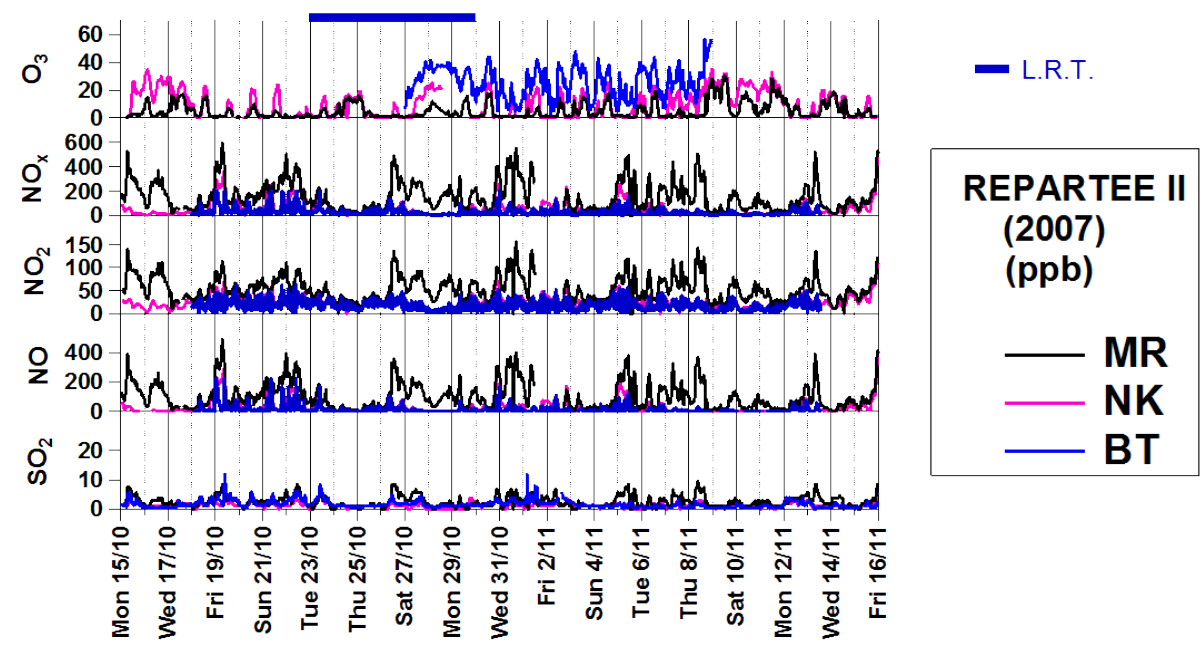

Fig. 18. Time series of gas phase species measured in REPARTEE II.

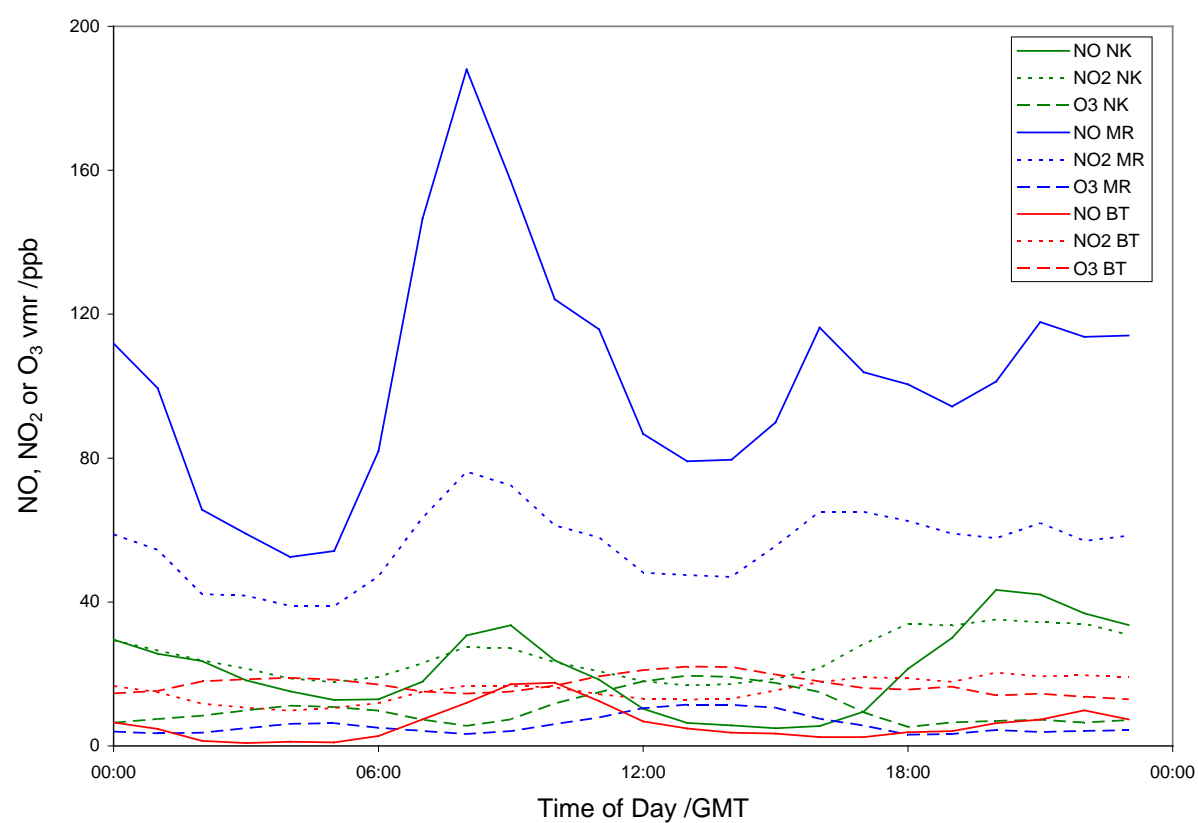

Fig. 19. Average diurnal profile for $\mathrm{NO}$ (solid lines), $\mathrm{NO}_{2}$ (dotted lines) and $\mathrm{O}_{3}$ (dashed lines) volume mixing ratios at the urban background North Kensington (NK, green) site, the kerbside M. Road (MR, blue) site and at the $190 \mathrm{~m}$ level of the BT Tower (BT, red).

\subsubsection{REPARTEE II}

A number of novel measurements were performed during REPARTEE II, including measuring ozone and nitrogen oxides at the BT Tower site. These data are discussed in some detail in Sect. 4.7.

Similar trends in the REPARTEE II data (shown in Fig. 18) were found for the NK and M. Road sites (relative to REPARTEE I) for most gases. In general, concentrations (ppb) at NK were higher for NO $(26 \pm 40), \mathrm{NO}_{2}(22 \pm 12)$ and $\mathrm{NO}_{\mathrm{x}}(47 \pm 47)$ relative to REPARTEE I and lower for ozone $(9 \pm 9 \mathrm{ppb})$. M. Road presented increased values for some gases relative to REPARTEE I $\left(\mathrm{NO}_{2}: 52 \pm 25 ; \mathrm{NO}_{\mathrm{x}}\right.$ : $166 \pm 100 ; \mathrm{O}_{3}: 4 \pm 5$ ). Data available at the BT Tower only for REPARTEE II gave concentrations (ppb) for $\mathrm{NO}(9 \pm 13)$ $\mathrm{NO}_{2}(17 \pm 9)$ and $\mathrm{NO}_{\mathrm{x}}(26 \pm 27)$, lower than for the NK site, but with higher ozone at the BT Tower $(32 \pm 14)$. Again, ozone at the BT Tower was always higher, and never went below $3 \mathrm{ppb}$. During daytime, values of ozone were similar at the NK and BT Tower site, but the trend was not observed during evening times. $\mathrm{NO}_{\mathrm{x}}$ was highest at $\mathrm{M}$. Road, but values of $\mathrm{NO}_{2}$ sometimes were higher at the BT Tower site relative to $\mathrm{NK}, \mathrm{NO}$ and $\mathrm{NO}_{\mathrm{x}}$ at the BT Tower site never exceeded concentrations at NK. This is consistent with a ground-level 


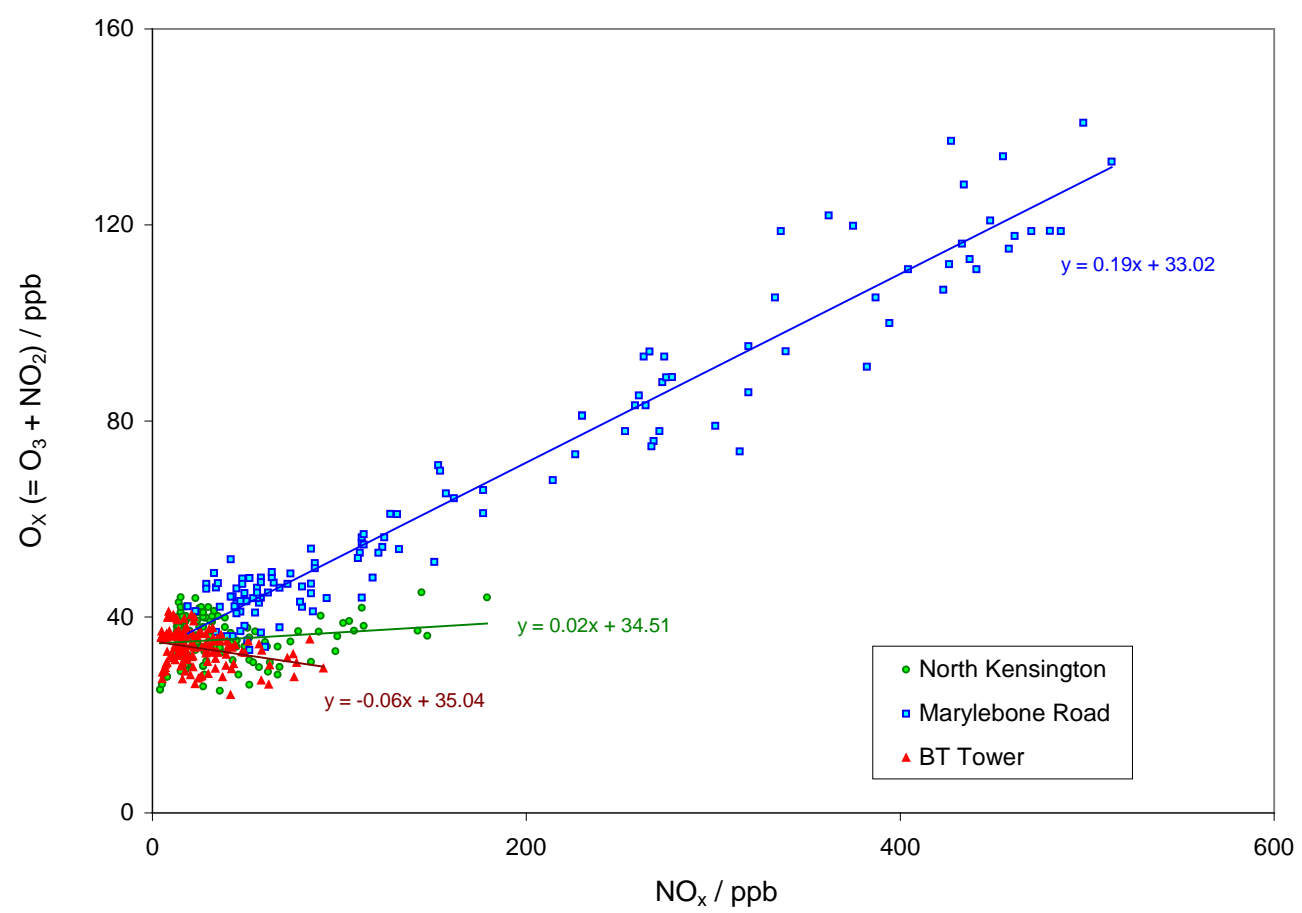

Fig. 20. Oxidant Plot of the variation in volume mixing ratio of $\mathrm{O}_{\mathrm{x}}\left(\mathrm{NO}_{2}+\mathrm{O}_{3}\right)$ as a function of $\left.\mathrm{NO}_{\mathrm{x}}(\mathrm{NO}+\mathrm{NO})_{2}\right)$ for the urban background North Kensington site (green) site, the kerbside Marylebone Road site (blue) site and at the $190 \mathrm{~m}$ level of the BT Tower (red). Data are daytime only (08:00-16:00) hourly averages for the whole REPARTEE II campaign period.

source of $\mathrm{NO}_{\mathrm{x}}$, predominantly as $\mathrm{NO}$, with enhanced conversion to $\mathrm{NO}_{2}$ at times due to greater availability of ozone aloft.

\subsection{Ozone/ $/ \mathrm{NO}_{\mathrm{x}}$ chemistry on the BT Tower}

$\mathrm{NO}, \mathrm{NO}_{2}$ and ozone data from the BT Tower were compared with measurements from two nearby Automatic Urban and Rural Network (AURN) Air Quality monitoring stations: M. Road and NK. Measurement methods appear in Table 2. $\mathrm{NO}_{2}$ was determined by thermal conversion (heated Mo catalyst)/chemiluminescence; the $\mathrm{NO}_{2}$ signal may therefore be subject to interferences from other $\mathrm{NO}_{\mathrm{y}}$ compounds (e.g. Dunlea et al., 2007).

Figure 19 shows the average diurnal profile in $\mathrm{NO}, \mathrm{NO}_{2}$ and $\mathrm{O}_{3}$ observed at each site over the period of the REPARTEE II campaign. Levels of $\mathrm{NO}_{\mathrm{x}}$ were clearly higher and displayed the traffic-volume related double peak for the M. Road site; the same features were apparent at the other locations, with lesser amplitude. Figure 20 shows an "oxidant plot", where the level of total oxidant $\left(\mathrm{O}_{\mathrm{x}}=\mathrm{O}_{3}+\mathrm{NO}_{2}\right)$ is plotted as a function of $\mathrm{NO}_{\mathrm{x}}\left(\mathrm{NO}+\mathrm{NO}_{2}\right)$. Oxidant plots such as these have been interpreted as showing both the regional background oxidant (ozone) level, indicated by the $y-$ axis intercept, and the local primary contribution to oxidant (potentially primary $\mathrm{NO}_{2}$ emissions), indicated by the gradient (Clapp and Jenkin, 2001). The data shown in Fig. 20 are hourly averages from the whole REPARTEE II campaign pe- riod (26 October-13 November 2007) for daylight only (defined conservatively here as 08:00-16:00 GMT). Figure 21 shows how the intercept and gradient of the $\mathrm{O}_{\mathrm{x}}-\mathrm{NO}_{\mathrm{x}}$ relationship varied for each measurement site for each hour over the 24-h period, again averaged over the REPARTEE II campaign period.

The reduction in the $\mathrm{NO}_{\mathrm{x}}$ range crudely indicates a mean dilution factor of five between the roadside site within the Marylebone Road street canyon and the $190 \mathrm{~m}$ BT Tower sampling point well above the height of the surrounding buildings. The agreement between the intercepts of the dataset shown in Fig. 21 indicates that all three locations experienced the same general air masses (hence the same point may be drawn for the BT Tower, R. Park and M. Road sites for REPARTEE) with incoming ozone levels of 33-35 ppb, typical for the UK in late autumn. The gradients of the $\mathrm{O}_{\mathrm{x}}-\mathrm{NO}_{\mathrm{x}}$ relationship shown in Fig. 20 are very different for the M. Road kerbside site $(0.19 \pm 0.008)$ vs. the BT Tower $(-0.06 \pm 0.02)$ and North Kensington sites $(0.02 \pm 0.02)-$ uncertainties are $2 \sigma$. As mentioned above, the gradient is thought to be indicative of local primary $\mathrm{NO}_{2}$ emissions, or of co-emissions (with $\mathrm{NO}_{\mathrm{x}}$ ) of species which promote NO-to- $\mathrm{NO}_{2}$ conversion, i.e. $\mathrm{HO}_{2}$ and $\mathrm{RO}_{2}$ radical precursors. The lower levels for the BT Tower and NK sites is likely to indicate that these do not experience significant direct primary $\mathrm{NO}_{2}$ (or equivalent) emissions, i.e. they are sufficiently removed from the (predominantly road traffic) sources that 


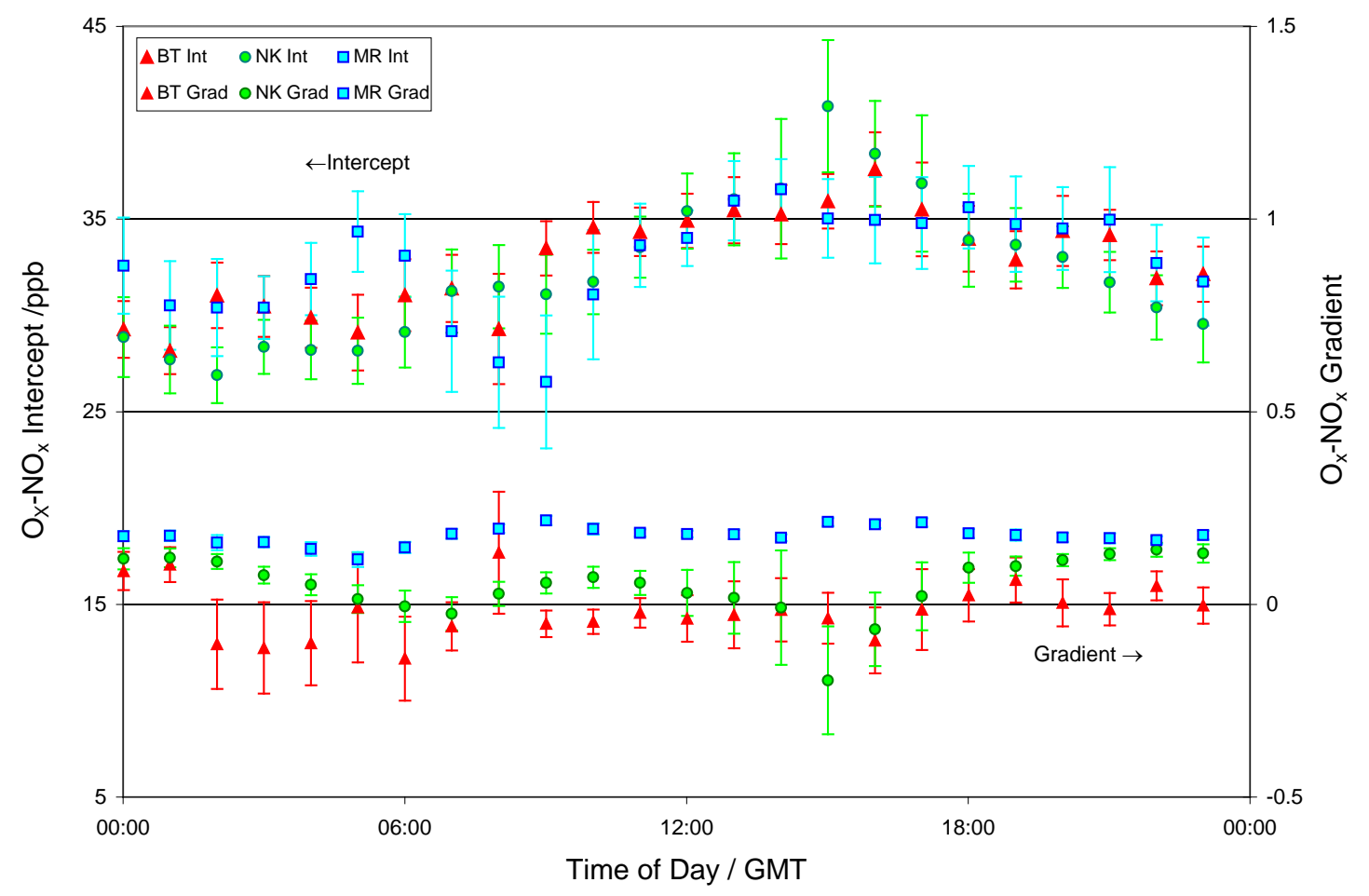

Fig. 21. Variation in the intercept (left-hand axis) and gradient (right hand axis) of the regression analyses of oxidant plots (as shown in Fig. 27), for each hour of the 24-h period averaged over the campaign duration. See comments in text re. application of this analysis during nighttime periods.

the measured composition is representative of the well-mixed regional background. This is a surprising finding for NK which is within and much affected by the London conurbation (Bigi and Harrison, 2010).

Interpreted purely as $\mathrm{NO}_{2}$ emissions, the gradient of the M. Road dataset in Fig. 21 would indicate that $19 \%$ of primary $\mathrm{NO}_{\mathrm{x}}$ is $\mathrm{NO}_{2}$, a fraction which is significantly greater than has been conventionally assumed in the past, but is consistent with other monitoring station data which has shown that the primary $\mathrm{NO}_{2}$ fraction as measured at a range of Central London sites ranged from 3-24\%, with a value of 9$10 \%$ determined for Marylebone Road (Carslaw and Beevers, 2005). Subsequent measurements indicated that the primary $\mathrm{NO}_{2}$ fraction at Marylebone Road increased between 2003 and 2005 to around $20 \%$; similar increases have been observed for other UK and European sites (AQEG, 2007). These findings have been rationalised in terms of changing vehicle fleet composition and technology, in particular increasing numbers of intermediate age (Euro-III) diesel vehicles, and potentially enhanced $\mathrm{NO}_{2}$ emissions resulting from fitting of regenerative diesel particulate traps to buses. Other causes of the observed trend at Marylebone Road include co-emissions of compounds which would be detected as $\mathrm{NO}_{2}$ (e.g. nitrous acid, $\mathrm{HONO}$, thought to comprise a small, but significant and uncertain, component of vehicle exhaust (e.g. Jenkin et al., 2008; Kurtenbach et al., 2001) and radical precursor species such as carbonyl compounds, although the timescales for their photolysis (of the order of a few hours for $\mathrm{HCHO}$ ) are long compared with the anticipated street canyon residence time. HONO itself may be both detected as $\mathrm{NO}_{2}$ by the monitors used, and will undergo photolysis on a timescale of a few minutes, leading to $\mathrm{OH}$ and hence peroxy radical formation, which will promote $\mathrm{NO}_{2}$ to $\mathrm{NO}$ conversion. Clapp and Jenkin (2001) performed model simulations showing that a $1 \%$ direct $\mathrm{HONO}$ emission can substantially increase the calculated $\mathrm{O}_{\mathrm{x}}-\mathrm{NO}_{\mathrm{x}}$ relationship slope, leading to apparent primary oxidant emissions of $3-4 \%$, a significant fraction of the $19 \%$ indicated by Fig. 20 .

The variation in incoming ozone over the diurnal period (indicated by the intercept in Fig. 21) shows a clear late morning/ early afternoon maximum, peaking at 15:00 GMT (also apparent in Fig. 19), reflecting (modest) regional photochemical ozone production, common to all three sites. The variation in the $\mathrm{O}_{\mathrm{x}}-\mathrm{NO}_{\mathrm{x}}$ relationship gradient over the 24$\mathrm{h}$ period is more complex: the gradient is zero (within uncertainty - error bars are $1 \sigma$ for clarity) for the BT Tower, and consistently ca. 0.2 for M. Road, but varies for the urban background North Kensington location. The measured composition is also notably more variable on the BT Tower (assuming the instrument performance was similar at all three locations). In the case of M. Road, night-time levels of NO 
were nearly always $25 \mathrm{ppb}$ or more, and $\mathrm{O}_{3}$ correspondingly low or negligible, while at NK and on the BT Tower, NO levels frequently fell below $1 \mathrm{ppb}$. As the rate constant for the $\mathrm{NO}+\mathrm{NO}_{3}$ reaction is high compared with those for (particularly) $\mathrm{NO}_{3}$ and $\mathrm{N}_{2} \mathrm{O}_{5}$ formation, the presence of constant $\mathrm{NO}$ emissions in the MR street canyon, removing both $\mathrm{O}_{3}$ and $\mathrm{NO}_{3}$, may effectively be curtailing the night time $\mathrm{NO}_{3}$ $\mathrm{N}_{2} \mathrm{O}_{5}$ chemistry allowing the $\mathrm{O}_{\mathrm{x}}-\mathrm{NO}_{\mathrm{x}}$ daytime relationship to be maintained, while at the $\mathrm{BT}$ Tower NO is much lower and the night time $\mathrm{N}_{2} \mathrm{O}_{5}$ formation is significant (Benton et al., 2010 and Sect. 4.8), a situation which may also prevail at NK. While this would not affect the $\mathrm{O}_{\mathrm{x}}-\mathrm{NO}_{\mathrm{x}}$ relationship if the thermal conversion/chemiluminescence $\mathrm{NO}_{2}$ measurement were free from interference, in practice $\mathrm{N}_{2} \mathrm{O}_{5}$ will contribute to the measured signal, leading to lower values of (measured) $\mathrm{O}_{\mathrm{x}}$ for a given (measured) $\mathrm{NO}_{\mathrm{x}}$; it will also result in smaller variations in (measured) $\mathrm{NO}_{\mathrm{x}}$ overnight. The increased gradient seen for NK in Fig. 21 in the period from 18:00 to 02:00 may be consistent with a shallow nocturnal boundary layer trapping local traffic emissions containing a comparable percentage $\mathrm{NO}_{2}$ to $\mathrm{M}$. Road. The subsequent decline in gradient (from 03:00 to 07:00) may reflect nitric acid formation via $\mathrm{N}_{2} \mathrm{O}_{5}$ and loss by deposition or aerosol formation leading to a reduction in the $\mathrm{O}_{\mathrm{x}}$ relative to $\mathrm{NO}_{\mathrm{x}}$ as $\mathrm{N}_{2} \mathrm{O}_{5}$ formation removes three $\mathrm{O}_{\mathrm{x}}$ species, but only two $\mathrm{NO}_{\mathrm{x}}$.

\section{8 $\quad \mathrm{NO}_{3}$ and $\mathrm{N}_{2} \mathrm{O}_{5}$ measurements}

A broadband cavity enhanced absorption spectroscopy (BBCEAS) instrument was deployed from the BT Tower during REPARTEE II, with the aim of providing insights into nocturnal nitrogen chemistry near the top of the urban boundary layer. The instrument is described in detail by Langridge et al. (2008) and has previously been used to measure $\mathrm{NO}_{3}$ and $\mathrm{N}_{2} \mathrm{O}_{5}$ at ground level at a coastal site (McFiggans et al., 2010): a successor instrument has very recently made $\mathrm{NO}_{3}$ and $\mathrm{N}_{2} \mathrm{O}_{5}$ measurements from on board the UK's Facility for Airborne Atmospheric Research (Kennedy et al., 2011). The instrument uses the broadband emission from a light emitting diode (LED) coupled into a high finesse optical cavity to record the absorption spectra of atmospheric samples over extended bandwidths, in this case covering the wavelength range 640-670 $\mathrm{nm}$ which includes the characteristic absorption band of the $\mathrm{NO}_{3}$ radical centred at $662 \mathrm{~nm} . \mathrm{N}_{2} \mathrm{O}_{5}$ is measured indirectly via its thermal decomposition to produce additional $\mathrm{NO}_{3}$ in the instrument's heated inlet, i.e. driving equilibrium (Eq. 2) to the left and so reversing the process by which $\mathrm{N}_{2} \mathrm{O}_{5}$ is produced from $\mathrm{NO}_{3}$ in the atmosphere itself:

$\mathrm{NO}_{3}+\mathrm{NO}_{2}+M \rightleftharpoons \mathrm{N}_{2} \mathrm{O}_{5}+M$

Thus in the configuration deployed during REPARTEE II, the LED-BBCEAS instrument measured the sum of $\mathrm{NO}_{3}$ and $\mathrm{N}_{2} \mathrm{O}_{5}$ concentrations, $\Sigma\left[\mathrm{NO}_{3}\right]+\left[\mathrm{N}_{2} \mathrm{O}_{5}\right]$.

The instrument was deployed from the 35 th floor of the BT Tower (160 m a.g.l.). It was sited on the south west side

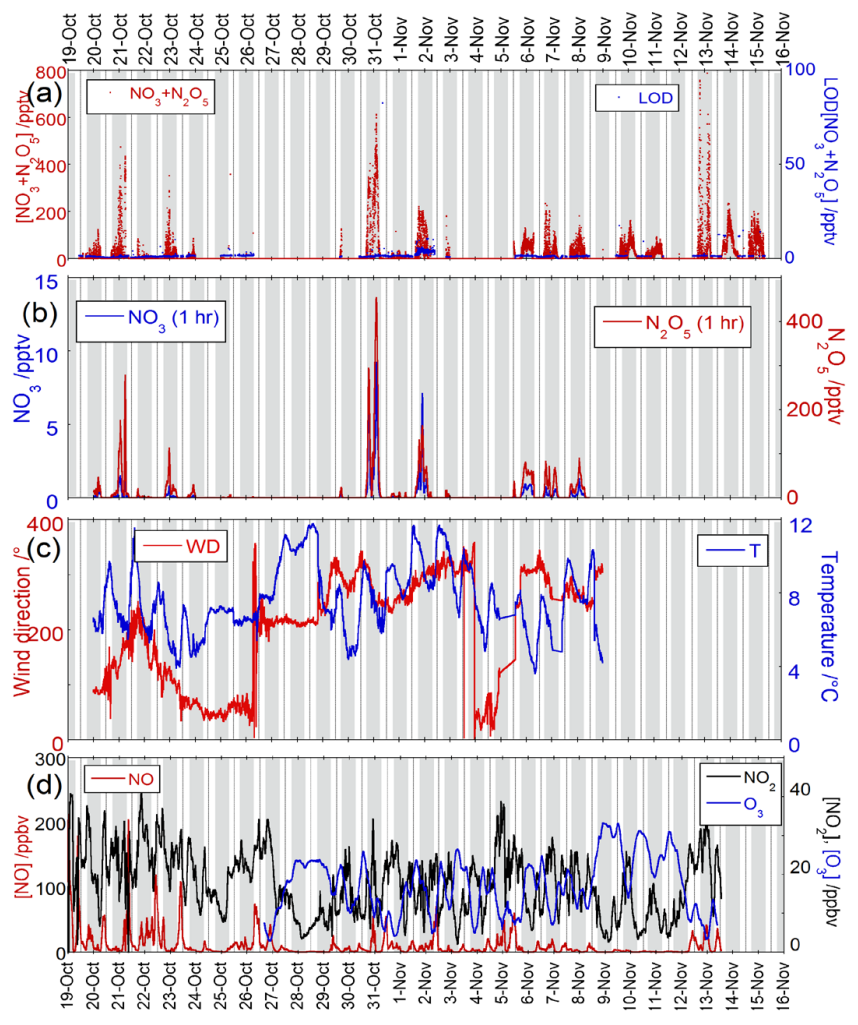

Fig. 22. $\mathrm{NO}_{\mathrm{y}}$ data summary for REPARTEE II. (Greyed background = night-time): (a) $\Sigma\left[\mathrm{NO}_{3}\right]+\left[\mathrm{N}_{2} \mathrm{O}_{5}\right]$ raw data and LOD (blue, note different scale) as measured using BBCEAS. (b) $\mathrm{NO}_{3}$ and $\mathrm{N}_{2} \mathrm{O}_{5}$ mixing ratios inferred from the $\left[\mathrm{NO}_{3}+\mathrm{N}_{2} \mathrm{O}_{5}\right]$ data in panel (a), and separate temperature and $\mathrm{NO}_{2}$ measurements (see below) under the assumption of a rapid equilibrium between $\mathrm{NO}_{3}$ and $\mathrm{N}_{2} \mathrm{O}_{5}$. The data are depicted as a $1 \mathrm{~h}$ moving means. The speciated $\mathrm{NO}_{3}$ and $\mathrm{N}_{2} \mathrm{O}_{5}$ data series ends after the night of $8 / 9$ November because no temperature data were available thereafter. (c) Wind direction and temperature data from the Vaisala instrument at the 35th floor. (d) $\mathrm{NO}, \mathrm{NO}_{2}$ and $\mathrm{O}_{3}$ data.

of the tower's balcony, with its heated inlet directed into the prevailing wind $\left(220^{\circ}\right)$ and protruding $20 \mathrm{~cm}$ through the balcony railings to sample the air flow past the tower. Absorption spectra were acquired at $15 \mathrm{~s}$ intervals from 10:00 on 19 October to 09:00 on 15 November 2007, with around $80 \%$ data coverage during that period. The instrument's limit of detection (LOD) for $\Sigma\left[\mathrm{NO}_{3}\right]+\left[\mathrm{N}_{2} \mathrm{O}_{5}\right]$ was generally around 2 pptv, with an absolute accuracy of $20 \%$.

The top panel of Fig. 22 shows the sum of $\Sigma\left[\mathrm{NO}_{3}\right]$ $+\left[\mathrm{N}_{2} \mathrm{O}_{5}\right]$ concentrations deduced from the $15 \mathrm{~s}$ absorption spectra. The measurements show the distinct diurnal profile expected for $\Sigma\left[\mathrm{NO}_{3}\right]+\left[\mathrm{N}_{2} \mathrm{O}_{5}\right]$, with night-time maxima and daytime values below the instrument's detection limit due to the efficient solar photolysis of $\mathrm{NO}_{3}$ during the day. Substantial night-to-night variability is evident, and this is associated with shifts in the altitude of the nocturnal boundary layer as indicated by the lidar 
(a)

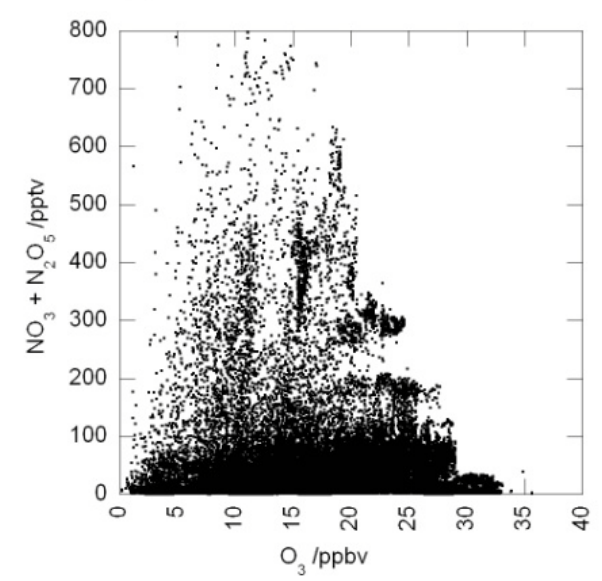

(b)

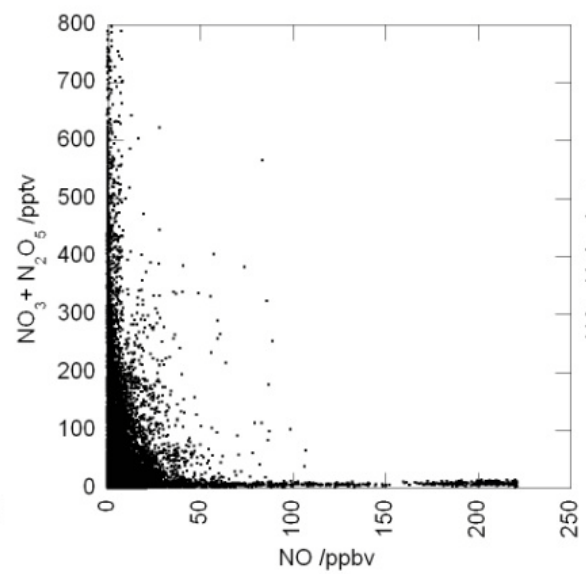

(c)

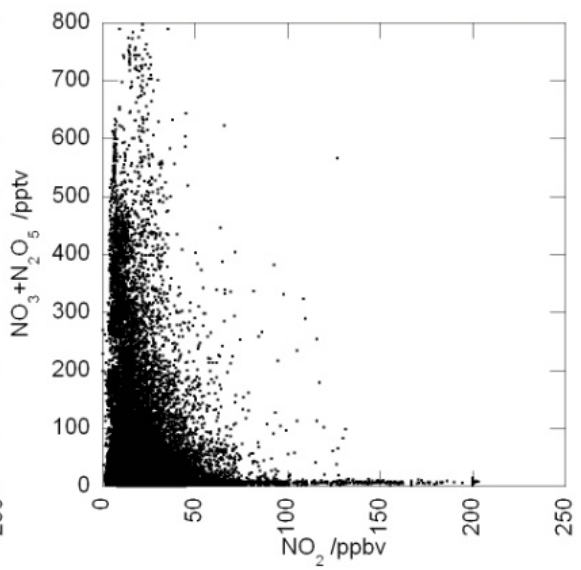

Fig. 23. Scatter plots of $\Sigma\left[\mathrm{NO}_{3}\right]+\left[\mathrm{N}_{2} \mathrm{O}_{5}\right]$ showing (a) a positive correlation with $\mathrm{O}_{3},(R=0.102, N=37$ 245), (b) negative correlation with $\mathrm{NO}(R=-0.057, N=37302)$, and (c) a negative correlation with $\mathrm{NO}_{2}(R=-0.160, N=50764)$ for all night-time data from panel (a) of Fig. 22. $N=$ number of points. All correlations are significant at the $99 \%$ confidence level.

observations made from the nearby University of Westminster on Marylebone Road. The peak night-time mixing ratio of $\Sigma\left[\mathrm{NO}_{3}\right]+\left[\mathrm{N}_{2} \mathrm{O}_{5}\right]=796 \mathrm{pptv}(15 \mathrm{~s}$ data) occurred in the early evening of 12 November 2007, although the night of 30-31 October 2007 had the highest night-averaged mixing ratio of $166 \mathrm{pptv}$ (night-time is taken as the period between sunset and sunrise times). On both occasions, data from the Lidar and from a sonic anemometer located on the top of the tower showed relatively slow vertical wind components and therefore the LED-BBCEAS sampling point to be somewhat decoupled from the mixed layer below (for example, see the lidar data from 31 October shown in Fig. 6). The vertical stratification of its sources and sinks are expected to lead to elevated concentrations of $\mathrm{NO}_{3}$ and $\mathrm{N}_{2} \mathrm{O}_{5}$ away from the surface (Aliwell and Jones, 1998; Fish et al., 1999; Brown et al., 2007a, b). The LED-BBCEAS data additionally show some very rapid fluctuations on timescales as fast as $\sim 1 \mathrm{~min}$. Of particular note are rapid extinctions in the $\Sigma\left[\mathrm{NO}_{3}\right]+\left[\mathrm{N}_{2} \mathrm{O}_{5}\right]$ signal associated with the uplift of NO (i.e. fresh pollution) to the LED-BBCEAS sampling height on the tower. A broadly positive correlation is observed between the $\Sigma\left[\mathrm{NO}_{3}\right]+\left[\mathrm{N}_{2} \mathrm{O}_{5}\right]$ data and $\mathrm{O}_{3}$, and negative correlations with $\mathrm{NO}$ and to a lesser extent with $\mathrm{NO}_{2}$ (Fig. 23). These correlations are consistent with the fast $\mathrm{NO}+\mathrm{NO}_{3} \rightarrow 2 \mathrm{NO}_{2}$ reaction being a sink for $\mathrm{NO}_{3}$ (and a minor source of $\mathrm{NO}_{2}$ ), and $\mathrm{NO}$ being a sink for $\mathrm{O}_{3}$ and therefore reducing the $\mathrm{NO}_{3}$ source strength from the reaction $\mathrm{NO}_{2}+\mathrm{O}_{3} \rightarrow \mathrm{NO}_{3}+\mathrm{O}_{2}$.

Under the assumption of a rapid equilibrium between $\mathrm{NO}_{3}$ and $\mathrm{N}_{2} \mathrm{O}_{5}$ (which was generally valid during REPARTEE II - see Benton et al., 2010), $\Sigma\left[\mathrm{NO}_{3}\right]+\left[\mathrm{N}_{2} \mathrm{O}_{5}\right]$ can be partitioned into $\mathrm{NO}_{3}$ and $\mathrm{N}_{2} \mathrm{O}_{5}$ using an independent measurement of the $\mathrm{NO}_{2}$ mixing ratios (TE42C-TL $\mathrm{NO}_{\mathrm{x}}$ analyser) and ambient temperature data to inform the temperature de- pendent equilibrium constant for the formation of $\mathrm{N}_{2} \mathrm{O}_{5}$ from $\mathrm{NO}_{3}$ and $\mathrm{NO}_{2}$ (Eq. 2). Hourly averaged $\mathrm{NO}_{3}$ and $\mathrm{N}_{2} \mathrm{O}_{5}$ data are shown in the second panel of Fig. 22. The relatively cold temperatures experienced during the campaign and the generally high $\mathrm{NO}_{\mathrm{x}}$ levels prevalent in central London led to the vast majority of $\Sigma\left[\mathrm{NO}_{3}\right]+\left[\mathrm{N}_{2} \mathrm{O}_{5}\right]$ being present as the $\mathrm{N}_{2} \mathrm{O}_{5}$ reservoir compound: $\mathrm{NO}_{3}$ was only $1-4 \%$ throughout the night-time dataset. The heterogeneous uptake of $\mathrm{N}_{2} \mathrm{O}_{5}$ onto aerosols and its rapid reaction with $\mathrm{H}_{2} \mathrm{O}$ to give $\mathrm{HNO}_{3}$ provides the main night-time loss mechanism for $\mathrm{NO}_{\mathrm{x}}$ and a production route for nitrate aerosol. The $\mathrm{N}_{2} \mathrm{O}_{5}$ reservoir also acts to replenish $\mathrm{NO}_{3}$ lost due to reaction with trace gases, and thus may sustain chemical processing of e.g. reactive VOCs at the interface between a pollution-rich layer below and an otherwise decoupled $\mathrm{N}_{2} \mathrm{O}_{5}$-rich layer above (Jones et al., 2005). The large concentrations of $\Sigma\left[\mathrm{NO}_{3}\right]+\left[\mathrm{N}_{2} \mathrm{O}_{5}\right]$ observed when the LED-BBCEAS sampling point was decoupled from the surface suggests that such chemical processing could be rather efficient at the interface of such stratified layers, or on the occasions when pollution is mixed into an $\mathrm{N}_{2} \mathrm{O}_{5}$-rich layer.

\subsection{Perfluorocarbon tracer results}

Previous studies during DAPPLE (Arnold et al., 2004; Martin et al., 2010a; 2010b; Wood et al., 2009) and CityFlux (Petersson et al., 2010) showed extensive channelling of the perfluorocarbon inert tracer through the urban street network in combination with rapid vertical dispersion. At some locations during CityFlux, paired samplers showed higher tracer levels aloft than at the ground. During REPARTEE I and II the objective was to inspect the spread of the tracer plume in the vertical and horizontal, taking advantage of the opportunity to sample at elevated levels afforded by the BT Tower. 
For the vertical distribution the shape component $S$ of the Gaussian plume model was inspected. The equation relating the ratio of the elevated concentration at height $z\left(X_{Z}\right)$ to that at the surface $\left(X_{0}\right)$ is given by

$$
\frac{X_{Z}}{X_{0}}=\exp \left(-b z^{S}\right)
$$

where $b$ is a constant, $z$ is the vertical height and $S$ is the so called shape component, where a value of $S=1$ leads to an exponential profile and $S=2$ leads to a Gaussian one. The combined set of experiments during REPARTEE I and II suggests that for source-receptor distances of approximately $1 \mathrm{~km}$, the shape exponent $S$ was approximately 2 (i.e. a Gaussian profile), and for distances greater than $1 \mathrm{~km} S$ was less than 2 (between Gaussian and exponential). Both campaigns were conducted at the same time of year and factors such as surface roughness, weather conditions (overcast for all experiments) wind direction and wind speed (on average $12 \mathrm{~m} \mathrm{~s}^{-1}$ in 2006 and $7.5 \mathrm{~m} \mathrm{~s}^{-1}$ in 2007) were very similar. In other studies (Shallcross et al., 2009) it was noted that concentrations due to moving sources (e.g. vehicles) decayed with a dependence on distance $z$ as $z^{-1}$ and during DAPPLE (Wood et al., 2009) a transition from a dependence of the decay of $z^{-2}$ to $z^{-1.5}$ was noted at distances greater than about $1 \mathrm{~km}$. The time taken for tracer to reach the top of the BT Tower $(\sim 190 \mathrm{~m})$ through turbulent transport by diffusion was estimated to be around $10 \mathrm{~min}$ for neutral conditions and as long as $20-50$ min under the most stable conditions encountered (Barlow et al., 2011). The lateral plume spread was observed to be described well by a Gaussian distribution. Since the samples were collected over a set period of time in tedlar bags, the Dose D (the time-integrated concentration over the sampling period) was compared with the normalized distance from the source according to the relationship:

$$
\frac{\mathrm{D} U_{H} H^{2}}{q}=K \frac{H^{2}}{x^{2}}
$$

Where $\mathrm{D}$ is the dose $\left(\mathrm{kg} \mathrm{m}^{-3} \mathrm{~s}\right), U_{H}$ is the wind speed at roof height in $\mathrm{m} \mathrm{s}^{-1}, H$ is the building height in metres, $q$ is the release rate $\left(\mathrm{kg} \mathrm{s}^{-1}\right)$ and $x$ is the downwind distance from the source in metres. Plotting all the data from these experiments, i.e. $\frac{\mathrm{D} U_{H} H^{2}}{q}$ vs. $\frac{H^{2}}{x^{2}}$ yielded an upper bound for $K$. For most data a value of $K=10$ was sufficient and in keeping with experiments during DAPPLE (e.g. Wood et al., 2009; Martin et al., 2010a, b) and other studies (as reviewed in Martin et al., 2011b), in particular those from cities in the USA with a different street geometry.

\subsection{Pollutant fluxes and their controls}

\subsubsection{Background}

Emissions of pollutants are usually estimated in bottom up inventory approaches by adding up the different sources. These approaches can be reliable for emissions that are dominated for well-characterised large industrial point sources, but tend to be less reliable for pollutants that originate mainly from diffuse area sources. They also tend to be more robust for compounds whose emission is easily linked to activity $\left(\mathrm{CO}_{2}\right.$ emissions are directly linked to fuel usage), than those which are further affected e.g. by engine/driving conditions (e.g. for $\mathrm{CO}$ ) or meteorological variables (for fugitive emissions of some volatile organic compounds, VOCs). Bottom-up inventories often only compile annual average emissions without further temporal information at the seasonal or hourly scale, and are limited to few pollutants or pollutant metrics.

By measuring pollutant fluxes with the micrometeorological eddy-covariance method well above the city an independent, integrated (top-down) estimate can be obtained at the city scale, which can be used to assess the bottom-up inventories, to study the control of the emissions, to derive emissions of novel metrics (such as total particle number) and, in some cases, to study chemical or physical transformations between the point of emission and arrival at the measurement height.

During the REPARTEE campaigns flux measurements were conducted from the top of the BT tower of momentum, sensible and latent heat (Wood et al., 2010; Helfter et al., 2011), together with a large number of pollutants. Table 6 summarises the compounds studied, their anticipated major sources and reference to the individual companion papers that discuss the results in more detail. These include carbon dioxide $\left(\mathrm{CO}_{2}\right)$, carbon monoxide $(\mathrm{CO})$, selected volatile organic compounds (VOCs) such as benzene, toluene and isoprene, ozone $\left(\mathrm{O}_{3}\right)$, total particle number as well as size and composition resolved particle fluxes (Wood et al., 2010; Helfter et al., 2011; Langford et al., 2010; Phillips et al., 2012; Nemitz et al., 2012a, b). Fluxes of VOCs and $\mathrm{O}_{3}$ were measured during REPARTEE I only, while measurements of momentum, heat and $\mathrm{CO}_{2}$ continued for a total of 18 months. This extensive flux measurement programme was possible by collaboration of REPARTEE with the UK NERC funded CityFlux project, which also contributed flux measurements to four other campaigns in Gothenburg (Sweden), Edinburgh, Manchester and Mexico City (e.g. Thomas, 2007; Langford et al., 2009; Martin et al., 2009; Petersson et al., 2010; Phillips et al., 2012). Here the results from the London measurements are summarised, where the other studies are referred to, it is for comparison. 
Table 6. Summary of pollutants whose fluxes were measured during REPARTEE.

\begin{tabular}{|c|c|c|c|}
\hline Compound & Instrument & Dominant urban sources/sinks & Literature reference \\
\hline Carbon dioxide $\left(\mathrm{CO}_{2}\right)$ & $\begin{array}{l}\text { IRGA Li-COR 6262, } \\
7000\end{array}$ & Traffic \& heating emissions & Helfter et al. (2011) \\
\hline Carbon monoxide (CO) & & Traffic \& other combustion & Phillips et al. (2012) \\
\hline Benzene & PTR-MS & Traffic & Langford et al. (2010) \\
\hline Toluene & PTR-MS & Traffic & Langford et al. (2010) \\
\hline C2-benzenes & PTR-MS & Traffic & Langford et al. (2010) \\
\hline Isoprene & PTR-MS & Traffic \& nature & Langford et al. (2010) \\
\hline Acetone & PTR-MS & Traffic \& solvents & Langford et al. (2010) \\
\hline Acetaldehyde & PTR-MS & Traffic \& solid fuel & Langford et al. (2010) \\
\hline Acetonitrile & PTR-MS & Solid fuel & Langford et al. (2010) \\
\hline Methanol & PTR-MS & Solvent, evaporative & Langford et al. (2010) \\
\hline Ozone $\left(\mathrm{O}_{3}\right)$ & $\begin{array}{l}\text { Fast chemiluminescence, } \\
\text { ROFI }\end{array}$ & Destruction by NO & Nemitz et al. (2012a) \\
\hline $\begin{array}{l}\text { Total ultrafine particle num- } \\
\text { ber (UFP) }\end{array}$ & CPC TSI 3010 & Traffic emissions & Martin et al. (2009) \\
\hline $\begin{array}{l}\text { Accumulation mode parti- } \\
\text { cle number }(80-1000 \mathrm{~nm})\end{array}$ & FAST & Traffic emissions & Nemitz et al. (2012c) \\
\hline Organic aerosol & AMS & $\begin{array}{l}\text { Emissions from traffic, solid fuel, } \\
\text { cooking }\end{array}$ & $\begin{array}{l}\text { Phillips et al. (2012); } \\
\text { Nemitz et al. (2012a, b) }\end{array}$ \\
\hline Aerosol nitrate & AMS & Gas-aerosol partitioning & $\begin{array}{l}\text { Phillips et al. (2012); } \\
\text { Nemitz et al. (2012a, b) }\end{array}$ \\
\hline Aerosol sulphate & AMS & Deposition from regional background & $\begin{array}{l}\text { Phillips et al. (2012); } \\
\text { Nemitz et al. (2012a, b) }\end{array}$ \\
\hline
\end{tabular}

\subsubsection{Site characterisation: turbulence and fluxes of momentum and energy}

Flux measurements were taken at about $190 \mathrm{~m}$ above the street level, which represents about 9 times the mean building height in the area. While this is advantageous for avoiding artefacts from the building structures (wake, roof heat flux) and has the potential for providing integrated fluxes averaged over large urban areas, there are also downsides. This high up in the boundary layer, fluxes may no longer be constant with height, and, especially during nighttime the top of the tower may be above the nocturnal boundary layer, and therefore decoupled from the surface. During this time, urban emissions may be stored within the urban air space rather than moving past the tower. Thus, the fluxes presented here reflect local fluxes at the measurement height, which will be a robust representation of the surface exchange only during daytime. Indeed the lidar measurements during REPARTEE II showed that the tower was above the mixing layer height during about $40 \%$ of the nights during that period (see Fig. 8). Conditions during REPARTEE I were warmer and less stratified, suggesting that the fraction would have been lower. Similarly, comparison of heat fluxes on the tower and a much lower eddy-covariance roof-top site demonstrates that, while heat fluxes are almost always upwards just above the buildings, this is no longer the case at $190 \mathrm{~m}$ (Barlow et al., 2009). From the 18-month measurement record of momentum, energy and $\mathrm{CO}_{2}$ fluxes, it is apparent that the importance of stable local stratification (defined as $\zeta=z / L>0.32$; with $\zeta$ being the Monin-Obukhov stability parameter, $z$ being height and $L$ the Obukhov length) on the tower depended on season and was most pronounced for daytime in winter and for nighttime in autumn (small heat fluxes combined with relatively little anthropogenic heating). However, it never exceeded $50 \%$ of the time.

Figure 24 compares the ratio of the $\mathrm{CO}_{2}$ flux to traffic flow on Marylebone Rd. with the boundary layer height products derived from the lidar measurements for a period during which particularly low nocturnal mixing heights were observed (Sect. 3.5). During nights when the convective mixing 


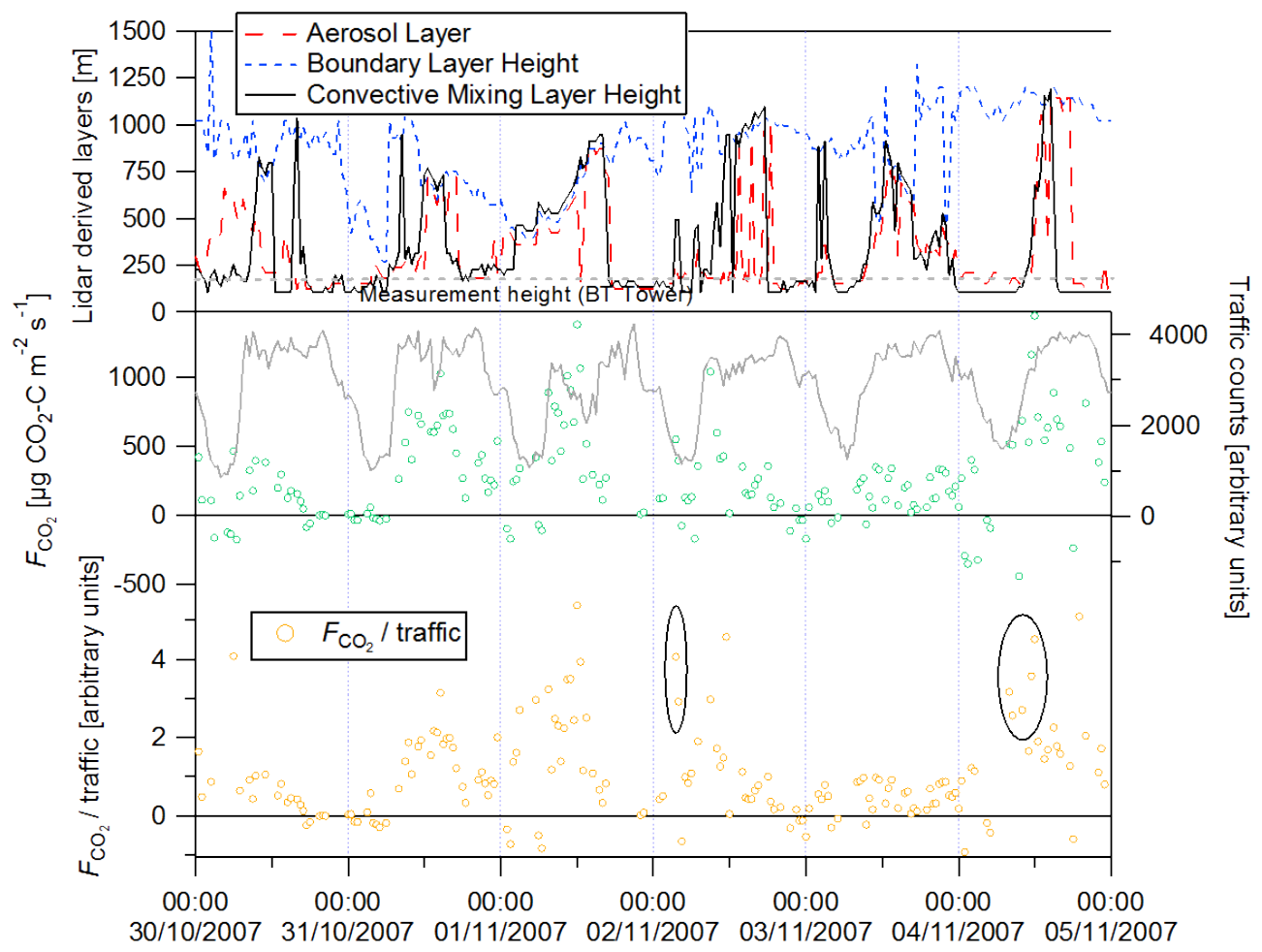

Fig. 24. Heights of the boundary layer and aerosol layer derived from the lidar measurements compared with the ratios of $\mathrm{CO}_{2}$ emission to traffic counts. The figure highlights observations of increased $\mathrm{F}_{\mathrm{CO}_{2}}$ /traffic ratios made in the early morning hour, when the boundary layer expanded.

layer was below the measurement height, $\mathrm{CO}_{2}$ fluxes were close to zero although there was still considerable traffic, and often there was a clear lag between the increase in the traffic volume and pollutant fluxes in the morning. Daytime emissions after these calm nights were often asymmetric, with an enhanced $\mathrm{CO}_{2}$ /traffic ratio in the morning. This reflects the fact that in the early morning emissions initially occur into a shallow residual nocturnal boundary layer, which then gradually expands, much of this accumulated material is then vented across the measurement height (circled events). This demonstrates that some of the material stored during night will moved past the measurement point in the morning and was captured at that time. However, some of the material may be advected horizontally out of the city, re-deposit or react chemically.

An analysis of the boundary layer turbulence using the vertical and horizontal turbulence scalars, $A_{i}=\sigma_{i} / u_{*}$, was conducted to validate the range of meteorological conditions for applicability of emission models. Here $u_{*}$ is the friction velocity and $i$ represents the orthogonal turbulent vector components, $u, v$ or $w . A_{i}$ is a function of the dimensionless Monin-Obukhov scaling parameter, which may also be applied to other scalars, e.g. temperature, $\mathrm{CO}_{2}$ or particle number concentration $(N)$ so that $A_{i}=\sigma_{i} / i_{*}$ and $i_{*}=-\overline{w^{\prime} i^{\prime}} / u_{*}$ where $w^{\prime}$ and $i^{\prime}$ are the fluctuations from the mean of the vertical wind speed and scalar, respectively. Using this approach, one can show that $A_{i}$, for the unstable atmospheric boundary layer regime, $\zeta<0$ can be described by the function

$A_{i}=a_{i}\left(1-b_{i} \zeta\right)^{c_{i}}$

where $a_{i}, b_{i}$ and $c_{i}$, are empirical constants and $c_{i}$ is commonly found to be $1 / 3$ for $w$ and $-1 / 3$ for $\mathrm{CO}_{2}$ fluxes, e.g. Vesala et al. (2007). The measurements by Vesala et al. (2007) over semi-urban surfaces broadly agreed with typical values for $w$ over complex terrain but can range between 1.11-1.42, and 2.58-5.36 for $\mathrm{CO}_{2}$ depending on the dominant surface type. They also analysed temperature and water vapour concentration scalars and found them to exhibit similar " $-1 / 3$ " power laws. Roth (2000) provided a review of similarity scaling applied to wind, temperature and humidity scalars over several different surfaces and showed that, despite the requirement for similarity theory for uniform homogeneous surfaces, the observed functional dependence agreed well with this theory, justifying its application to urban surfaces. Figure 25a-c shows the same functional analysis applied to the REPARTEE flux data sets and compared with the model proposed by Roth (2000). The empirically derived constants described in Eq. (5), along with their neutral intercepts for London are summarized in Table 7. Again 
(a)

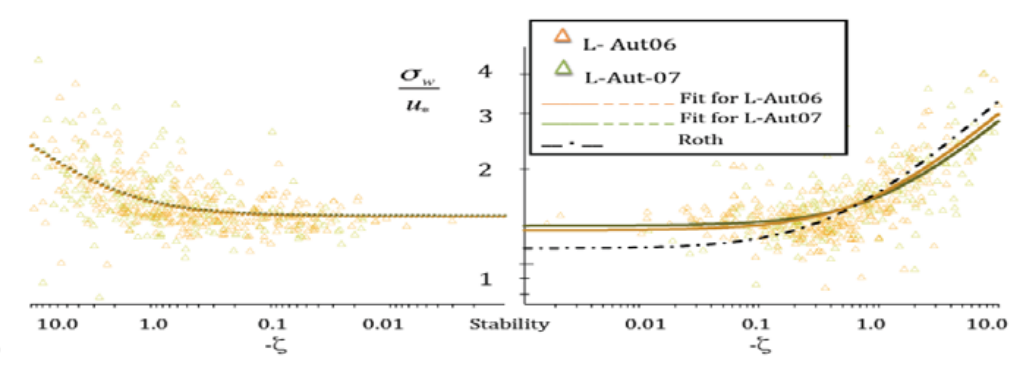

(b)

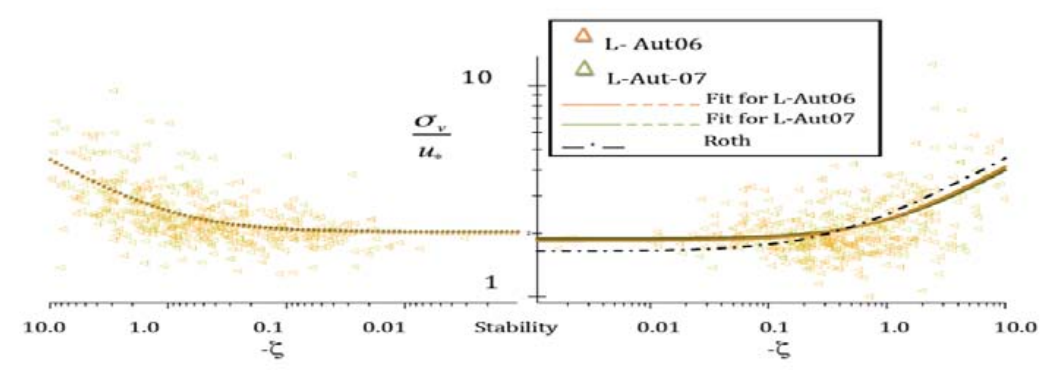

(c)

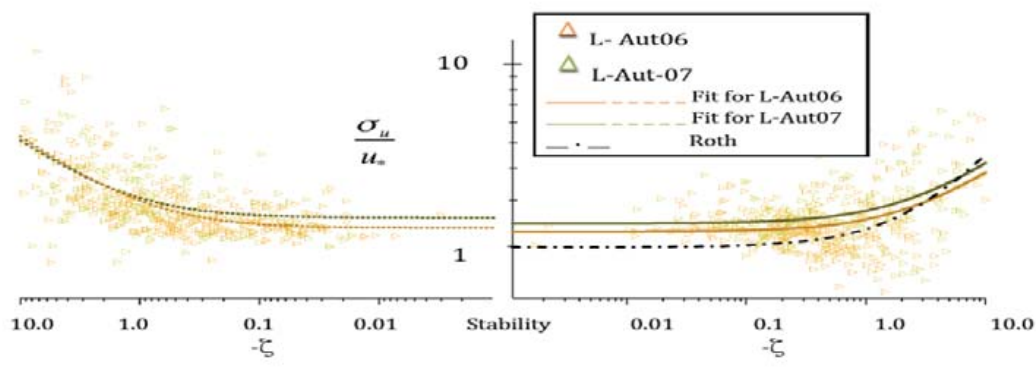

(d)

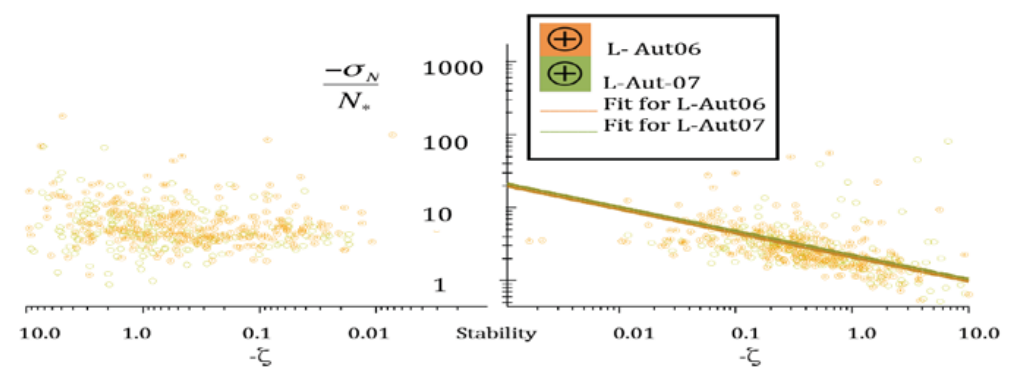

Fig. 25. Normalised standard deviations of (a) vertical wind speed $(w)$, (b) horizontal wind component $(u)$, (c) transverse wind component $(v)$ and (d) UFP concentration $(N)$, versus dimensionless Monin-Obukhov stability parameter, $\zeta(=z / L)$ for both REPARTEE experiments compared to the model prediction by Roth (2000) and regression fits. 
Table 7. Empirically derived constants to fit Eq. (5) for wind speed under unstable conditions with coefficient of determination $\left(r^{2}\right)$ between the observed and predicted data. Neutral intercept in each case is given by $A_{i}$ (compiled from Martin, 2009; Helfter et al., 2011; Wood et al., 2010).

\begin{tabular}{llcrrrrc}
\hline$i_{\text {unstable }}$ & Experiment & $r^{2}$ & $a_{i}$ & \pm & $b_{i}$ & \pm & $A_{i}$ \\
\hline$u$ & 2006 & 0.157 & 2.273 & 0.0539 & 0.3912 & 0.102 & 2.27 \\
& 2007 & 0.185 & 2.444 & 0.0790 & 0.4059 & 0.103 & 2.44 \\
\hline$v$ & 2006 & 0.160 & 1.834 & 0.0831 & 1.066 & 0.312 & 1.83 \\
& 2007 & 0.238 & 1.881 & 0.0914 & 0.8682 & 0.237 & 1.88 \\
\hline$w$ & 2006 & 0.483 & 1.279 & 0.0306 & 1.215 & 0.178 & 1.28 \\
& 2007 & 0.490 & 1.322 & 0.0387 & 1.149 & 0.148 & 1.32 \\
& Full year (seasons) & & $1.31(1.24-1.36)$ & $0.65(0.28-0.66)$ & \\
\hline $\mathrm{CO}_{2}$ & Full year (seasons) & & $2.02(2.00-2.12)$ & $0.43(0.22-0.66)$ & \\
\hline$N$ & 2006 & & & & & -10.28 \\
& 2007 & & & & & & -9.46 \\
\hline
\end{tabular}

\pm denotes one standard deviation

there is good agreement between the REPARTEE observations and the model prediction.

This analysis was then applied to the Ultrafine Particle (UFP) number $(N)$ fluxes (Fig. 25d), with the neutral intercepts for $A_{N}$, from each REPARTEE study summarized in Table 7. It should be noted that the correlation for $A_{N}$ was weaker than for $A_{u, v, w}$ as expected and consistent with that found for $\mathrm{CO}_{2}$.

The evolution in turbulent transport scales during the experimental period is encapsulated in Fig. 26a. Plotted is the normalized energy spectral density of the vertical velocity component, $n S_{w}(n) / \sigma_{w}^{2}$, where $S_{w}(n)$ is the spectral density of the vertical velocity, $n$ is the sampling frequency and $\sigma_{w}^{2}$ is the variance in the vertical velocity component, with each spectrum averaged over a period of one hour. These are plotted against the normalised frequency $(f=n z / U)$ and cover a 24 day period from the 2006 experiment. In particular, stagnant conditions are seen where higher energy levels dominate at lower frequencies, e.g. 4, 12, 24 and 29 October. This is consistent with the analysis of the turbulence by Wood et al. (2010) who showed that for the high measurement height employed here the mixing layer scale (i.e. scaling on the basis of the boundary layer height, $z_{i}$ ), becomes more appropriate than measurement height as used for surface layer scaling.

Significantly, the aerosol flux co-spectra, Fig. 26b, show a weaker diurnal variation, which is consistent with the smaller dependence of the mixing scales on stability, and may suggest mass transport is less sensitive to mixing layer height. Generally, the position of the $w^{\prime} N^{\prime}$ co-spectral peak is controlled by wind speed whereas the magnitude of the peak in the $w$ spectrum exhibits a diurnal pattern. Figure 26b also demonstrates on the basis of the aerosol fluxes that mass fluxes have a larger contribution from low frequency eddies than the momentum transport, with implications for the flux averaging time needed to capture most of the flux. Analysis of the ogives (cumulative frequency distributions) for particle number flux (Fig. S3 in Supplement) demonstrates that during individual periods up to $15 \%$ of the flux may be carried in eddies slower than $30 \mathrm{~min}$. This is consistent with a similar analysis carried out by Langford et al. (2010) for the heat flux which indicated that an averaging time of 1.5 and $2 \mathrm{~h}$ increased the heat flux by an average of 5.8 and $8 \%$ compared with 30-min calculations. Nevertheless, to avoid nonstationarities and to provide more information on the variability of the fluxes and their response to other parameters, most fluxes, except the UFP flux, were calculated on 30-min averaging times.

In summary, although turbulence at the tower is "well behaved" and agrees with observations above less complex terrain, some uncertainties remain in linking the nocturnal (and thus average) measurements on the tower to surface fluxes. Multi-point and height flux and concentration measurements would be required to quantify advection and storage effects.

\subsubsection{Trace gas fluxes}

As mentioned before, anthropogenic $\mathrm{CO}_{2}$ emissions are particularly closely linked to fossil fuel combustion and therefore annual national bottom-up inventories are thought to be fairly accurate. Spatial attribution becomes more uncertain and not much is known about temporal patterns. Thus, the annual average measured above the city should provide a reasonably robust test of the accuracy with which the urban fluxes can be measured. Indeed, the 18-month $\mathrm{CO}_{2}$ flux dataset above London compared with the UK National Atmospheric Emissions Inventory to within $3 \%$ for the London Borough of the City of Westminster (Helfter et al., 2011), 

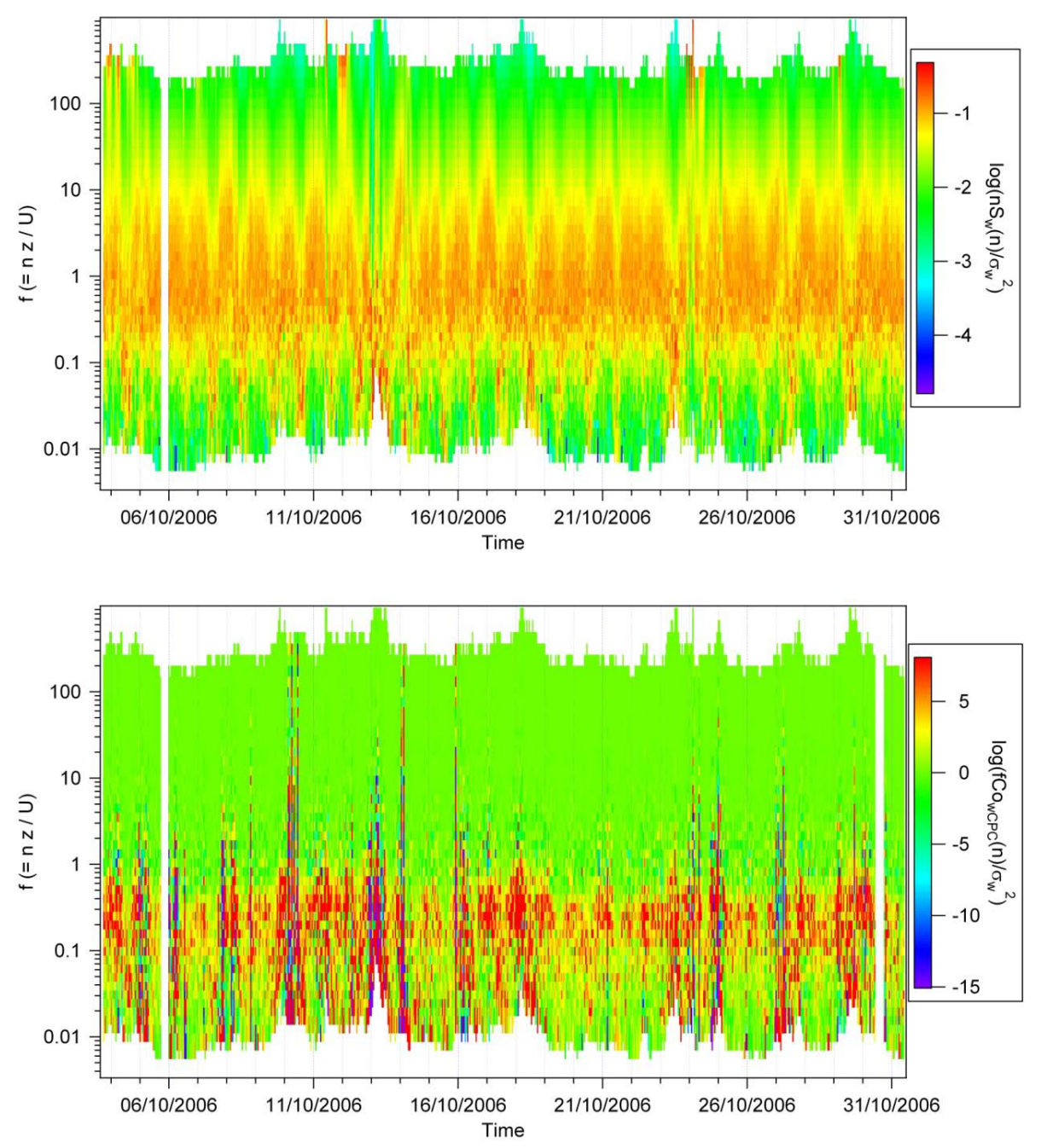

Fig. 26. Time series of normalized (a) vertical velocity energy spectral density, $n S_{w}(n) / \sigma_{\omega}^{2}$ and (b) ultrafine aerosol co-spectra, $n C_{w N}(n) /<w^{\prime} N^{\prime}>$ as a function of normalized frequency $f=n z / U$, observed on the BT Tower during the period 5/11-31/10/2006. Low frequencies (long time scales) are to the bottom of the y-axis, with red contours denoting high spectral density values, and blue, low values.

which must be considered somewhat fortuitous given the uncertainties in the $\mathrm{CO}_{2}$ flux measurement and the correction for biogenic contributions to the net exchange. However, the biogenic correction was estimated to be small which reflects the dense urban nature of the London city centre position and is similar to previous measurements above Edinburgh city centre (Nemitz et al., 2001). This contrasts with many other urban $\mathrm{CO}_{2}$ flux measurements which were often made above sub-urban residential areas with less traffic and more green spaces. In North America in particular, the high building height often prevents measurements being made in the city centres.

In London, emissions were largest in the SE direction of the BT Tower where the city centre is located. By contrast, emissions were very small in the NW sector, which contains Regent's Park. Here the uptake by the biosphere balances some of the emission. Concentrations behaved differently, with the highest concentrations observed when the air masses were coming from the NE. This is a wind direction commonly observed with the advection of European continental air masses. Flux magnitudes were somewhat lower in summer than during the other seasons, probably reflecting the drawdown by photosynthesis and the minimum in emissions related to residential and institutional space heating. For the same reason winter emissions were elevated, in particular at low traffic counts. See Helfter et al. (2011) for a fuller discussion of the long-term dataset.

Carbon monoxide (CO) is another popular tracer for fossil fuel combustion. For this compound effects from biosphere/atmosphere exchange are expected to be negligible and chemistry is inefficient at the typical urban transport time scale. However, the $\mathrm{CO} / \mathrm{CO}_{2}$ emission ratio is very variable for different fuels and combustion conditions (including engine and driving conditions for traffic emissions) and thus the 

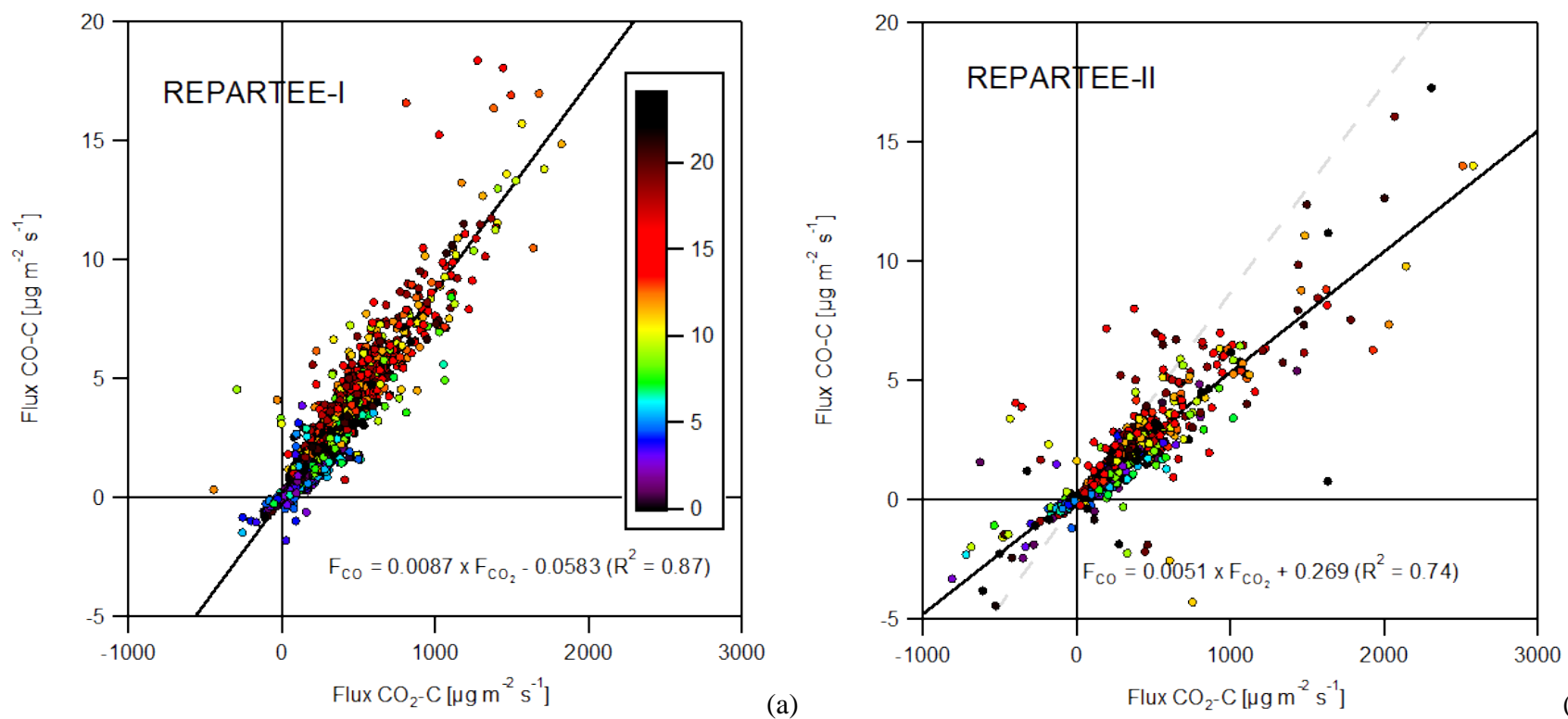

(b)

Fig. 27. Relationship between $\mathrm{CO}$ and $\mathrm{CO}_{2}$ flux during (a) REPARTEE-I and (b) REPARTEE-II in relation to the hour-of-the-day (colour scale). The grey dashed line on plot (b) is a repeat of the fit from plot (a) for comparison.

emission ratio is thought to be variable. In this light the tight correlation between $\mathrm{CO}$ and $\mathrm{CO}_{2}$ flux (Fig. 27) is therefore surprising, with average emission ratios of 0.87 and $0.51 \%$ (in terms of $\left.\mathrm{CO}-\mathrm{C}\left(\mathrm{g} \mathrm{CO}_{2}-\mathrm{C}\right)^{-1}\right)$ during the two campaigns. The relationships suggest a slight curvature with the highest emission ratios at midday and lower ratios in the early morning hours (00:00-08:00 UTC), which is consistent with the lower $\mathrm{CO} / \mathrm{CO}_{2}$ emission ratio from heating-related residential gas combustion which makes a fractionally larger contribution to the $\mathrm{CO}_{2}$ emission at night. For comparison, a somewhat higher emission ratio of $2.14 \%$ was derived above Edinburgh using the same methodology, also within CityFlux (Famulari et al., 2010). To our knowledge these are the first published direct eddy-covariance flux measurements of $\mathrm{CO}$.

Urban sources of volatile organic compounds (VOCs) are less well characterised and quantified. During REPARTEEI a proton transfer reaction mass spectrometer (PTR-MS) was applied for the eddy-covariance measurement of fluxes of a range of VOCs which were selected according to the VOCs that can be identified by this technique (Langford et al., 2010). Because some fragmentation occurs during the proton transfer reaction and because the quadrupole mass spectrometer used in this PTR-MS cannot distinguish different fragments of the same (integer) mass to charge ratio $(\mathrm{m} / \mathrm{z})$, the fluxes measured at some $\mathrm{m} / \mathrm{z}$ could also represent some other compounds. The results show distinct average diurnal cycles for the different compounds. Emission fluxes of acetaldehyde, benzene, ethylbenzene, toluene and acetonitrile are closely related to those of $\mathrm{CO}$ with $R^{2}>0.85$.

Acetone shows a similar pattern overall and an increase around 07:00 a.m. like the other CO-related compounds, but emissions tail off more sharply after 10:00 a.m., possibly indicating that acetone is either related to cold start emissions or that a chemical destruction kicks in later in the day which does not operate in the early morning hours when temperatures and light levels are lower. Methanol and isoprene show much flatter diurnal profiles and larger fluxes during night, probably representing non-traffic fugitive sources for methanol and biogenic sources for isoprene, which were estimated to contribute $65 \%$ and $47 \%$, respectively. Measured emissions of benzene, toluene, ethylbenzene and acetone compared with the NAEI estimates within a factor of 2 , while measured methanol emissions were twice the bottomup estimate. Measured fluxes of acetaldehyde, isoprene and acetonitrile were many times larger than the emission inventory suggests.

Fluxes of ozone $\left(\mathrm{O}_{3}\right)$ were measured for the first time above an urban area during REPARTEE I (Nemitz et al., 2012a). Although urban emissions of nitrogen oxides contribute to $\mathrm{O}_{3}$ production at the regional scale, within the urban area the traffic-related NO emission destroys much of the $\mathrm{O}_{3}$ and therefore the urban air space below the measurement provides an efficient sink. Above London deposition fluxes peaked at typically $2-6 \mu \mathrm{g} \mathrm{O} \mathrm{O}_{3} \mathrm{~m}^{-2} \mathrm{~s}^{-1}$, which relates to effective local deposition velocities $\left(V_{\mathrm{d}}=\right.$ - flux/concentration) of typically 50 to $100 \mathrm{~mm} \mathrm{~s}^{-1}$, bearing in mind that most of the $\mathrm{O}_{3}$ will not deposit to the urban surface, but be destroyed by reaction with $\mathrm{NO} . \mathrm{NO}_{\mathrm{x}}$ fluxes were not determined during the campaigns. The correlation between fluxes of $\mathrm{O}_{3}$ and $\mathrm{CO}_{2}$ is fairly weak $\left(R^{2}=0.49\right.$; cf. Table 8), which indicates that there are other factors that contribute to the efficiency at which $\mathrm{O}_{3}$ is destroyed in 
Table 8. Matrix of correlation coefficients between hourly fluxes of the different components during REPARTEE I (bottom left triangle) and REPARTEE II (top right). Correlations with $R^{2}>0.3$ are highlighted in bold. Negative $R^{2}$ indicate anti-correlations. Each correlation coefficient was calculated from between 188 and 587 hourly data points. AMP is accumulation mode particles.

\begin{tabular}{|c|c|c|c|c|c|c|c|c|c|c|c|c|c|c|c|c|c|c|}
\hline & $\overbrace{}^{N}$ & O & $0^{\infty}$ & 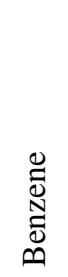 & 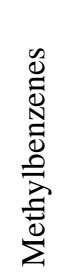 & 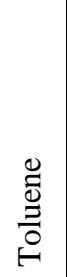 & $\begin{array}{l}\stackrel{\mathscr{U}}{0} \\
\stackrel{0}{0} \\
\stackrel{0}{0}\end{array}$ & $\begin{array}{l}\stackrel{0}{0} \\
\stackrel{0}{0} \\
\stackrel{U}{U}\end{array}$ & 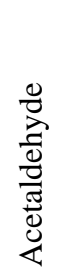 & 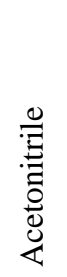 & 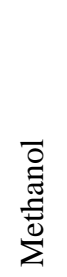 & $\frac{\rho}{D}$ & 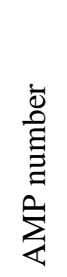 & 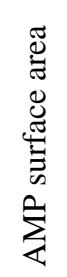 & 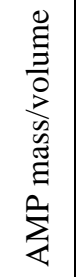 & 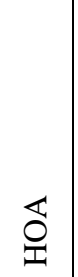 & $\bigodot^{1}$ & $\stackrel{\sim}{i}^{+}$ \\
\hline $\mathrm{CO}_{2}$ & - & 0.61 & - & - & - & - & - & - & - & - & - & 0.50 & 0.08 & 0.07 & 0.05 & & & \\
\hline $\mathrm{CO}$ & 0.88 & - & - & - & - & - & - & - & - & - & - & 0.51 & 0.11 & 0.09 & 0.06 & & & \\
\hline $\mathrm{O}_{3}$ & -0.49 & -0.45 & - & - & - & - & - & - & - & - & - & - & - & - & - & - & - & - \\
\hline Benzene & 0.10 & 0.12 & -0.05 & - & - & - & - & - & - & - & - & - & - & - & - & - & - & - \\
\hline Methylbenzenes & 0.18 & 0.18 & -0.23 & 0.08 & - & - & - & - & - & - & - & - & - & - & - & - & - & - \\
\hline Toluene & 0.17 & 0.18 & -0.07 & 0.11 & 0.30 & - & - & - & - & - & - & -7 & $2-1$ & $2-\Delta$ & 25 & $\Rightarrow+1$ & $\square-$ & - \\
\hline Isoprene & 0.22 & 0.19 & -0.21 & 0.21 & 0.39 & 0.30 & - & - & - & - & - & -1 & - & -1 & 2- & -1 & - & - \\
\hline Acetone & 0.26 & 0.27 & -0.26 & 0.14 & 0.37 & 0.32 & 0.41 & - & - & - & - & -7 & - & - & - & - & - & - \\
\hline Acetaldehyde & 0.09 & 0.07 & -0.21 & 0.07 & 0.17 & 0.09 & 0.14 & 0.32 & - & - & - & -1 & - & - & - & - & - & - \\
\hline Acetonitrile & 0.25 & 0.29 & -0.27 & 0.12 & 0.20 & 0.20 & 0.44 & 0.29 & 0.00 & - & - & - & - & - & - & - & - & - \\
\hline Methanol & 0.16 & 0.22 & -0.42 & 0.10 & 0.14 & 0.04 & 0.20 & 0.13 & 0.06 & 0.34 & - & - & - & - & - & - & - & - \\
\hline UFP & 0.70 & 0.71 & -0.24 & 0.17 & 0.30 & 0.24 & 0.41 & 0.45 & 0.11 & 0.51 & 0.40 & - & 0.16 & 0.11 & 0.07 & & & \\
\hline AMP number & - & - & - & - & - & - & - & - & - & - & - & - & - & 0.82 & 0.60 & & & \\
\hline AMP surface area & - & - & 2.7 & 7 & $D$ & $-1-1$ & $F$ & - & - & - & - & - & - & - & 0.98 & & & \\
\hline AMP mass/volume & - & - & - & - & - & - & - & - & - & - & - & - & - & - & - & & & \\
\hline HOA & 0.09 & 0.09 & 0.08 & 0.00 & 0.04 & 0.01 & 0.05 & 0.01 & 0.00 & 0.04 & 0.10 & 0.12 & - & - & - & - & & \\
\hline $\mathrm{NO}_{3}^{-}$ & & & & & & & & & & & & & - & - & - & & - & \\
\hline $\mathrm{SO}_{4}{ }^{2-}$ & & & & & & & & & & & & & - & - & - & & & - \\
\hline
\end{tabular}

addition to fossil fuel combustion. These are likely to include the $\mathrm{NO} / \mathrm{CO}_{2}$ emission ratio, the transport timescale between emission and measurement on the tower as well as the $\mathrm{O}_{3}$ photolysis rate. Future measurements at this London flux site will address this interaction in more detail, as the $\mathrm{O}_{3}$ flux measurement provides a powerful constraint for urban chemical transport models.

\subsubsection{Aerosol fluxes}

\section{Ultrafine particle number}

Urban particle number flux measurements were pioneered within our earlier NERC SASUA project (Dorsey et al., 2002), with more comprehensive investigations for different cities subsequently provided by Mårtensson et al. (2006), Järvi et al. (2009) and Martin et al. (2009). The latter measured and compared the diurnal patterns of particle number fluxes measured over several different cities as a function of season, including preliminary measurements from the CityFlux sites and first REPARTEE experiment in London. Here we summarise results from both REPARTEE experiments where measured fluxes typically covered the particle diameter range 0.01 to $2 \mu \mathrm{m}$ with a dominant size mode at
$0.05 \mu \mathrm{m}$ (cf. Fig. 14 and Dall'Osto et al., 2011). Average di-

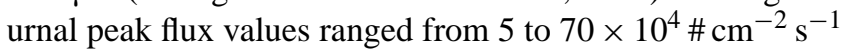
with a clear dependence on traffic activity, confirming the role of traffic as the major source of UFP in the urban area. These data were used to test a simple parameterized UFP emission model applicable to London. Several increasingly sophisticated parameterisations for city-scale aerosol fluxes have been developed (Dorsey et al., 2002; Mårtensson et al., 2006 and Martin et al., 2009). For example, Mårtensson et al. (2006) proposed a refinement to the basic emission model of Dorsey et al. (2002) of the form

$$
f=\mathrm{EF}_{\mathrm{fm}} \mathrm{TA}\left(u_{*} / \overline{u_{*}}\right)^{0.4}+f_{0}
$$

where $f$ is the flux, $\mathrm{EF}_{\mathrm{fm}}$ is the emission factor of a mixed fleet (vehicle ${ }^{-1} \mathrm{~km}^{-1}$ ), TA is the traffic activity (vehicle $\left.\mathrm{km} \mathrm{m}^{-2} \mathrm{~s}^{-1}\right), u_{*}$ is the friction velocity, $\overline{u_{*}}$ is the average friction velocity and $f_{0}$ is the contribution by any non-traffic related sources. This parameterisation, for the city of Stockholm, was refined further to give the respective contributions from light and heavy duty fleet components, the latter contributing a greater emission factor for that city.

The experimental setup used on the BT tower was described by Martin et al. (2009) and is similar to that first 

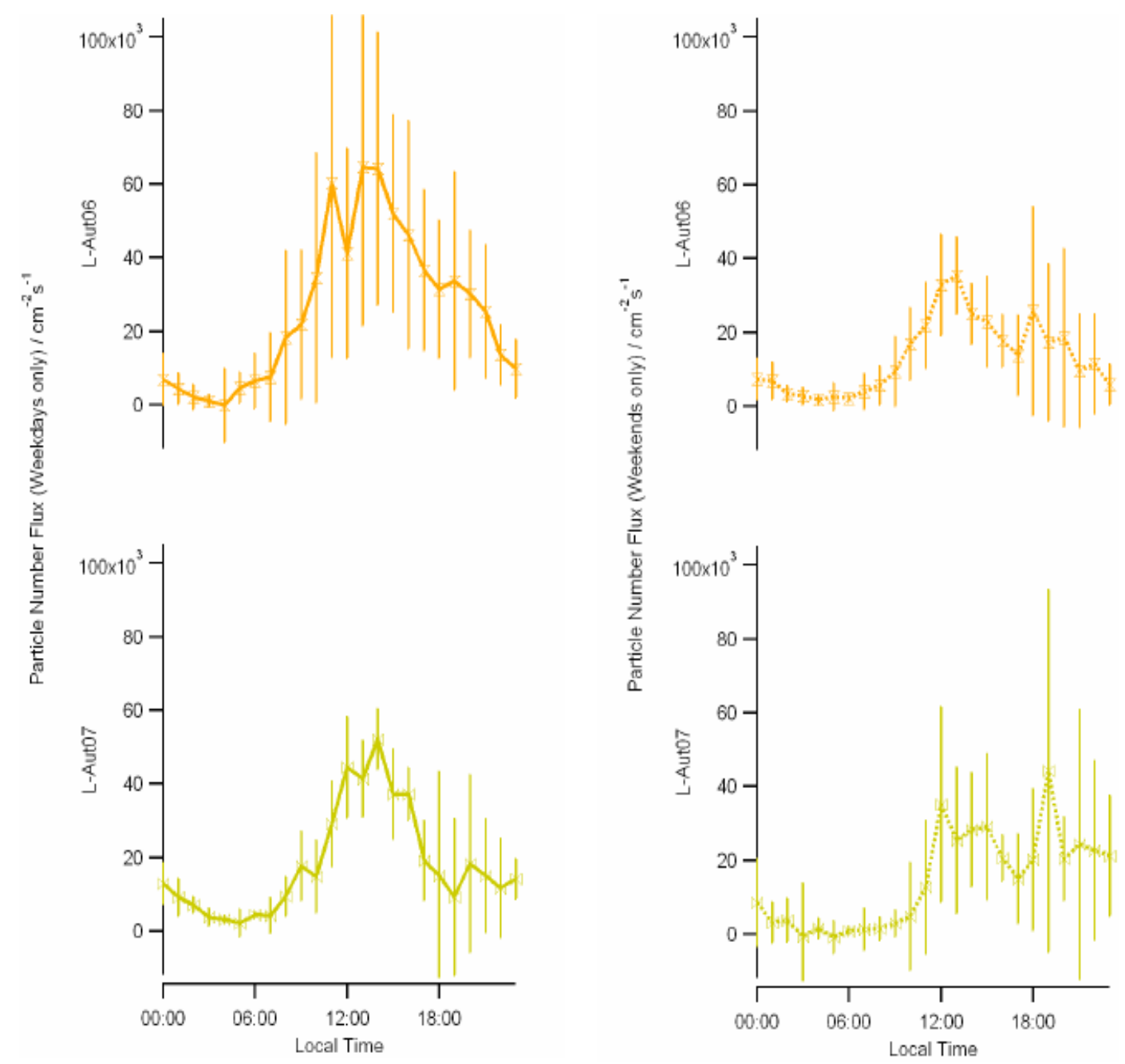

Fig. 28. Averaged diurnal cycles of vertical UFP number flux for weekdays (left) and weekends (right) during the Autumn 2006 experiment (top) and Autumn 2007 experiment (bottom).

described by Buzorius et al. (1998). Net particle fluxes corresponded to particle sizes $>0.01 \mu \mathrm{m}$. Data analysis and quality control measures follow those described by Foken et al. (1996) and are discussed in Martin et al. (2009). As explained above, all fluxes and parameterisations for UFPs are based on hourly values. Confirmation of the performance of the experimental setup was provided by spectral and cospectral analysis of the particle concentration and turbulence time series which agreed well with theoretical predictions of near scalar turbulent transport and are comparable to the expected performance of an aerosol eddy flux system (Buzorius et al., 1998 and Fairall et al., 1984).

Average diurnal cycles of vertical UFP number fluxes for both REPARTEE experiments for weekdays and weekends are summarised in Fig. 28. The majority of fluxes, as expected, were positive (i.e. upwards) with only a small minority of negative (downward) fluxes, the latter mainly, but not always, occurring either at night or when the prevailing wind was from a sector with increased parkland and reduced source activity. There is a clear daily cycle with fluxes peaking during the day at 14:00, and minima at 04:00 in the early morning. Smaller peak emission fluxes were observed at 11:00 and between 13:00-14:00 and appear to correlate with increased average traffic activity at these times. During the Autumn 2007 experiment secondary peaks occurred at 12:00 and 16:00, following the pattern of the diurnal sensible heat flux cycle. The Autumn 2006 weekend diurnal cycle is very similar to the weekday cycle except in the evening. The $\mathrm{Au}-$ tumn 2007 cycle was more variable which explains the lower regression obtained when fitted to the emission model.

During periods of peak emission a characteristic ellipsoidal behaviour (Fig. S4 in Supplement) was observed in the $w^{\prime} N^{\prime}$ quadrant analyses (Longley et al., 2004; Kruijt et al., 1995), with emission dominating deposition in the lower left quadrant and small deposition in the upper right quadrant, consistently. 

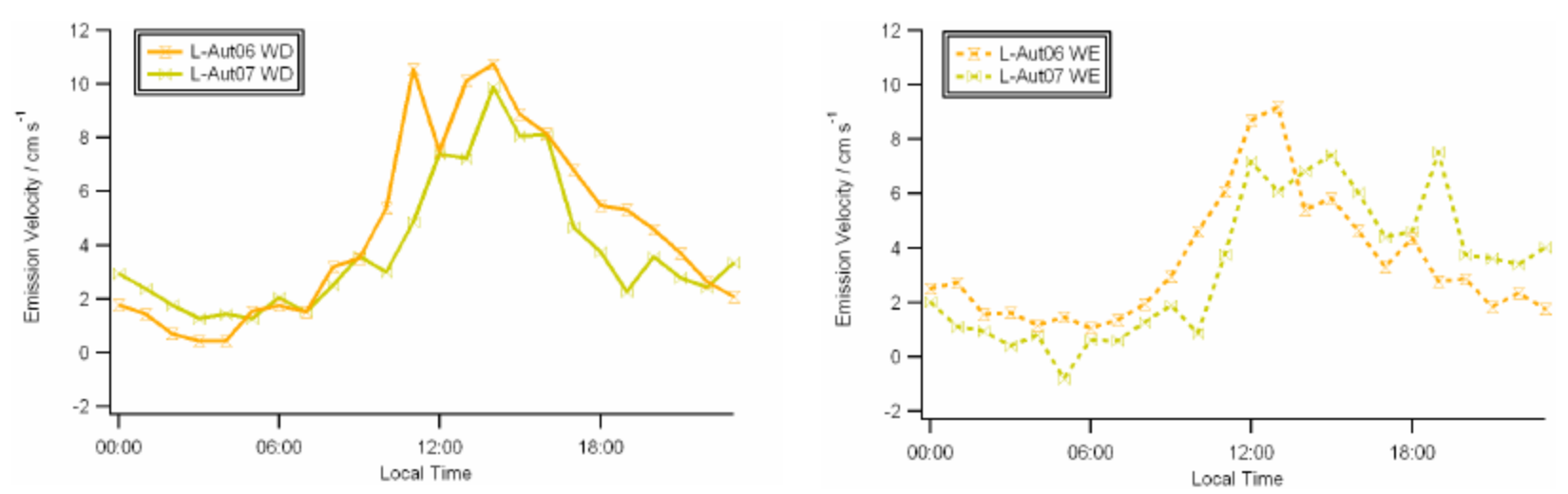

Fig. 29. Averaged diurnal cycles of ultrafine particle emission velocity, $V_{\mathrm{e}},\left(\mathrm{cm} \mathrm{s}^{-1}\right)$ for weekdays (left) and weekends (right) over London.

Very good consistency was also seen in the diurnal particle emission velocity, $V_{\mathrm{e}}\left(V_{\mathrm{e}}=F_{\mathrm{p}} / C\right.$, where $F_{\mathrm{p}}$ is the particle flux and $C$ is the particle concentration), with weekday peak values of the order $9-10 \mathrm{~cm} \mathrm{~s}^{-1}$ and slightly lower at weekends, $7-9 \mathrm{~cm} \mathrm{~s}^{-1}$ (Fig. 29).

When segregated by wind sector the fluxes revealed a clear pattern with both the weekday plots showing the highest fluxes between 11:00 and 17:00 from the 90 to $180^{\circ}$ wind sectors. This was consistent with the geographical location of main traffic routes and urban/business sectors within the expected tower measurement footprint whereas the westerly sector, $315^{\circ}$ (see Martin et al., 2009), consistently displayed the lowest fluxes over all days during both experiments. Again this can be explained by the proximity of the large Regent's Park area in this sector. The lowest fluxes occurred during early morning, between 01:00 and 08:00, reflecting a decrease in both traffic emissions and other UFP sources at these times. During the weekends however there were additional evening peaks in the $135^{\circ}$ sector seen in both experiments.

For the London study, mixed fleet emission factors could not be calculated, as for the Stockholm study by Mårtensson et al. (2006), due to lack of a suitable fleet database. Therefore a multi-regression emission model was derived based solely on net traffic activity (Martin et al., 2009), collected from the nearby Marylebone Road. The most suitable emission model was found to be

$f_{\mathrm{p}}=C\left[\left(\mathrm{EF}_{\text {friction }} u_{*}\right)+\left(\mathrm{EF}_{\text {heat }} H\right)\right]_{\mathrm{fm}}+\left(\mathrm{EF}_{\text {traffic }} \mathrm{TA}\right)-f_{0}$

where $f_{\mathrm{p}}$ is the predicted particle number flux $\left(\# \mathrm{~cm}^{-2} \mathrm{~s}^{-1}\right)$, $\mathrm{EF}_{\text {traffic, friction, heat }}$ are the factors associated with traffic activity, TA, friction velocity, $u_{*}$, and sensible heat flux , $H$, respectively. $C$ is a dimensionless coefficient and $f_{0}$ a compensation or sink term whose sign may vary depending on the urban surface type as well as the source or sink density within the measurement footprint (Schmid, 1994). These coefficients will vary for different cities and must be determined experimentally. For London the results are summarized in the papers in Table 6 , for weekday periods, and were found to be similar to those from other UK cities (Martin et al., 2009). Using this approach $\mathrm{EF}_{\text {traffic }} \mathrm{TA}$ is the source term due to predominantly anthropogenic activity, described through the proxy of traffic activity (TA), whereas the $\mathrm{EF}_{\text {friction }} u_{*}$ term describes the turbulent transport of particles to the measurement height. The sensible heat flux $\mathrm{EF}_{\text {heat }} H$ term describes both the coupling between particle emission and boundary layer transport due to convection but this contribution was significantly weaker than the $\mathrm{EF}_{\text {friction }} u_{*}$ term. A key limitation is that the non-traffic UFP emissions are not segregated at this level of analysis.

\section{Size-resolved accumulation mode particle number fluxes}

Size-segregated measurements of urban aerosol fluxes appear to have been made only three times, above Edinburgh, UK (Nemitz et al., 2001, 2012b), Münster, Germany (Schmidt and Klemm, 2008) and Stockholm, Sweden (Vogt et al., 2011a, b), covering the diameter ranges of 0.1 to $10 \mu \mathrm{m}, 0.03$ to $10 \mu \mathrm{m}$ and 0.25 to $2.5 \mu \mathrm{m}$, respectively. Above the centre of the windy city of Edinburgh, emissions were found to be composed of two modes: fine mode fluxes correlated closely with traffic flow, while super-micron particle emissions correlated with wind speed and dominated the mass flux. Similar observations were made during the yearlong Stockholm city centre flux study, where the mass flux was again dominated by super-micron particles (although the particle counter only started at $0.25 \mu \mathrm{m}$ and thus covers less of the fine mode) and emission factors increased with wind speed. The highest super-micron fluxes were observed in spring, probably related to the resuspension of road wear following the use of studded tyres in winter. Conversely, at the less densely urban site at Münster, subject to lower wind speeds, the particle number flux tended to be upwards and related to traffic, while the mass flux was on average downwards.

During REPARTEE II, size-segregated particle number fluxes were made with an optical particle counter ("UHSAS" 

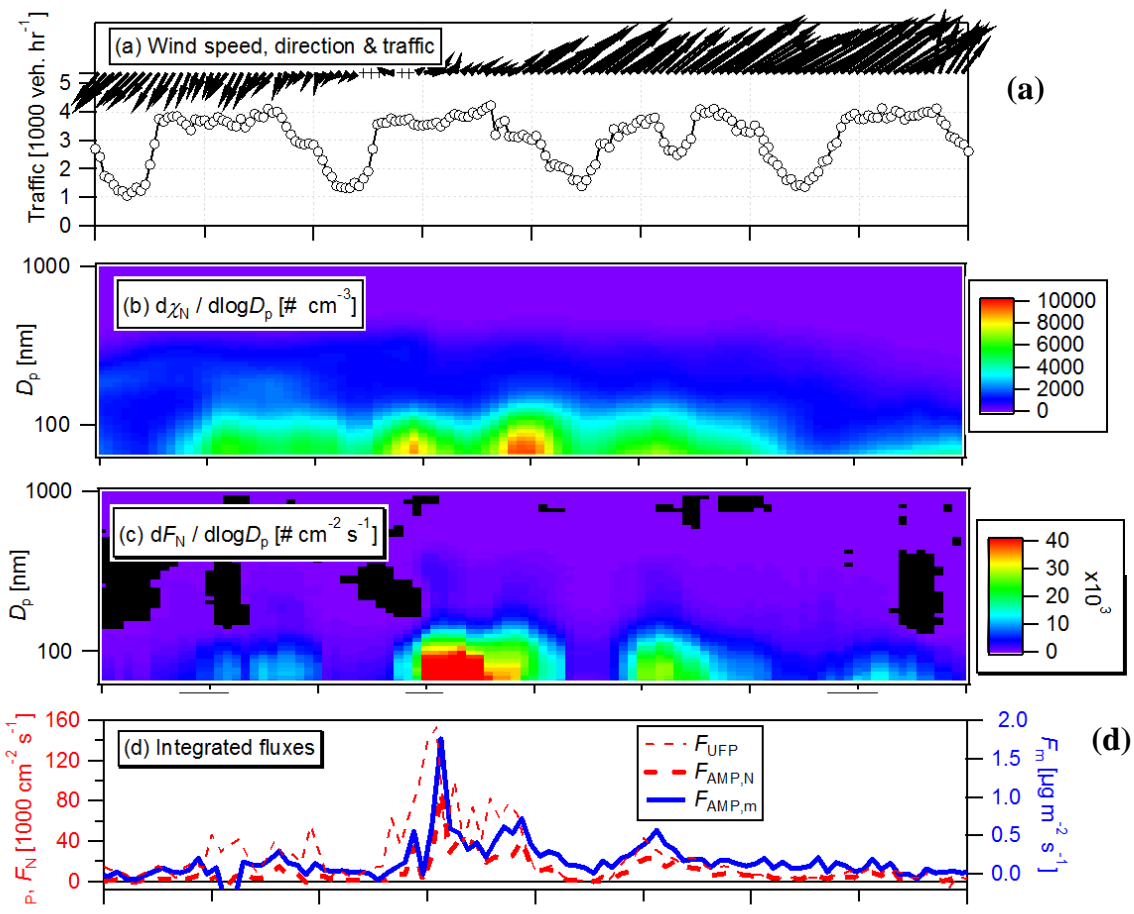

(d)
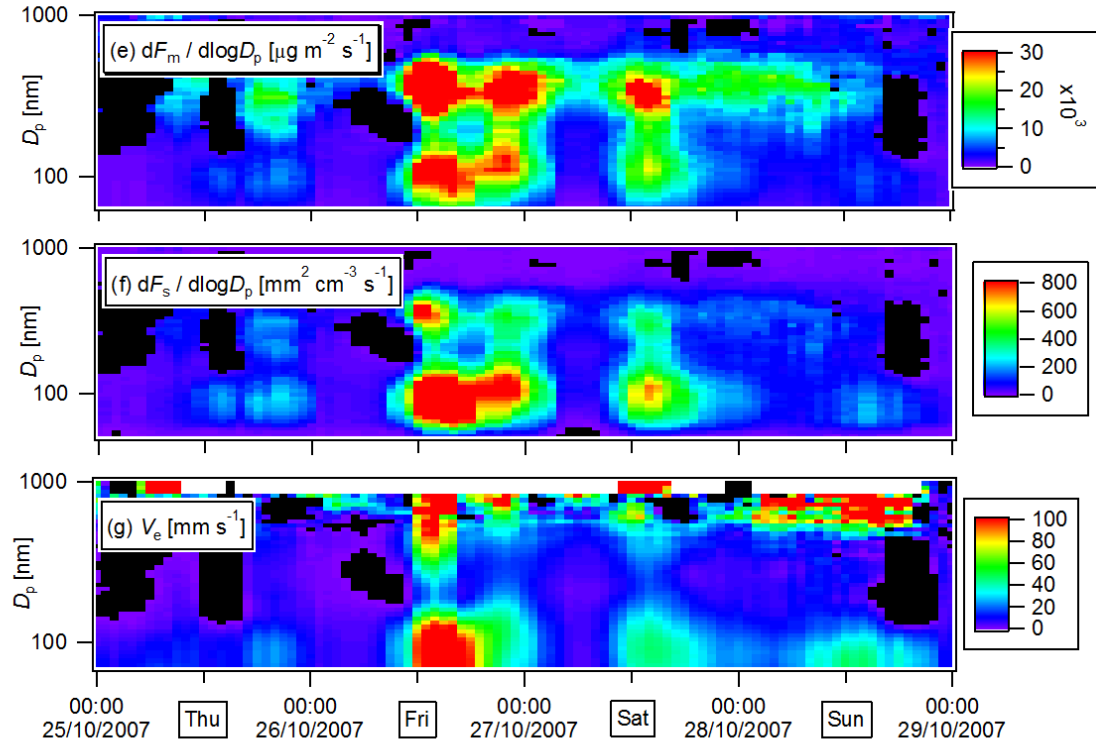

(g)

Fig. 30. Example time-series of size-resolved particle number fluxes across the accumulation mode. (a) Wind speed and direction and traffic counts on Marylebone Road, (b) particle number concentration, (c) bulk flux in terms of number $\left(F_{N}\right)$ and mass $\left(F_{\mathrm{m}}\right)$, (d) particle number flux spectra, (e) exchange velocity $\left(V_{\mathrm{e}}\right)$ as well as flux spectra in terms of (f) mass and (g) surface area. Black areas indicate downward fluxes. The surface graphs represent 4 -h running means. $V_{\mathrm{e}}$ becomes increasingly uncertain for $D_{\mathrm{p}}>0.4 \mu \mathrm{m}$, due to poor counting statistics.

Ultra High Sensitivity Aerosol Spectrometer; Particle Measurement Instruments, Boulder, USA) that counts and sizes particles according to their optical diameter into 99 logarithmically spaced size bins spanning the range 0.05 to $1 \mu \mathrm{m}$ and saves data at $10 \mathrm{~Hz}$ during REPARTEE II, although the counting efficiency of the instrument appeared to be reduced $<\sim 0.065 \mu \mathrm{m}$. Super-micron particle number fluxes were logistically not feasible, because for these measure- ments the counter would have had to be placed near the sonic anemometer.

A four day example time series shows that concentrations (Fig. 30b) were regulated by wind speed (Fig. 30a) and air mass trajectory, with elevated concentrations observed during conditions of lower wind speed, and European air masses (not shown). Total particle number flux and submicron mass fluxes (estimated assuming spherical particle size 
and a particle density of $1.7 \mathrm{~g} \mathrm{~cm}^{-3}$ ) followed each other closely (Fig. 30d) and peaked during low S wind direction (where also the $\mathrm{CO}_{2}$ emissions were largest; Helfter et al., 2011). The particle number fluxes are dominated by particles $<0.2 \mu \mathrm{m}$ (Fig. 30c) and over this time period the particle number flux derived by the UHSAS $\left(F_{\mathrm{AMP}, N}\right)$ represents on average $39 \%$ of the total UFP flux $\left(F_{\text {UFP }}\right)$ measured by the CPC setup, which implies that $61 \%$ of the measured UFP particle flux was due to particles in the size range $10 \mathrm{~nm}$ $<D_{\mathrm{p}}<50 \mathrm{~nm}$, although this ratio showed clear temporal variability and was $10 \%$ during the first and close to $100 \%$ during the second half of this period (Fig. 30d). Mass and surface area flux distributions (Fig. 30e and f) were bimodal with contributions from modes centred around $100 \mathrm{~nm}$ and $400 \mathrm{~nm}$. The observation of accumulation mode emissions was somewhat surprising, because Nemitz et al. (2012b) did not find an efficient urban source in this size range over Edinburgh, while Deventer et al. (2011), also using an UHSAS, recently reported deposition of the accumulation mode to Münster. It is possible that in London, due to the high measurement height, more time is provided for secondary organic aerosol to form in the accumulation mode. The exchange velocity (Fig. 30g) was highly variable and ranged from $<10 \mathrm{~mm} \mathrm{~s}^{-1}$ for the centre of the accumulation mode $\left(0.2 \mu \mathrm{m}<D_{\mathrm{p}}<0.5 \mu \mathrm{m}\right)$ to $>60 \mathrm{~mm} \mathrm{~s}^{-1}$ for peak values found for the smallest particles. Deposition was at times observed for the accumulation mode $(0.2$ to $0.8 \mu \mathrm{m})$, when the wind was bringing more polluted European air masses to the measurement point and the flux footprint was situated in the less intensely urban northern wind sector. A tail from the supermicron resuspension mode was not observed, which would have led to $\mathrm{d} F_{\mathrm{m}} / \mathrm{d} \log D_{\mathrm{p}}$ increasing again towards the largest sizes.

\section{Chemically resolved mass fluxes}

Eddy covariance flux measurement systems for individual (non-refractory) $\mathrm{PM}_{1}$ chemical components have recently been developed based on the Aerodyne Aerosol Mass Spectrometer (AMS), utilising either a quadrupole (Q-) or timeof-flight (ToF-) mass spectrometer (Nemitz et al., 2008; Farmer et al., 2011). The former was applied during REPARTEE I and the latter during REPARTEE II (Phillips et al., 2012; Nemitz et al., 2012c). Both systems are capable of deriving fluxes of aerosol nitrate $\left(\mathrm{NO}_{3}^{-}\right)$and sulphate $\left(\mathrm{SO}_{4}^{2-}\right)$, but the Q-AMS derives the organic mass fluxes by circulating through a small number of pre-selected $\mathrm{m} / \mathrm{z}$, while the ToF-AMS can monitor all $\mathrm{m} / \mathrm{z}$ 's at $10 \mathrm{~Hz}$, providing a more robust organic mass flux and additional information on the mass spectral "fingerprints" associated with the fluxes. Due to its higher mass resolution the ToF-AMS can also derive fluxes of $\mathrm{NH}_{4}^{+}$.

Fluxes of $\mathrm{SO}_{4}^{2-}$ were near zero which is consistent with measurements above other cities in the developed world (Ne- mitz et al., 2008; Phillips et al., 2012) and suggests that there are no significant sources of submicron $\mathrm{SO}_{4}^{2-}$ in the urban environment. This is also consistent with the relatively small gradients in $\mathrm{SO}_{4}^{2-}$ concentration that were measured between the Tower and the Park, except for the period around 13-18 October 2006 (Sect. 4.2). Fluxes of $\mathrm{NO}_{3}^{-}$were variable, with small fluxes on some days and considerable emission on others, contradicting the gradients which indicated smaller $\mathrm{NO}_{3}^{-}$ concentrations at ground level inside the Park than aloft. There are two possible reasons for this apparent contradiction: there could be a maximum of nitrate at an intermediate layer so that fluxes at the tower are upwards, but concentrations on the tower still higher than at ground level. More probably, however, is that the Park is an efficient sink area for $\mathrm{NH}_{4} \mathrm{NO}_{3}$ as discussed in Sect. 4.2. Both $\mathrm{NH}_{3}$ and $\mathrm{HNO}_{3}$ can deposit efficiently to vegetation, while long-term measurements at a kerbside location indicate significantly higher concentrations of $\mathrm{NH}_{3}$ at street level than on the BT Tower. As a result, there is likely to be a potential for $\mathrm{NH}_{4} \mathrm{NO}_{3}$ evaporation in the Park at the same time as there is a potential for $\mathrm{NH}_{4} \mathrm{NO}_{3}$ formation at the roadside location, with the latter dominating the observed net flux above the city.

Non-refractory submicron chemical aerosol fluxes (as resolved by the AMS) were, however, dominated by the organic aerosol fraction. Unlike the concentrations (see Sect. 4.4) the fluxes could only be divided into two factors, HOA and OOA, where other contributions (COA and SFOA) will be convolved into these two factors. While OOA fluxes were small and bi-directional, HOA showed clear diurnal cycles with an average emission of $136 \mathrm{ng} \mathrm{m}^{-2} \mathrm{~s}^{-1}$ and midday values of up to $600 \mathrm{ng} \mathrm{m}^{-2} \mathrm{~s}^{-1}$ during REPARTEE I. The comparison of the HOA and estimated sub-micron aerosol mass flux (Fig. 30c) confirms that HOA accounts for the bulk of the submicron mass flux. The HOA/CO emission ratio was $0.024 \mathrm{ng} \mathrm{HOA} / \mathrm{ng} \mathrm{CO}$, which is in the range of ratios derived from concentration measurements. Interestingly, the HOA flux somewhat lags the $\mathrm{CO}$ flux and the HOA/CO ratio peaks in the evening, which indicates a change in the sources over the day, with a source that is particularly high in HOA/CO contributing in the evening. This might suggest a contribution of COA to the HOA flux in the evening and would be consistent with the diurnal pattern of the COA concentration observed in the Park and the lack of a quantitative link between COA and CO by multilinear regression (Allan et al., 2010). The importance of cooking aerosol in contributing to urban OA emissions and concentrations is further substantiated by the emission ratio between accumulation mode particles and $\mathrm{CO}_{2}$ peaking at lunchtime and in the evening in another UK city (Edinburgh) (Nemitz et al., 2012c).

\subsubsection{Relationships between fluxes}

Table 8 summarises the Pearson correlation coefficients between hourly fluxes of the different components measured on the BT Tower. Note that the correlation coefficient can 
increase significantly if averaged diurnal values are considered (e.g. Langford et al., 2010): the averaging reduces the effect of random errors on the individual flux measurements and averages out any potential differences in the spatial pattern of the emissions of the different pollutants. Clearly, a correlation is no proof of a causal link in emissions or a common source, but some of the patterns are interesting:

- The ozone depletion in the urban air space correlates as well with the emission of methanol as it does with $\mathrm{CO}$ and $\mathrm{CO}_{2}$, although methanol is poorly correlated with these two gases. This may indicate that while $\mathrm{CO}$ and $\mathrm{CO}_{2}$ may be reasonable proxies for the $\mathrm{NO}_{\mathrm{x}}$ emission that dominates the $\mathrm{O}_{3}$ destruction, the methanol flux may reflect a second common control through the residence time and photochemical activity in the air space.

- The total UFP number flux correlates almost as well with methanol, acetonitrile, acetone and isoprene as it does with $\mathrm{CO}_{2}$ and $\mathrm{CO}$. By contrast, the UFP flux is poorly correlated with the flux of the accumulation mode particles, which is not as much dominated by the urban emission but also influenced by concurrent deposition of accumulation mode particles advected into the city.

- Of the other VOCs measured, the flux of acetonitrile correlates best with that of isoprene - both compounds are thought to have a biospheric contribution. Methylbenzenes, toluene, isoprene and acetone all correlate with each other and form a cluster, possibly dominated by the same sources.

\subsubsection{Summary of flux experiments}

The REPARTEE campaigns generated arguably the most comprehensive dataset of pollutant fluxes in the urban environment to date, including the first urban eddy-covariance flux measurements of ozone and carbon monoxide. The turbulence follows the scaling laws expected for the convective mixed layer rather than the surface layer and decoupling could be observed during some nights, especially during the colder REPARTEE II period, when stable conditions were more frequent. Thus, the fluxes measured at the tower are affected not only by the surface emission, but transport and storage as well as chemical conversions, but are nevertheless closely linked to surface activity, at least during the day. Increased pollutant emissions in the morning, and close agreement of measured annual $\mathrm{CO}_{2}$ flux with emission inventory predictions suggests that long-term average fluxes are reasonably robust. The comparison of other compounds with bottom-up emission inventories is variable: emissions are reasonably close for $\mathrm{CO}$ and some key VOCs, but fluxes of some compounds (isoprene, acetaldehyde and acetonitrile) are many times larger than emission inventories predict. In addition, it was possible to measure fluxes directly of primary aerosol using metrics that are not covered by the inventories. A parameterization was derived for ultrafine particles (Eq. 6): comparison of the diurnal cycles of both the predicted and observed particle number flux for London (Fig. 28) suggests that the model explained more than $90 \%$ of the observed variance $\left(r^{2}>0.9\right)$, although some individual features are not reproduced. These are likely due to infrequent, fugitive emissions or synoptic transport contributions that are not fully captured in this simplistic approach. The diurnal results however are in good agreement with Mårtensson et al. (2006) and Martin et al. (2009), suggesting simple model parameterisations of emissions based on flux analyses perform well over urban surfaces.

While UFP particles are closely linked to fluxes of $\mathrm{CO}$ and $\mathrm{CO}_{2}$, the behaviour of the accumulation mode particle fluxes is more complex, as these are also affected by the deposition of regional aerosol to the city. The diurnal cycles of HOA and $\mathrm{CO}$ in London and particle number and $\mathrm{CO}_{2}$ in Edinburgh are both consistent with the contribution of cooking aerosol emissions during lunch time and in the evening.

For the future we recommend complementing urban flux measurements with profile measurements in the air space below, to quantify storage effects. In addition, concurrent flux measurements of $\mathrm{NO}$ and $\mathrm{NO}_{2}$ would assist greatly in the interpretation of the $\mathrm{O}_{3}$ fluxes.

\section{Synthesis and conclusions}

Earlier analyses of data from single sites in London have been instrumental in gaining an understanding of the air pollution climate of a background site (Bigi and Harrison, 2010) and in the understanding of processes affecting trafficgenerated pollutants (e.g. Charron and Harrison, 2005; Harrison et al., 2011). In some cases paired sites have been used (e.g. Charron et al., 2007) in order to better understand the traffic-generated pollutants by subtraction of the roadside increment. The REPARTEE study has advanced the science considerably by simultaneous use of data from a number of ground-level sites together with both concentration and flux data from aloft on the BT Tower. It should be noted that the fluxes measured on the tower are averaged over large flux footprints (cf. Helfter et al., 2011), while the ground-based measurements are made at individual locations within the urban matrix: in a source region in the case of M. Road and a sink region in R. Park. This may be responsible for some of the inconsistencies between the apparent vertical gradient between Tower and Park and the fluxes. A further asset available to this study, which has not previously been used in studies of London, is the deployment of the Doppler lidar which has provided valuable information on the vertical structure of the atmosphere, and in particular, the mixing depths, turbulence and transport time-scales.

A key question is how representative the sampling sites are of Europe in general, and whether the two one-month 
snapshots well represent the longer-term position. Comparative data for particulate matter are available from Putaud et al. (2010). Concentrations of $\mathrm{PM}_{10}$ and $\mathrm{PM}_{2.5}$ at urban background sites in London (including North Kensington, as used in REPARTEE) are fairly typical of north-western Europe (excluding Scandinavia), similar to central Europe and generally lower than southern European sites. It is less easy to compare chemical composition, as analytical protocols were not identical across Europe, but the composition of $\mathrm{PM}_{10}$ at London sites is fairly typical, as is the number concentration of sub- $\mu \mathrm{m}$ particles (Putaud et al., 2010). Data for roadside sites is less abundant, but Marylebone Road lies within the range of other European sites (Putaud et al., 2010).

In REPARTEE I, the pollution levels were fairly typical of the annual mean. $\mathrm{PM}_{10}$ at $\mathrm{NK}$ averaged $26 \mu \mathrm{g} \mathrm{m}^{-3}$ during the month of REPARTEE, while the annual mean was also $26 \mu \mathrm{g} \mathrm{m}^{-3}$. At M. Road, the monthly mean was $56 \mu \mathrm{g} \mathrm{m}^{-3}$, compared to an annual mean of $47 \mu \mathrm{g} \mathrm{m}^{-3}$. The month of REPARTEE II was also fairly representative with the monthly $\mathrm{PM}_{10}$ averages at $\mathrm{NK}$ and $\mathrm{M}$. Road respectively $29 \mu \mathrm{g} \mathrm{m}^{-3}$ and $48 \mu \mathrm{g} \mathrm{m}^{-3}$ compared to annual means of $25 \mu \mathrm{g} \mathrm{m}^{-3}$ and $45 \mu \mathrm{g} \mathrm{m}^{-3}$.

The site at M. Road is on the northern boundary of the London congestion zone. Introduction of the zone had a relatively minor impact upon the emissions of traffic-generated pollutants (Beevers and Carslaw, 2005) and consequently only a small effect upon pollutant concentrations (Atkinson et al., 2009).

The weather during the two campaigns was fairly typical of the autumn in London. Weather during the REPARTEE I campaign was markedly warmer than in REPARTEE II (mean $15.5^{\circ} \mathrm{C}$ and $10.4^{\circ} \mathrm{C}$, respectively). This compares with long-term averages for October of $12.05^{\circ} \mathrm{C}$ (corresponding to REPARTEE I) and $9.9^{\circ} \mathrm{C}$ for the mean of October and November (corresponding to REPARTEE II).

\subsection{Local versus regional pollution}

Earlier work (Charron et al., 2007) has emphasised the importance of regional pollution in affecting concentrations of particulate matter within London and has highlighted its importance in relation to exceedences of the $50 \mu^{-3} \mathrm{~g} \mathrm{~m}^{-3} 24-\mathrm{h}$ Limit Value for $\mathrm{PM}_{10}$. By comparison of observations made aloft at $160 \mathrm{~m}$ on the BT Tower with those made at ground level in R. Park, it has been possible to gain a clearer understanding of the influence of regional processes. Because of its relatively slow formation within the atmosphere and its presence predominantly in the accumulation mode, sulphate is an excellent marker of regional transport processes. For the majority of the campaign period during REPARTEE I, concentrations of sulphate on the BT Tower were insignificantly different from those at ground level in R. Park and during the campaign as a whole, the measured fluxes of sulphate on the BT Tower were generally near zero. However, during the regional pollution episode from 14 to 19 October, concentrations on the Tower exceeded those at ground level (Fig. 11a) giving a clear indication that regionally transported sulphate was driving the concentrations measured at ground level. This work provides no significant evidence for formation of sulphate, which is a major component of London's particulate matter, within London itself. The behaviour of nitrate shows some similarities to that of sulphate (Fig. 11b), but also some differences and will be discussed later.

The behaviour of elemental and organic carbon showed a marked contrast. In the case of elemental carbon (Fig. 11d), which in the UK derives very largely from diesel vehicle emissions, concentrations in R. Park exceeded those on the BT Tower by a substantial margin except on one day when the Tower showed a marginally higher concentration. This is behaviour expected for a pollutant predominantly from a strong ground level source within London. On the other hand, organic carbon (Fig. 11a) showed a proportionately smaller positive increment at the R. Park site relative to the BT Tower suggestive of ground-level emissions of primary organic carbon but a substantial regional presence of secondary organic carbon. The AMS results (Fig. 16) suggest a slight excess of OOA (reflecting secondary organic carbon) over HOA (reflective of primary organic carbon from road traffic at ground level). The flux data for OOA showed fluxes that were small and bi-directional giving a clear indication that regional processes dominate the concentrations of secondary organic aerosol within London and that formation within the city itself, although possibly having influence from time-to-time, is not a significant contributor overall. On the other hand, the AMS HOA fraction reflecting primary traffic aerosol showed a flux accounting for the bulk of the submicron mass flux.

The comparison of particle size distributions between M. Road, R. Park and the BT Tower (Fig. 13) shows that particle volume reduces substantially from M. Road to R. Park to BT Tower, as would be expected, and that the peak in the accumulation mode distribution becomes progressively coarser from M. Road to BT Tower probably reflecting the greater relative importance of more aged regionally transported particles at the altitude of the Tower. There is also a notable reduction in the coarsest $(>10 \mu \mathrm{m})$ particle mode at R. Park and the BT Tower relative to M. Road which might possibly be an artefact of different sample inlet characteristics, but more probably reflects an important source of coarse particles from road traffic at the roadside site which are significantly reduced within the Park and on the Tower due to the short atmospheric lifetime of this size fraction with respect to dry deposition.

\subsection{Aerosol particle dynamics}

One of the less expected findings of this study was the remarkable change in the nanoparticle region of the particle size distributions between the M. Road, R. Park and BT Tower sites. This is not described in detail in this overview as 
it is reported in depth by Dall'Osto et al. (2011). This study has provided the most compelling evidence published to date for the volatile loss of semi-volatile hydrocarbon components of the aerosol during advection of traffic-generated particles into R. Park and vertical transfer to the BT Tower site. It has long been known that the nucleation mode within fresh road traffic exhaust arose from the condensation of semi-volatile compounds during mixing of hot exhaust gases with cooler ambient air, but the subsequent behaviour of such particles had not previously been elucidated so clearly. There seems little doubt from the observations during REPARTEE that once such particles leave the immediate environment of the road and the vapour phase components become diluted with cleaner air, such particles begin to shrink by evaporation. The advection times of particles from road traffic sources to the R. Park site and the vertical transfer to the BT Tower site would typically take tens of minutes (Barlow et al., 2011), which gives an indication of the timescale for shrinkage. In the case of the BT Tower site, where transport times under the more stable conditions could extend to around an hour, such nucleation mode particles are totally lost from the measured size distribution having shrunk to below $5 \mathrm{~nm}$ diameter. The shrinkage process has clearly been shown to relate to vertical transport times using turbulence as a surrogate measure (Dall'Osto et al., 2011) which is only possible because of the high quality data on vertical wind velocities as a function of height available from the Doppler lidar.

\subsection{Sources of organic aerosol}

Application of the elemental carbon tracer method (Castro et al., 1999) to the R. Park data indicates a primary OC/EC ratio of 1.0 in the $\mathrm{PM}_{2.5}$ fraction. This is somewhat higher than the minimum OC/EC ratio measured in Birmingham of 0.65 by Harrison and Yin (2008). However, Pio et al. (2011) have recently demonstrated that minimum OC/EC ratios are around 0.3-0.4 very close to a source of traffic emissions and progressively increase with the distance from source. This may be attributable to mixing with particles from sources with higher intrinsic OC/EC ratios such as from wood burning, or relatively rapid formation of secondary organic carbon (SOC) from volatile precursors which associates itself with the primary particles thereby raising the minimum ratio. The higher OC/EC ratio in R. Park is consistent with the greater distance from road traffic activity than the Birmingham city centre site and the source of VOCs from vegetation in the Park. If one takes the minimum OC/EC ratio as descriptive of this "primary" organic carbon, then the mean concentration of primary organic carbon at R. Park in REPARTEE I was $1.51 \mu \mathrm{g} \mathrm{m}^{-3}$ with $1.43 \mu \mathrm{g} \mathrm{m}^{-3}$ of secondary organic carbon. If the same primary ratio is applied to the data from the BT Tower, the split at the Tower is estimated as $0.96 \mu \mathrm{g} \mathrm{m}^{-3}$ of primary organic carbon and $1.40 \mu \mathrm{g} \mathrm{m}^{-3}$ of secondary organic carbon, almost equal to that measured at ground-level. While there is inevitably significant uncertainty associated with these figures, they are highly suggestive of regional processes dominating the secondary organic carbon concentrations and of only a relatively minor influence of processes within London itself upon concentrations of SOC. Such an interpretation is broadly consistent with the results of the AMS measurements made in R. Park during REPARTEE I in which $53 \%$ of organic aerosol mass was attributed to secondary OOA with $47 \%$ attributable to the sum of HOA and COA. It is also consistent with the flux data referred to above.

The AMS measurements have provided valuable differentiation of the organic aerosol according to source. The breakdown to OOA and HOA had been seen regularly in AMS studies but the work in REPARTEE (and associated work in Manchester) was one of the first identifications of cooking organic aerosol, COA, as distinct from meat cooking aerosol, as a significant contributor to atmospheric concentrations. Since these observations, there have been a number of other reports of the COA factor from other parts of the world. The identification of solid fuel organic aerosol, SFOA, largely from wood burning in the REPARTEE II data, but not during the warmer period of REPARTEE I, is also important and has led to further studies with wood smoke tracers in London. The ATOFMS was less successful in characterising sources of organic aerosol, although it was able to identify two particle types termed Ca-EC and OC which correlated with traffic activity together with two organic particle types with a much more complex behaviour which made clear source attribution very difficult.

\subsection{Processes affecting nitrate}

Some aspects of nitrate behaviour were broadly similar to those of sulphate, but other aspects proved very different. For periods with relatively low concentrations of nitrate, there was no marked difference between concentrations in R. Park and on the BT Tower (Fig. 11b). However, during the episode period commencing around 7 October 2006 and continuing until 19 October 2006, there was a very major depression of measured concentrations at the R. Park site. The comparison of nitrate data from the Partisol samples and GRAEGOR instrument are suggestive of a substantial negative sampling artefact for the Partisol data even on the BT Tower, and this is likely to have affected both sites. Our earlier work on the size distribution of nitrate (Abdalmogith et al., 2006) has indicated that at lower nitrate concentrations in the UK atmosphere, the nitrate is largely present in the form of involatile sodium nitrate, but at higher concentrations semivolatile ammonium nitrate predominates. This is consistent with the form of the instrument comparison shown by $\mathrm{Ne}$ mitz et al. (2012a). The large excess of nitrate on the BT Tower relative to R. Park during the pollution episode is strongly suggestive of regional transport of nitrate and mixing down to influence concentrations at R. Park. However, the much greater depression of concentrations of nitrate relative to sulphate at R. Park suggests that the strong potential of 
vegetation to remove gas phase nitric and ammonia is likely to have promoted the dissociation of ammonium nitrate leading to the much lower ground-level concentrations. The fact that fluxes of nitrate measured on the BT Tower were variable with small downward fluxes on some days and considerable emissions on others is consistent with higher ammonia concentrations in heavily trafficked areas suppressing the dissociation of ammonium nitrate and leading to ammonium nitrate formation within the urban atmosphere. Abdalmogith and Harrison (2006) in an analysis of urban and rural data suggested a modest level of net formation of nitrate within the boundaries of London. The results of this study are consistent with that picture but add to its mechanistic understanding. They indicate that the $\mathrm{NH}_{3}-\mathrm{HNO}_{3}$ $\mathrm{NH}_{4} \mathrm{NO}_{3}$ system is sufficiently dynamic to result in a considerable variability of $\mathrm{NH}_{4} \mathrm{NO}_{3}$ at ground level. Measurements of nitrate aerosol with the ATOFMS showed two types of nitrate-rich particle with contrasting behaviour. The regionally transported nitrate dominated during the main episode period in the middle of the REPARTEE I campaign and the ATOFMS data show clearly the diurnal cycling of nitrate into the aerosol as the air temperature reduces and humidity increases and release from the particles in the warmer part of the day. The ATOFMS also identified a secondary type of nitrate-rich particle which appeared to be associated with local formation processes and occurred in the main at times outside of the long-range transport episode. This observation further supports the dynamic behaviour of $\mathrm{NO}_{3}^{-}$formation, which in the urban environment can be re-located onto the locally emitted aerosol. The combination of ATOFMS and AMS provided a very powerful combination in elucidating the processes affecting nitrate aerosol.

Measurements from other instruments are also highly relevant to the question of nitrate concentrations. The measurements of dinitrogen pentoxide, $\mathrm{N}_{2} \mathrm{O}_{5}$, and the nitratefree radical, $\mathrm{NO}_{3}$ during REPARTEE II show considerable episodicity of formation at the level of the BT Tower. Because of the strong excess of NO from "fresh" pollution at ground-level, formation of $\mathrm{NO}_{3}$ and $\mathrm{N}_{2} \mathrm{O}_{5}$ at ground-level is likely to be insignificant. While it was not possible to follow the incorporation of $\mathrm{N}_{2} \mathrm{O}_{5}$ and $\mathrm{NO}_{3}$ into aerosol, this is an inevitable sink for these species and it appears certain that there will have been formation of nitrate aerosol aloft at some times during the REPARTEE II campaign. Such formation of nitrate above the city may have contributed to some of the observed downward fluxes of nitrate. The highly variable and sometimes rather large concentrations of $\Sigma\left[\mathrm{NO}_{3}\right]+\left[\mathrm{N}_{2} \mathrm{O}_{5}\right]$ observed when the LED-BBCEAS sampling height was decoupled from the surface have implications for the sometimes efficient, sometimes highly patchy nature of night-time gas-phase oxidation chemistry initiated by the $\mathrm{NO}_{3}$ radical.

\subsection{Gas phase species}

The gas phase was not a major focus of this study but the results available from the many measurements undertaken provide some useful insights into gas phase species and processes. The examination of vertical profiles clearly shows the predominant influence of $\mathrm{NO}_{\mathrm{x}}$, predominantly $\mathrm{NO}$, and a source of ozone aloft. The oxidant plot (Fig. 20) demonstrates that the source of ozone is the same both at ground level and aloft but the differing gradients of the plot of $\mathrm{O}_{\mathrm{x}}$ versus $\mathrm{NO}_{\mathrm{x}}$ suggests some rather different processes. The significant upward gradient of the plot for Marylebone Road indicates $19 \%$ of $\mathrm{NO}_{\mathrm{x}}$ to comprise primary $\mathrm{NO}_{2}$ consistent with other estimates of traffic emissions for around the same time. However, the lack of a significant upward gradient in the case of the background site at North Kensington is surprising. Concentrations of $\mathrm{NO}_{\mathrm{x}}$ on the $\mathrm{BT}$ Tower were generally too low to generate a meaningful plot, with variation in background ozone tending to dominate the behaviour. However, the diurnal variation of the intercept in the oxidant plot (shown in Fig. 21) is interesting in showing significant formation of regional ozone during the afternoon period affecting all sites, even in October/November during which sunlight levels are relatively modest. Alternatively a deepening boundary layer may have brought ozone-rich air from aloft.

The other notable feature of the gas phase data is the fact that the flux estimations indicate that bottom-up estimates of emissions of carbon dioxide are very close to those estimated from the flux data. Fluxes of some some VOCs were highly correlated with those of carbon monoxide and emission rates estimated from the fluxes corresponded within a factor of two to the bottom-up emissions in the National Atmospheric Emissions Inventory for benzene, toluene, ethylbenzene and acetone. However, for methanol, acetaldehyde, isoprene and acetonitrile, measured fluxes were many times larger than the emission inventory reports and this is a matter warranting further investigation.

\subsection{Flux estimation}

Careful investigation of the atmospheric properties measured on the Tower gave confidence that it was a suitable platform for the estimation of vertical fluxes. Combination of these measurements with the availability of data from the Doppler lidar proved an extremely valuable combination. Not unexpectedly, fluxes tended to peak when atmospheric mixing was at its best, and at certain periods the flux measurement site was above the atmospheric mixed layer and fluxes were suppressed although there was some evidence of pollutant storage. Advection might be important during these periods as a mechanism for removing pollutants from the local atmosphere. The REPARTEE campaigns generated a highly comprehensive set of pollutant flux data including the first urban eddy covariance flux measurements of ozone and carbon monoxide. The measured ozone fluxes indicate that the 
urban air space provides a much more efficient sink for ozone than vegetation canopies. This has the substantial advantage of reducing ground level ozone concentrations but at the cost of increasing nitrogen dioxide. In addition, other pollutants emitted in the city have the potential to contribute to tropospheric ozone production downwind.

\subsection{Purposeful tracer experiments}

Although these took place during REPARTEE, they have not been used in interpretation of other datasets from the two campaigns. However, looked at on their own, they make an important contribution to understanding urban dispersion processes. The studies showed that the time taken for tracer to reach the measurement height on the BT Tower through turbulent transport was around $10 \mathrm{~min}$ for neutral conditions and as long as $20-50$ min under the most stable conditions encountered, consistent with estimates derived from the Doppler lidar results. The lateral plume spread was well described by a Gaussian distribution. The results yielded values of an empirical parameter, which together with meteorological, building height and release rate data, allows estimation of downwind time-integrated concentrations, highly valuable in estimating the consequences of accidental and terrorist releases of toxic substances.

\section{Progress against objectives}

- To study aerosol chemical and dynamical processes within the atmosphere of central London in three spatial dimensions. This has been achieved successfully especially in relation to aerosol dynamical processes. The experiments have provided the first convincing demonstration of the volatilisation of traffic-generated nanoparticles under realistic atmospheric conditions. Results from the project also highlight the very dynamic behaviour of ammonium nitrate.

- To measure the fluxes of selected aerosol and gas phase species above the city, and where possible, compare fluxes with estimates derived from emission inventories. Flux measurement work has succeeded in providing a very large base of information on the fluxes of nanoparticles, accumulation mode particles, specific chemical components of the aerosol and a range of gas phase species. Processes which determine those fluxes have been substantially elucidated. Comparisons with emission inventories have shown a good agreement for a number of substances, most notably carbon dioxide but has highlighted major discrepancies for other compounds including methanol, isoprene, acetaldehyde and acetonitrile.

- To quantify gradients in selected aerosol and trace gas species from ground level to altitudes of sampling on the BT Tower and to use such information to better understand the respective roles of local emission, local transformations and regional transport of pollutants in influencing the composition within and above London. The consideration of the flux and vertical profile data has clearly demonstrated the important role of regional transport in influencing concentrations of sulphate, nitrate and secondary organic compounds within the atmosphere of London. While there is evidence for some secondary formation of organic aerosol and nitrate within the atmosphere of London, this is relatively modest and no evidence is seen for the formation of sulphate within London itself.

- To study the structure of the atmospheric boundary layer and the influence of boundary layer vertical structure upon trace gas and aerosol fluxes and air pollution processes, especially in the context of diurnal changes. The application of the Doppler lidar to the measurement of atmospheric structure and turbulence has proved extremely successful and has provided valuable information to assist in the interpretation of the flux data. Fluxes are influenced by source strength but typically peak when the atmosphere is best mixed in the vertical. Mixed layer depths shallower than the sampling point on the BT Tower were encountered on around $40 \%$ of nights during this autumn period, which showed highly suppressed vertical fluxes, with other data indicative of some pollutant storage and the potential for advective loss of pollutants from the city.

- To deploy purposeful tracer releases at ground level while monitoring the surface and aloft in order to evaluate the dispersion of trace gases released at low level within the city. New data have been generated which provide important insights into the travel time of trace gas releases at ground level within London and the form of the downwind plume.

- To determine spatial differences in aerosol particle size distributions and to interpret those differences in terms of the sources and physico-chemical transformations responsible. This area of work has been most successful in relation to the number size distributions of traffic-generated nanoparticles which have been shown to evolve substantially with advection away from the traffic source and vertical mixing to the sampling point on the BT Tower. The predominant process appears to be one of particle shrinkage due to evaporative loss of semi-volatile materials. Particle size distributions within the accumulation and coarse particle ranges have also been contrasted and reflect the physico-chemical processes affecting particle behaviour. 
- To study the properties of nitrate aerosol in the atmosphere of London together with mechanisms of formation, physico-chemical properties and dynamics of nitrate particles. This area of work would have been more successful had planned continuous measurements of ammonia and nitric acid been achieved at more than one site. Nonetheless, the combination of flux data, vertical profiles between the Tower and R. Park and the insights provided by both the aerosol mass spectrometer and Aerosol Time-of-Flight Mass Spectrometer have shed significant light on the behaviour of nitrate in the urban atmosphere. The diurnal cycling of nitrate between aerosol and gas phase is clearly seen through the use of the ATOFMS and AMS. There is evidence both for net formation and loss of nitrate consistent with the extremely dynamic behaviour of semi-volatile ammonium nitrate. The measurements of $\mathrm{N}_{2} \mathrm{O}_{5}$ and $\mathrm{NO}_{3}$ on the BT Tower have confirmed the ability of nocturnal reactions of nitrogen dioxide and ozone to lead to nitrate formation although the transition into aerosol was not observed directly due to an absence of the necessary instrumentation. However, the ATOFMS data demonstrates this process in REPARTEE I.

- To throw new light on the source apportionment of $P M_{1}$, $P M_{2.5}$ and $P M_{10}$ in the atmosphere of London. The mass closure study has shown the dominance of sulphates, nitrates and carbonaceous material in making up $\mathrm{PM}_{2.5}$ within the atmosphere of London. Comprehensive information on $\mathrm{PM}_{10}$ composition was not sought although some data were generated concerning the sea salt component of $\mathrm{PM}_{10}$. Source apportionment data has come from the AMS and ATOFMS instruments giving valuable quantitative information on primary and secondary components of the organic aerosol including one of the first reports of cooking organic aerosol (COA) determined from an AMS instrument.

\section{Supplementary material related to this article is available online at: http://www.atmos-chem-phys.net/12/3065/2012/ acp-12-3065-2012-supplement.pdf.}

Acknowledgements. The authors are grateful to BT for allowing access to the BT Tower and to the Royal Parks for providing facilities at Regent's Park. Funding was provided by the Natural Environment Research Council through the National Centre for Atmospheric Science and the CityFlux grant, and the BOC Foundation. Bristol ChemLabS and Eurochlor supported work at the University of Bristol.

Edited by: W. T. Sturges

\section{References}

Abdalmogith, S. S. and Harrison, R. M.: An analysis of spatial and temporal properties of daily sulphate, nitrate and chloride concentrations at UK urban and rural sites, J. Environ. Monit., 8, 691-699, 2006.

Abdalmogith, S. S., Harrison, R. M., and Derwent, R. G.: Particulate sulphate and nitrate in southern England and Northern Ireland during 2002/3 and its formation in a photochemical trajectory model, Sci. Total Environ., 368, 769-780, 2006.

Alfarra, M. R., Prevot, A. S. H., Szidat, S., Sandradewi, J., Weimer, S., Lanz, V. A., Schreiber, D., Mohr, M., and Baltensperger, U.: Identification of the mass spectral signature of organic aerosols from wood burning emissions, Environ. Sci. Technol., 41, 57705777, doi:10.1021/Es062289b, 2007.

Aliwell, S. R. and Jones, R. L.: Measurements of tropospheric $\mathrm{NO}_{3}$ at midlatitude, J. Geophys. Res., 103, 5719-5727, 1998.

Allan, J. D., Coe, H., Bower, K. N., Alfarra, M. R., Delia, A. E., Jimenez, J. L., Middlebrook, A. M., Drewnick, F., Onasch, T. B., Canagaratna, M. R., Jayne, J. T., and Worsnop, D. R.: A generalised method for the extraction of chemically resolved mass spectra from Aerodyne aerosol mass spectrometer data, J. Aerosol. Sci., 35, 909-922, 2004.

Allan, J. D., Jimenez, J. L., Williams, P. I., Alfarra, M. R., Bower, K. N., Jayne, J. T., Coe, H., and Worsnop, D. R.: Quantitative sampling using an Aerodyne aerosol mass spectrometer - 1 . Techniques of data interpretation and error analysis, J. Geophys. Res.-Atmos., 108, 4090, doi:10.1029/2002JD002358, 2003.

Allan, J. D., Williams, P. I., Morgan, W. T., Martin, C. L., Flynn, M. J., Lee, J., Nemitz, E., Phillips, G. J., Gallagher, M. W., and Coe, H.: Contributions from transport, solid fuel burning and cooking to primary organic aerosols in two UK cities, Atmos. Chem. Phys., 10, 647-668, doi:10.5194/acp-10-647-2010, 2010.

Allen, A. G., Harrison, R. M., and Erisman, J. W.: Field Measurements of the dissociation of ammonium nitrate and ammonium chloride aerosols, Atmos. Environ., 23, 1591-1599, 1989.

Anderson, H. R., Limb, E. S., Bland, J. M., Ponce de Leon, A., Strachan, D. P., and Bower, J. S.: Health effects of an air pollution episode in London, December 1991, Thorax, 50, 11881193, 1995.

Angelino, S., Suess, D. T., and Prather, K. A.: Formation of aerosol particles from reactions of secondary and tertiary alkylamines: Characterization by Aerosol Time-of-Flight Mass Spectrometry, Environ. Sci. Technol., 35, 3130-3138, 2001.

AQEG: Particulate Matter in the United Kingdom, Air Quality Expert Group, Department for Environment, Food and Rural Affairs, London, 2005.

AQEG: Trends in Primary Nitrogen Dioxide in the UK, Air Quality Expert Group, Department for Environment, Food and Rural Affairs, London, 2007.

Arnfield, A. J.: Two decades of urban climate research: A review of turbulence, exchanges of energy and water, and the urban heat island, Int. J. Climatol., 23, 1-26, 2003.

Arnold, S., ApSimon, H., Barlow, J., Belcher, S., Bell, M., Britter, R., Colvile, R., Cheng, H., Dobre, A., Greally, B., Kaur, S., Knights, A., Lawton, T., Makepeace, A., Martin, D., Neophytou, M., Nieuwenhuijsen, M., Nickless, G., Price, C., Robins, A., Shallcross, D., Simmonds, P., Smalley, R., Tate, J., Tomlin, A., and Wang, A.: Dispersion of air pollution and penetration into the local environment DAPPLE, Sci. Total Environ., 332, 
139-153, 2004.

Atkinson, R. W., Barratt, B., Armstrong, B., Anderson, H. R., Beevers, S. D., Mudway, I. S., Green, D., Derwent, R. G., Wilkinson, P., Tonne, C., and Kelly, F. J.: The impact of the congestion charging scheme on ambient air pollution concentrations in London, Atmos. Environ., 43, 5493-5500, 2009.

Baggott, S., Cai, X., McGregor, G., and Harrison, R. M.: Model simulation of meteorology and air quality during the summer PUMA intensive measurement campaign in the UK West Midlands conurbation, Sci. Total Environ., 360, 26-42, 2006.

Barlow, J. F., Dobre, A., Smalley, R. J., Arnold, S. J., Tomlin, A. S., and Belcher, S. E.: Referencing of street-level flows: results from the DAPPLE 2004 campaign in London, UK, Atmos. Environ., 43, 5536-5544, 2009.

Barlow, J. F., Dunbar, T. M., Nemitz, E. G., Wood, C. R., Gallagher, M. W., Davies, F., O'Connor, E., and Harrison, R. M.: Boundary layer dynamics over London, UK, as observed using Doppler lidar during REPARTEE-II, Atmos. Chem. Phys., 11, 2111-2125, doi:10.5194/acp-11-2111-2011, 2011.

Beddows, D. C. S., Dall'Osto, M., and Harrison, R. M.: Cluster analysis of rural, urban, and curbside atmospheric particle size data, Environ. Sci. Technol., 43, 4694-4700, 2009.

Beddows, D. C. S., Dall'Osto, M., and Harrison, R. M.: An enhanced procedure for the merging of atmospheric particle size distribution data measured using electrical mobility and time-offlight analysers, Aerosol Sci. Technol., 44, 930-938, 2010.

Beevers, S. D. and Carslaw, D. C.: The impact of congestion charging on vehicle emissions in London, Atmos. Environ., 39, 1-5, 2005.

Benton, A. K., Langridge, J. M., Ball, S. M., Bloss, W. J., Dall'Osto, M., Nemitz, E., Harrison, R. M., and Jones, R. L.: Night-time chemistry above London: measurements of $\mathrm{NO}_{3}$ and $\mathrm{N}_{2} \mathrm{O}_{5}$ from the BT Tower, Atmos. Chem. Phys., 10, 9781-9795, doi:10.5194/acp-10-9781-2010, 2010.

Bigi, A. and Harrison, R. M.: Analysis of the air pollution climate at a central urban background site, Atmos. Environ., 44, 2004 2012, 2010.

Bond, T. C., Habib, G., and Bergstrom, R. W.: Limitations in the enhancement of visible light absorption due to mixing state, J. Geophys. Res.-Atmos., 111, D20211, doi:10.1029/2006jd007315, 2006.

Brimblecombe, P: The Big Smoke, Methuen \& Co., London, 1987. Brown, S. S., Dube, W. P., Osthoff, H. D., Stutz, J., Ryerson, T. B., Wollny, A. G., Brock, C. A., Warneke, C., De Gouw, J. A., Atlas, E., Neuman, J. A., Holloway, J. S., Lerner, B. M., Williams, E. J., Kuster, W. C., Goldan, P. D., Angevine, W. M., Trainer, M., Fehsenfeld, F. C., and Ravishankara, A. R.: Vertical profiles in $\mathrm{NO}_{3}$ and $\mathrm{N}_{2} \mathrm{O}_{5}$ measured from an aircraft: Results from the NOAA P-3 and surface platforms during the New England Air Quality Study 2004, J. Geophys. Res., 112, D22304, 10.1029/2007jd008883, 2007a.

Brown, S. S., Dubé, W. P., Osthoff, H. D., Wolfe, D. E., Angevine, W. M., and Ravishankara, A. R.: High resolution vertical distributions of $\mathrm{NO}_{3}$ and $\mathrm{N}_{2} \mathrm{O}_{5}$ through the nocturnal boundary layer, Atmos. Chem. Phys., 7, 139-149, doi:10.5194/acp-7-139-2007, 2007b.

Brunekreef, B. and Holgate, S. T.: Air pollution and health, The Lancet, 360, 1233-1242, 2002.

Buzorius, G., Rannik, U., Makela, J. M., Vesala, T., and Kulmala,
M.: Vertical aerosol particle fluxes measured by eddy covariance technique using a condensational particle counter, J. Aerosol Sci., 29, 157-171, 1998.

Canagaratna, M. R., Jayne, J. T., Ghertner, D. A., Herndon, S., Shi, Q., Jimenez, J. L., Silva, P. J., Williams, P., Lanni, T., Drewnick, F., Demerjian, K. L., Kolb, C. E., and Worsnop, D. R.: Chase studies of particulate emissions from in-use New York City vehicles, Aerosol Sci. Technol., 38, 555-573, 2004.

Canagaratna, M. R., Jayne, J. T., Jimenez, J. L., Allan, J. D., Alfarra, M. R., Zhang, Q., Onasch, T. B., Drewnick, F., Coe, H., Middlebrook, A., Delia, A., Williams, L. R., Trimborn, A. M., Northway, M. J., DeCarlo, P. F., Kolb, C. E., Davidovits, P., and Worsnop, D. R.: Chemical and microphysical characterization of ambient aerosols with the aerodyne aerosol mass spectrometer, Mass Spectrom. Rev., 26, 185-222, 2007.

Carslaw, D. C. and Beevers, S. D.: Estimations of road vehicle primary $\mathrm{NO}_{2}$ exhaust emission fractions using monitoring data in London, Atmos. Environ., 38, 3585-3594, 2005.

Castro, L. M., Pio, C. A., Harrison, R. M., and Smith, D. J. T.: Carbonaceous aerosol in urban and rural European atmospheres: Estimation of secondary organic carbon concentrations, Atmos. Environ., 33, 2771-2781, 1999.

Charron, A. and Harrison, R. M.: Fine $\left(\mathrm{PM}_{2.5}\right)$ and coarse $\left(\mathrm{PM}_{2.5-10}\right)$ particulate matter on a heavily trafficked London highway: Sources and processes, Environ. Sci. Technol., 39, 7768-7776, 2005.

Charron, A., Harrison, R. M., and Quincey, P.: What are the sources and conditions responsible for exceedences of the $24 \mathrm{~h} \mathrm{PM}_{10}$ limit value $\left(50 \mu \mathrm{g} \mathrm{m}^{-3}\right)$ at a heavily trafficked London site?, Atmos. Environ., 41, 1960-1975, 2007.

Clapp, L. J. and Jenkin, M. E.: Analysis of the relationship between ambient levels of $\mathrm{O}_{3}, \mathrm{NO}_{2}$ and $\mathrm{NO}$ as a function of $\mathrm{NO}_{\mathrm{x}}$ in the UK, Atmos. Environ., 35, 6391-6405, 2001.

Cohen, A. J., Anderson, H. R., Ostra, B., Pandey, K. D., Krzyzanowski, M., Kunzli, N., Gutschmidt, K., Pope, A., Romieu, I., Samet, J. M., and Smith, K.: The global burden of disease due to outdoor air pollution, J. Toxicol. Env. Health A, 68, 1-7, 2005.

Colvile, R. N., Kaur, S., Britter, R., Robins, A., Bell, M. C., Belcher, S. E., Shallcross, D. E., and D.A.P.P.L.E. Project Coinvestigators.: Sustainable development of urban transport systems and human exposure to air pollution, Sci. Total Environ., 334-335, 481-487, 2004.

Cros, B., Durand, P., Cachier, H., Drobinski, Ph., Fréjafon, E., Kottmeier, C., Perros, P. E., Peufch, V.-H., Ponche, J.-L., Robin, D., Saïd, F., Toupance, G., and Wortham, H.: The ESCOMPTE program: an overview, Atmos. Res., 69, 241-279, 2004.

Dall'Osto, M. and Harrison, R. M.: Urban organic aerosols measured by single particle mass spectrometry in the megacity of London, Atmos. Chem. Phys. Discuss., 11, 5043-5078, doi:10.5194/acpd-11-5043-2011, 2011.

Dall'Osto, M., Harrison, R. M., Beddows, D. C. S., Freney, E. J., Heal, M. R., and Donovan, R. J.: Single particle detection efficiencies of Aerosol Time-of-Flight mass spectrometry during the North Atlantic Marine Boundary Layer Experiment, Environ. Sci. Technol., 40, 5029-5035, 2006.

Dall'Osto, M., Harrison, R. M., Coe, H., and Williams, P.: Realtime secondary aerosol formation during a fog event in London, Atmos. Chem. Phys., 9, 2459-2469, doi:10.5194/acp-9-2459- 
2009, 2009a.

Dall'Osto, M., Harrison, R. M., Coe, H., Williams, P. I., and Allan, J. D.: Real time chemical characterization of local and regional nitrate aerosols, Atmos. Chem. Phys., 9, 3709-3720, doi:10.5194/acp-9-3709-2009, 2009b.

Dall'Osto, M., Thorpe, A., Beddows, D. C. S., Harrison, R. M., Barlow, J. F., Dunbar, T., Williams, P. I., and Coe, H.: Remarkable dynamics of nanoparticles in the urban atmosphere, Atmos. Chem. Phys., 11, 6623-6637, doi:10.5194/acp-11-66232011, 2011.

DeCarlo, P. F., Kimmel, J. R., Trimborn, A., Northway, M. J., Jayne, J. T., Aiken, A. C., Gonin, M., Fuhrer, K., Horvath, T., Docherty, K. S., Worsnop, D. R., and Jimenez, J. L.: Field-deployable, high-resolution, time-of-flight aerosol mass spectrometer, Anal. Chem., 78, 8281-8289, 2006.

Deventer, M. J., Griessbaum, F., and Klemm, O.: Highly sizeresolved particle fluxes over an urban area, Abstract 10D3, European Aerosol Conference 2011, 4-9 September, Manchester, UK, 2011.

Dorsey, J. R., Nemitz, E., Gallagher, M. W., Fowler, D., Williams, P. I., Bower, K. N., and Beswick, K. M.: Direct measurements and parameterisation of aerosol flux, concentration and emission velocity above a city, Atmos. Environ., 36, 791-800, 2002.

Drewnick, F., Hings, S. S., DeCarlo, P., Jayne, J. T., Gonin, M., Fuhrer, K., Weimer, S., Jimenez, J. L., Demerjian, K. L., Borrmann, S., and Worsnop, D. R.: A New Time-of-Flight Aerosol Mass Spectrometer (TOF-AMS)-Instrument Description and First Field Deployment, Aerosol Sci. Technol., 39, 637-658, 2005.

Dunlea, E. J., Herndon, S. C., Nelson, D. D., Volkamer, R. M., San Martini, F., Sheehy, P. M., Zahniser, M. S., Shorter, J. H., Wormhoudt, J. C., Lamb, B. K., Allwine, E. J., Gaffney, J. S., Marley, N. A., Grutter, M., Marquez, C., Blanco, S., Cardenas, B., Retama, A., Ramos Villegas, C. R., Kolb, C. E., Molina, L. T., and Molina, M. J.: Evaluation of nitrogen dioxide chemiluminescence monitors in a polluted urban environment, Atmos. Chem. Phys., 7, 2691-2704, doi:10.5194/acp-7-2691-2007, 2007.

Emmerson, K. M., Carslaw, N., Carpenter, L. J., Heard, D. E., Lee, J. D., and Pilling, M. J.: Urban atmospheric chemistry during the PUMA campaign 1: Comparison of modelled $\mathrm{OH}$ and $\mathrm{HO}_{2}$ concentrations with measurements, J. Atmos. Chem., 52, 143164, 2005

Fairall, C. W.: Interpretation of eddy-correlation measurements of particulate deposition and aerosol flux, Atmos. Environ., 18, 1329-1337, 1984.

Famulari, D., Nemitz, E., Di Marco, C., Phillips, G. J., Thomas, R., House, E., and Fowler, D.: Eddy-covariance measurements of nitrous oxide fluxes above a city, Agr. Forest Meteorol., 150, 786-793, doi:10.1016/j.agrformet.2009.08.003, 2010.

Farmer, D. K., Kimmel, J. R., Phillips, G., Docherty, K. S., Worsnop, D. R., Sueper, D., Nemitz, E., and Jimenez, J. L.: Eddy covariance measurements with high-resolution time-offlight aerosol mass spectrometry: a new approach to chemically resolved aerosol fluxes, Atmos. Meas. Tech., 4, 1275-1289, doi:10.5194/amt-4-1275-2011, 2011.

Fish, D. J., Shallcross, D. E., and Jones, R. L.: The vertical distribution of $\mathrm{NO}_{3}$ in the atmospheric boundary layer, Atmos. Environ., 33, 687-691, 1999.

Foken, T. and Wichura, B.: Tools for quality assessment of surface- based flux measurements, Agr. Forest Meteorol., 78, 83-105, 1996.

Gabey, A. M., Gallagher, M. W., Whitehead, J., Dorsey, J. R., Kaye, P. H., and Stanley, W. R.: Measurements and comparison of primary biological aerosol above and below a tropical forest canopy using a dual channel fluorescence spectrometer, Atmos. Chem. Phys., 10, 4453-4466, doi:10.5194/acp-10-4453-2010, 2010.

Gard, E., Mayer, J. E., Morrical, B. D., Dienes, T., Fergenson, D. P., and Prather, K. A.: Real-time analysis of individual atmospheric aerosol particles: Design and performance of a portable ATOFMS, Anal. Chem., 69, 4083-4091, 1997.

Harrison, R. M. and Yin, J.: Sources and processes affecting carbonaceous aerosol in central England, Atmos. Environ., 42, 1413-1423, 2008.

Harrison, R. M., Jones, A. M., and Lawrence, R. G.: A pragmatic mass closure model for airborne particulate matter at urban background and roadside sites, Atmos. Environ., 37, 4927-4933, 2003.

Harrison, R. M., Yin, J., Tilling, R. M., Cai, X., Seakins, P. W., Hopkins, J. R., Lansley, D. L., Lewis A. C., Hunter, M. C., Heard, D. E., Carpenter, L. J., Creasey D. J., Lee, J. D., Pilling, M. J., Carslaw, N., Emmerson, K. M., Redington, A., Derwent, R. G., Ryall, D., Mills, G., and Penkett, S. A.: Measurement and modelling of air pollution and atmospheric chemistry in the UK West Midlands conurbation: overview of the PUMA consortium project, Sci. Total Environ., 360, 5-25, 2006.

Harrison, R. M., Stedman, J., and Derwent, D.: Why are PM $_{10}$ Concentrations in Europe not falling?, New Directions, Atmospheric Science Perspectives Special Series, Atmos. Environ., 42, 603606, 2008.

Harrison, R. M., Beddows, D. C. S., and Dall'Osto, M.: PMF analysis of wide-range particle size spectra collected on a major highway, Environ. Sci. Technol., 45, 5522-5528, 2011.

Helfter, C., Famulari, D., Phillips, G. J., Barlow, J. F., Wood, C. R., Grimmond, C. S. B., and Nemitz, E.: Controls of carbon dioxide concentrations and fluxes above central London, Atmos. Chem. Phys., 11, 1913-1928, doi:10.5194/acp-11-1913-2011, 2011.

Huang, Z., Harrison, R. M., Allen, A. G., James, J. D., Tilling, R. M., and Yin, J.: Field intercomparison of filter pack and impactor sampling for aerosol nitrate, ammonium, and sulphate at coastal and inland sites, Atmos. Res., 71, 215-223, 2004.

Ibrom, A., Dellwik, E., Flyvbjerg, H., Jensen, N. O., and Pilegaard, K.: Strong low-pass filtering effects on water vapour flux measurements closed-path eddy correlation systems, Agr. Forest Metorol., 147, 140-156, 2007.

Järvi, L., Rannik, Ü., Mammarella, I., Sogachev, A., Aalto, P. P., Keronen, P., Siivola, E., Kulmala, M., and Vesala, T.: Annual particle flux observations over a heterogeneous urban area, Atmos. Chem. Phys., 9, 7847-7856, doi:10.5194/acp-9-7847-2009, 2009.

Jayne, J. T., Leard, D. C., Zhang, X., Davidovits, P., Smith, K. A., Kolb, C. E., and Worsnop, D. R.: Development of an aerosol mass spectrometer for size and composition analysis of submicron particles, Aerosol Sci. Technol., 33, 49-70, 2000.

Jenkin, M. E., Utembe, S. R., and Derwent, R. G.: Modelling the impact of elevated primary $\mathrm{NO}_{2}$ and $\mathrm{HONO}$ emissions on regional scale oxidant formation in the UK, Atmos. Environ., 42, 323-336, 2008.

Jimenez, J. L., Canagaratna, M. R., Donahue, N. M., Prevot, A. S. 
H., Zhang, Q., Kroll, J. H., DeCarlo, P. F., Allan, J. D., Coe, H., Ng, N. L., Aiken, A. C., Docherty, K. S., Ulbrich, I. M., Grieshop, A. P., Robinson, A. L., Duplissy, J., Smith, J. D., Wilson, K. R., Lanz, V. A., Hueglin, C., Sun, Y. L., Tian, J., Laaksonen, A., Raatikainen, T., Rautiainen, J., Vaattovaara, P., Ehn, M., Kulmala, M., Tomlinson, J. M., Collins, D. R., Cubison, M. J., E, Dunlea, J., Huffman, J. A., Onasch, T. B., Alfarra, M. R., Williams, P. I., Bower, K., Kondo, Y., Schneider, J., Drewnick, F., Borrmann, S., Weimer, S., Demerjian, K., Salcedo, D., Cottrell, L., Griffin, R., Takami, A., Miyoshi, T., Hatakeyama, S., Shimono, A., Sun, J. Y., Zhang, Y. M., Dzepina, K., Kimmel, J. R., Sueper, D., Jayne, J. T., Herndon, S. C., Trimborn, A. M., Williams, L. R., Wood, E. C., Middlebrook, A. M., Kolb, C. E., Baltensperger, U., and Worsnop, D. R.: Evolution of Organic Aerosols in the Atmosphere, Science, 326, 1525-1529, 2009.

Jones, A. M., Yin, J., and Harrison, R. M.: The weekday-weekend difference and the estimation of the non-vehicle contributions to the urban increment of airborne particulate matter, Atmos. Environ., 42, 4467-4479, 2008.

Jones, R. L., Ball, S. M., and Shallcross, D. E.: Small scale structure in the atmosphere: implications for chemical composition and observational methods, Faraday Discuss., 130, 165-179, 2005.

Kennedy, O. J., Ouyang, B., Langridge, J. M., Daniels, M. J. S., Bauguitte, S., Freshwater, R., McLeod, M. W., Ironmonger, C., Sendall, J., Norris, O., Nightingale, R., Ball, S. M., and Jones, R. L.: An aircraft based three channel broadband cavity enhanced absorption spectrometer for simultaneous measurements of $\mathrm{NO}_{3}, \mathrm{~N}_{2} \mathrm{O}_{5}$ and $\mathrm{NO}_{2}$, Atmos. Meas. Tech., 4, 1759-1776, doi:10.5194/amt-4-1759-2011, 2011.

Kruijt, B., Klaassan, W., and Hutjes, R. W. A.: Adjustment of turbulent momentum flux over forest downwind of an edge, in: Wind and Trees, edited by: Coutts, M. P. and Grace, J., Cambridge Univ. Press., 485 pp., 1995.

Kunzli, N., Kaiser, R., Medina, S., Studnicka, M., Chanel, O., Filliger, P., Herry, M., Horak Jr., F., Puybonnieux-Texier, V., and Quenel, P.: Public-health impact of outdoor and traffic-related air pollution: a European assessment, The Lancet, 356, 795-801, 2000.

Kurtenbach, R., Becker, K. H., Gomes, J. A. G., Kleffmann, J., Lörzer, J. C., Spittler, M., Wiesen, P., Ackermann, R., Geyer, A., and Platt, U.: Investigations of emissions and heterogeneous formation of HONO in a road traffic tunnel, Atmos. Environ., 35, 3385-3394, 2001.

Langford, B., Davison, B., Nemitz, E., and Hewitt, C. N.: Mixing ratios and eddy covariance flux measurements of volatile organic compounds from an urban canopy (Manchester, UK), Atmos. Chem. Phys., 9, 1971-1987, doi:10.5194/acp-9-1971-2009, 2009.

Langford, B., Nemitz, E., House, E., Phillips, G. J., Famulari, D., Davison, B., Hopkins, J. R., Lewis, A. C., and Hewitt, C. N.: Fluxes and concentrations of volatile organic compounds above central London, UK, Atmos. Chem. Phys., 10, 627-645, doi:10.5194/acp-10-627-2010, 2010.

Langridge, J. M., Ball, S. M., Shillings, A. J. L., and Jones, R. L.: A broadband absorption spectrometer using light emitting diodes for ultrasensitive, in situ trace gas detection, Rev. Sci. Instrum., 79, 123110, doi:10.1063/1.3046282, 2008.

Lanz, V. A., Alfarra, M. R., Baltensperger, U., Buchmann, B., Hueglin, C., and Prévôt, A. S. H.: Source apportionment of submicron organic aerosols at an urban site by factor analytical modelling of aerosol mass spectra, Atmos. Chem. Phys., 7, 1503-1522, doi:10.5194/acp-7-1503-2007, 2007.

Longley, I. D., Gallagher, M. W., Dorsey, J. R., and Flynn, M.: A case study of fine particle concentrations and fluxes measured in a busy street canyon in Manchester, UK, Atmos. Environ., 38, 3595-3603, 2004.

Mårtensson, E. M., Nilsson, E. D., Buzorius, G., and Johansson, C.: Eddy covariance measurements and parameterisation of traffic related particle emissions in an urban environment, Atmos. Chem. Phys., 6, 769-785, doi:10.5194/acp-6-769-2006, 2006.

Martin, C. L., Longley, I. D., Dorsey, J. R., Thomas, R. M., Gallagher, M. W., and Nemitz, E.: Ultrafine particle fluxes above four major European cities, Atmos. Environ., 43, 4714-4721, 2009.

Martin, D., Price, C. S., White, I. R., Nickless, G., Dobre, A., and Shallcross, D. E.: A study of pollutant concentration variability in an urban street under low wind speeds, Atmos. Sci. Lett., 9, 147-152, 2008.

Martin, D., Price, C. S., Nickless, G., Britter, R. E., Londou, A.N., Neophytou, M. K., Cheng, H., Robins, A. G., Dobre, A., Belcher, S. E., Barlow, J. F., Tomlin, A. S., Smalley, R. J., Tate, S. E., Arnold, S. J., Colvile, R. N., and Shallcross, D. E.: Urban tracer dispersion experiments in London (DAPPLE) 2003: Field studies and comparisons with empirical prediction, Atmos. Sci. Letts., 11, 241-248, 2010a.

Martin, D., Price, C. S., Nickless, G., Britter, R. E., Londou, A.-N., Neophytou, M. K., Cheng, H., Robins, A. G., Dobre, A., Belcher, S. E., Barlow, J. F., Tomlin, A. S., Smalley, R. J., Tate, S. E., Arnold, S. J., Colvile, R. N., and Shallcross, D. E.: Urban tracer dispersion experiments during the second DAPPLE field campaign in London 2004, Atmos. Environ., 44, 3043-3052, $2010 \mathrm{~b}$.

Martin, D., Petersson, K. F., White, I. R., Henshaw, S. J., Nickless, G., Lovelock, A., Barlow, J. F., Dunbar, T., Wood, C. R., and Shallcross, D. E.: Tracer concentration profiles measured in central London as part of the REPARTEE campaign, Atmos. Chem. Phys., 11, 227-239, doi:10.5194/acp-11-227-2011, 2011a.

Martin, D., Petersson, K. F., and Shallcross, D. E.: The use of cyclic perfluoralkanes and $\mathrm{SF}_{6}$ in atmospheric dispersion experiments, Q. J. Roy. Meteor. Soc., 137, 2047-2063, doi:10.1002/qj.881, 2011b.

Matthew, B. M., Middlebrook, A. M., and Onasch, T. B.: Collection efficiencies in an Aerodyne Aerosol Mass Spectrometer as a function of particle phase for laboratory generated aerosols, Aerosol Sci. Technol., 42, 884-898, 2008.

McFiggans, G., Alfarra, M. R., Allan, J., Bower, K., Coe, H., Cubison, M., Topping, D., Williams, P., Decesari, S., Facchini, C., and Fuzzi, S.: Simplification of the representation of the organic component of atmospheric particulates, Faraday Discuss., 130, 341-362, 2005.

McFiggans, G., Bale, C. S. E., Ball, S. M., Beames, J. M., Bloss, W. J., Carpenter, L. J., Dorsey, J., Dunk, R., Flynn, M. J., Furneaux, K. L., Gallagher, M. W., Heard, D. E., Hollingsworth, A. M., Hornsby, K., Ingham, T., Jones, C. E., Jones, R. L., Kramer, L. J., Langridge, J. M., Leblanc, C., LeCrane, J.-P., Lee, J. D., Leigh, R. J., Longley, I., Mahajan, A. S., Monks, P. S., Oetjen, H., Orr-Ewing, A. J., Plane, J. M. C., Potin, P., Shillings, A. J. L., Thomas, F., von Glasow, R., Wada, R., Whalley, L. K., and Whitehead, J. D.: Iodine-mediated coastal particle formation: 
an overview of the Reactive Halogens in the Marine Boundary Layer (RHaMBLe) Roscoff coastal study, Atmos. Chem. Phys., 10, 2975-2999, doi:10.5194/acp-10-2975-2010, 2010.

Mohr, C., Huffman, J. A., Cubison, M. J., Aiken, A. C., Docherty, K. S., Kimmel, J. R., Ulbrich, I. M., Hannigan, M., and Jimenez, J. L.: Characterization of primary organic aerosol emissions from meat cooking, trash burning, and motor vehicles with highresolution aerosol mass spectrometry and comparison with ambient and chamber observations, Environ. Sci. Technol., 43, 24432449, 2009.

Molina, L. T., Madronich, S., Gaffney, J. S., Apel, E., de Foy, B., Fast, J., Ferrare, R., Herndon, S., Jimenez, J. L., Lamb, B., Osornio-Vargas, A. R., Russell, P., Schauer, J. J., Stevens, P. S., Volkamer, R., and Zavala, M.: An overview of the MILAGRO 2006 Campaign: Mexico City emissions and their transport and transformation, Atmos. Chem. Phys., 10, 8697-8760, doi:10.5194/acp-10-8697-2010, 2010.

Nemitz, E. and Sutton, M. A.: Gas-particle interactions above a Dutch heathland: III. Modelling the influence of the $\mathrm{NH}_{3}$ $\mathrm{HNO}_{3}-\mathrm{NH}_{4} \mathrm{NO}_{3}$ equilibrium on size-segregated particle fluxes, Atmos. Chem. Phys., 4, 1025-1045, doi:10.5194/acp-4-10252004, 2004.

Nemitz, E., Fowler, D., Gallagher, M. W., Dorsey, J. R., Theobald, M. R., and Bower, K.: Measurement and interpretation of landatmosphere aerosol fluxes: current issues and new approaches, edited by: Midgley, P. M., Reuther, M., and Williams, M., Proceedings of EUROTRAC Symposium 2000, Springer Verlag Berlin, Heidelberg, 45-53, 2001.

Nemitz, E., Dorsey, J. R., Flynn, M. J., Gallagher, M. W., Hensen, A., Erisman, J.-W., Owen, S. M., Dämmgen, U., and Sutton, M. A.: Aerosol fluxes and particle growth above managed grassland, Biogeosciences, 6, 1627-1645, doi:10.5194/bg-6-16272009, 2009.

Nemitz, E., Jimenez, J. L., Huffman, J. A., Ulbrich, I. M., Canagaratna, M. R., Worsnop, D. R., and Guenther, A. B.: An eddycovariance system for the measurement of surface/atmosphere exchange fluxes of submicron aerosol chemical species - first application above an urban area, Aerosol Sci. Techol., 42, 636657, 2008.

Nemitz, E., Phillips, G. J., DiMarco, C. F., Allan, J. D., Barlow, J. F., Coe, H., Dall'Osto, M., Harrison, R. M., and Williams, P. I.: Controls of concentrations, gradients and fluxes of inorganic reactive gases and aerosol components above London, Atmos. Chem. Phys. Discuss., in preparation, 2012a.

Nemitz, E., McDonald, A. G., Theobald, M. R., Dorsey, J.R., Gallagher, M.W., Williams, P.I., Bower, K. N., and Fowler, D.: Sizesegregated particle emissions above a city and their controls, Atmos. Chem. Phys. Discuss., in preparation, 2012b.

Nemitz, E., Langford, B., Phillips, G. J., Di Marco, C. F., Farmer, D., Kimmel, J., Sueper, D., and Jimenez, J. L.: Eddy-covariance fluxes of organic aerosol above London measured with a high resolution aerosol mass spectrometer. Atmos. Chem. Phys. Discuss., in preparation, 2012c.

Paatero, P.: Least squares formulation of robust non-negative factor analysis, Chemometr Intell Lab, 37, 23-35, 1997.

Patra, A., Colvile, R., Arnold, S., Bowen, E., Shallcross, D., Martin, D., Price, C., Tate, J., ApSimon, H., and Robins, A.: On street observations of particulate matter movement and dispersion due to traffic on an urban road, Atmos. Environ., 42, 3911-3926,
2008.

Pearson, G. N., Davies, F., and Collier, C. G.: An analysis of the performance of the UFAM pulsed Doppler lidar for observing the boundary layer, J. Atmos. Ocean. Tech., 26, 240-250, 2009.

Petersson, F. K., Martin, D., White, I. R., Henshaw, S. J., Nickless, G., Longley, I., Percival, C. J., Gallagher, M., and Shallcross, D. E.: CityFlux perfluorocarbon tracer experiments, Atmos. Chem. Phys., 10, 5991-5997, doi:10.5194/acp-10-5991-2010, 2010.

Petzold, A. and Schonlinner, M.: Multi-angle absorption photometry - a new method for the measurement of aerosol light absorption and atmospheric black carbon, Aerosol Sci., 35, 421-441, 2004.

Phillips, G. J., Thomas, R., Famulari, D.,Williams, P. I., Crosier, J., Allan, J. D., Coe, H., Gallagher, M., Flynn, M., and Nemitz, E.: Fluxes of submicron aerosol components above three UK cities, Atmos. Chem. Phys. Discuss., in preparation, 2012.

Pio, C., Cerqueira, M., Harrison, R. M., Nunes, T., Mirante, F., Alves, C., Oliveira, C., Artiñano, B., Sanchez de la Campa, A., Artinano, B., and Matos, M.: OC/EC ratio observations in Europe: Re-thinking the approach for apportionment between primary and secondary organic carbon, Atmos. Environ., 45, 61216132, 2011.

Platt, U., Alicke, B., Dubois, R., Geyer, A., Hofzumahaus, A., Holland, F., Martinez, M., Mihelcic, D., Klüpfel, T., Lohrmann, B., Pätz, W., Perner, D., Rohrer, F., Schäfer, J., and Stutz, J.: Free radicals and fast photochemistry during BERLIOZ, J. Atmos. Chem., 42, 359-394, 2002.

Putaud, J.-P., Van Dingenen, R., Alastuey, A., Bauer, H., Birmili, W., Cyrys, J., Flentje, H., Fuzzi, S., Gehrig, R., Hansson, H. C., Harrison, R. M., Herrmann, H., Hitzenberger, R., Huglin, C., Jones, A. M., Kasper-Giebl, A., Kiss, G., Kousa, A., Kuhlbusch, T. A. J., Loschau, G., Maenhaut, W., Molnar, A., Moreno, T., Pekkanen, J., Perrino, C., Pitz, M., Puxbaum, H., Querol, X., Rodriguez, S., Salma, I., Schwarz, J., Smolik, J., Schneider, J., Spindler, G., ten Brink, H., Tursic, J., Viana, M., Wiedensohler, A., and Raes, F.: A European Aerosol Phenomenology - 3: Physical and chemical characteristics of particulate matter from 60 rural, urban, and kerbside sites across Europe, Atmos. Environ., 44, 1308-1320, 2010.

Robinson, A. L., Donahue, N. M., Shrivastava, M. K., Weitkamp, E. A., Sage, A. M., Grieshop, A. P., Lane, T. E., Pierce, J. R., and Pandis, S. N.: Rethinking organic aerosols: Semivolatile emissions and photochemical aging, Science, 315, 1259-1262, 2007.

Roth, M.: Review of atmospheric turbulence over cities, Q. J. Roy. Meteorol. Soc., 126, 941-990, 2000.

Sanchez-Reyna, G. R., Wang, K.-Y., Gallardo, J. C., and Shallcross, D. E.: Association between $\mathrm{PM}_{10}$ concentrations and wind direction in London, Atmos. Sci. Lett., 6, 204-210, 2005.

Schmid, H. P.: Source areas for scalars and scalar fluxes, Bound.Lay. Meteorol., 67, 293-318, 1994.

Schmidt, A. and Klemm, O.: Direct determination of highly sizeresolved turbulent particle fluxes with the disjunct eddy covariance method and a 12 - stage electrical low pressure impactor, Atmos. Chem. Phys., 8, 7405-7417, doi:10.5194/acp-8-74052008, 2008.

Schneider, J., Weimer, S., Drewnick, F., Borrmann, S., Helas, G., Gwaze, P., Schmid, O., Andreae, M. O., and Kirchner, U.: Mass spectrometric analysis and aerodynamic properties of various types of combustion-related aerosol particles, Int. J. Mass 
Spectrom., 258, 37-49, 2006.

Shallcross, D. E., Martin, D., Price, C. S., Nickless, G., White, I. R., Petersson, F., Britter, R. E., Neophytou, M. K., Tate, J. E., Tomlin, A. S., Barlow, J. F., and Robins, A.: Short range mobile urban dispersion experiments using an instrumented vehicle, Atmos. Sci. Lett., 10, 59-65, 2009.

Simmonds, P. G., Greally, B. R., Olivier, S., Nickless, G., Cooke, K. M., and Dietz, R. N.: The background atmospheric concentrations of cyclic perfluorocarbon tracers determined by negative ion-chemical ionization mass spectrometry, Atmos. Environ., 36, 2147-2156, 2002.

Smith, S., Ward, M., Lin, R., Brydson, R., Dall'Osto, M., and Harrison, R. M.: Comparative study of single particle characterisation by Transmission Electron Microscopy and Time-of-Flight Aerosol Mass Spectrometry in the London atmosphere, Atmos. Environ., submitted, 2012.

Spanton, A. M. and Williams, M. L.: A comparison of the structure of the atmospheric boundary layers in central London and a rural/suburban site using acoustic sounding, Atmos. Environ., 22, 211-223, 1988.

Su, J. G., Jerrett, M., de Nazelle, A., and Wolch, J.: Does exposure to air pollution in urban parks have socioeconomic, racial or ethnic gradients?, Environ. Res., 111, 319-328, 2011.

Thomas, R. M.: Measurement of speciated aerosol fluxes, Ph.D. thesis, University of Manchester, Manchester, UK, 2007.

Thomas, R. M., Trebs, I., Otjes, R., Jongejan, P. A. C., ten Brink, H., Phillips, G., Kortner, M., Meixner, F. X., and Nemitz, E.: An automated analyser to measure surface-atmosphere exchange fluxes of water soluble inorganic aerosol compounds and reactive trace gases, Environ. Sci. Technol., 43, 1412-1418, doi:10.1021/es8019403, 2009.

Ulbrich, I. M., Canagaratna, M. R., Zhang, Q., Worsnop, D. R., and Jimenez, J. L.: Interpretation of organic components from Positive Matrix Factorization of aerosol mass spectrometric data, Atmos. Chem. Phys., 9, 2891-2918, doi:10.5194/acp-9-2891-2009, 2009.

Vesala, T., Jarvi, L., Launiainen, S., Sogachev, A., Rannik, U., Mammarella, I., Siivola, E., Keronen, P., Rinne, J., Riikonen, A., and Nikinmaa, E.: Surface-atmosphere interactions over complex urban terrain in Helsinki, Finland, Tellus B, 60, 188-199, 2007.
Vogt, M., Nilsson, E. D., Ahlm, L., Mårtensson, E. M., and Johansson, C.: The relationship between $0.25-2.5 \mu \mathrm{m}$ aerosol and $\mathrm{CO}_{2}$ emissions over a city, Atmos. Chem. Phys., 11, 4851-4859, doi:10.5194/acp-11-4851-2011, $2011 \mathrm{a}$.

Vogt, M., Nilsson, D., Ahlm, L., Martensson, M. and Johansson, C.: Seasonal and diurnal cycles of $0.25-2.5 \mu \mathrm{m}$ aerosol fluxes over urban Stockholm, Sweden, Tellus B, 63, 935-951, 2011 b.

Webb, E. K., Pearman, G. I., and Leuning, R.: Correction of flux measurements for density effects due to heat and water vapour transfer, Q. J. Roy. Meteorol. Soc., 106, 85-100, 1980.

White, I. R., Martin, D., Paz Muñoz, M., Petersson, F. K., Henshaw, S. J., Nickless, G., Lloyd-Jones, G. C., and Clemitshaw, K. C., Shallcross, D. E.: The use of reactive tracers to determine ambient $\mathrm{OH}$ radical concentrations: application within the indoor environment, Environ. Sci. Technol., 44, 6269-6274, 2010.

Wilczak, J. M., Oncley, S. P., and State, S. A.: Sonic anemometer tilt correction algorithms, Bound.-Lay. Meteorol., 99, 127-150, 2001.

Wood, C. R., Arnold, S. J., Balogun, A. A., Barlow, J. F., Belcher, S. E., Britter, R. E., Cheng, H., Dobre, A., Lingard, J. J. N., Martin, D., Neophytou, M., Petersson, F. K., Robins, A. G., Shallcross, D. E., Smalley, R. J., Tate, J. E., Tomlin, A. S., and White, I. R.: Dispersion experiments in central London: the 2007 DAPPLE project, B. Am. Meteorol. Soc., 90, 955-969, 2009.

Wood, C. R., Lacser, A., Barlow, J. F., Padhra, A., Belcher, S. E., Nemitz, E., Helfter, C., Famulari, D., and Grimmond, C. S. B.: Turbulent flow at $190 \mathrm{~m}$ height above London during 2006-2008: A climatology and the applicability of similarity theory, Bound.Lay. Meteorol., 137, 77-96, 2010.

Wroth, C. and Wiles, A.: Key Population and Vital Statistics, Series VS No 34, PPI No 30, 2007 Data, Office for National Statistics, http://www.ons.gov.uk/ons/search/index.html? newquery=key+population+and+vital+statistics, 2007.

Yamulki, S., Harrison, R. M., and Goulding, K. W. T.: Ammonia surface-exchange above an agricultural field in southeast England, Atmos. Environ., 30, 109-118, 1996.

Yin, J. and Harrison, R. M.: Pragmatic mass closure study for $\mathrm{PM}_{1.0}, \mathrm{PM}_{2.5}$ and $\mathrm{PM}_{10}$ at roadside, urban background and rural sites, Atmos. Environ., 42, 980-988, 2008. 